\author{
Universidade de São Paulo \\ Instituto de Física
}

\title{
Desenvolvendo novas fontes de estados coerentes da luz para aplicações em ótica quântica
}

\author{
Raúl Leonardo Rincón Celis
}

Orientador: Prof. Dr. Marcelo Martinelli

Dissertação de mestrado apresentada ao Instituto de Física da Universidade de São Paulo, como requisito parcial para a obtenção do título de Mestre em Ciências.

Banca Examinadora:

Prof. Dr. Marcelo Martinelli - Orientador (IFUSP)

Prof. Dr. Reinaldo Luiz Cavasso Filho (UFABC)

Prof. Dr. Cleber Renato Mendonça (IFSC) 


\section{FICHA CATALOGRÁFICA}

\section{Preparada pelo Serviço de Biblioteca e Informação}

do Instituto de Física da Universidade de São Paulo

\section{Rincón Celis, Raúl Leonardo}

Desenvolvendo novas fontes de estados coerentes da luz para aplicações em ótica quântica. São Paulo, 2018.

Dissertação (Mestrado) - Universidade de São Paulo. Instituto de Física. Depto. de Física Experimental

Orientador: Prof. Dr. Marcelo Martinelli Área de Concentração: Ótica.

Unitermos: 1. Laser; 2. Interação da luz com a matéria; 3. Teoria da luz; 4. Emissão da luz. 


\title{
University of São Paulo \\ Physics Institute
}

\section{Developing new sources of coherent states of light for applications in quantum optics}

\author{
Raúl Leonardo Rincón Celis
}

Supervisor: Prof. Dr. Marcelo Martinelli

Dissertation submitted to the Physics Institute of the University of São Paulo in partial fulfillment of the requirements for the degree of Master of Science.

Examining Committee:

Prof. Dr. Marcelo Martinelli - Orientador (IFUSP)

Prof. Dr. Reinaldo Luiz Cavasso Filho (UFABC)

Prof. Dr. Cleber Renato Mendonça (IFSC) 

Para todos aquellos que puedo llamar familia y amigos. 



\section{Agradecimentos}

Agradeço primeiramente a minha família, aquele núcleo onde sempre posso chegar e sentir felicidade e amor. Aos meus pais, Raúl e Patricia, a minha avó María, que são o principal motor para chegar até este ponto e querer continuar, por serem eles o meu principal exemplo de humildade, a guia de quem quero ser. A minha irmã Cindy por me ensinar sobre fortaleza e esforço para com os sonhos. Ao meu irmão David por me ajudar a conservar uma atitude crítica e pelas grandes aventuras a cada momento juntos. A minha namorada Melisa pela alegria de viver, a alegria de procurar o diferente entre a homogeneidade e a criatividade na monotonia.

Quero agradecer ao nosso laboratório $L M C A L$, por ser um equipe de pessoas competente abertas a discussão que propõe temáticas atuais junto com a com a companhia dos nossos orientadores e a equipe completo. Ao Professor Marcelo Martinelli pela grande orientação na cotidianidade do laboratório e o seu esforço para conosco. Ao Professor Paulo Nussenzveig pelos conselhos procurando a nossa formação argumentativa. Ao Dr. Breno Marques por transmitir em cada discussão essa alegria única que tem. Ao Carlos González pelas mãos extras no experimento e as explicações a cada passo avançado. Agradeço também ao Túlio Brito, Dr. Renné Medeiros, Rayssa Bruzaca, Igor Konieczniak, Renato Domeneguetti e Dr. Hans Marin por estarem sempre dispostos a dar uma explicação e uma ajuda, mesmo quando não dispõem de tempo. Luiz Couto, Lucas Nunes e Roger Kögler, obrigado por sempre estarem dispostos a discutir ideias, mesmo fora da física. Finalmente para o Álvaro e o Pablo não tenho palavras, só amizade.

Também quero agradecer a muitas pessoas que fazem este andar mais fácil, cheio de risos e ideias, que são tantas que é mais fácil não escrever os nomes aqui, mais agradecer em pessoa a cada uma delas. Finalmente quero agradecer à USP e ao governo Brasileiro, ao $\mathrm{CNPq}$ pelo financiamento recebido e por me permitir contribuir ao desenvolvimento de este hermoso y atareado pais. 

"Nunca me interessou uma ideia que não resista a muitos anos de abandono." Gabriel García Marquez 



\section{RESUMO}

Os diodos laser são amplamente usados em física atômica em configurações de cavidade externa com uma rede de difração (Configuração Littrow ou Littrow-Metcalf), que permite sintonizar o seu comprimento de onda e filtrar do seu espectro. Mesmo com este controle, eles apresentam um excesso de ruído por volta de $40 \mathrm{~dB}$ acima do ruído quântico padrão, dificultando seu uso em ótica quântica. Nosso propósito neste projeto é diminuir os valores típicos de ruído do diodo laser até níveis aceitáveis que permitam trabalhar em ótica quântica. Para conseguir isto, construímos um laser em estrutura em anel com o diodo semicondutor como o meio de ganho.

Caracterizamos a potência de saída do laser em função da corrente de injeção no chip. Também introduzimos um mecanismo de controle das perdas da cavidade para caracterizar a potência de saída em função das perdas. Alcançamos uma potência máxima de $\sim 25 \mathrm{~mW}$ para 0,8 A, com um limiar de oscilação de $\sim 0,45 \mathrm{~A}$, e uma potência máxima de $\sim 10 \mathrm{~mW}$ (a 0,8A) com um limiar de $\sim 0,41 A$. Para caracterizar as suas propriedades de ruído, usamos a técnica da rotação de elipse para diferentes valores da corrente de injeção e de perdas controladas. Finalmente, comparamos o ruído das quadraturas do nosso novo sistema com o ruído de um laser de diodo em configuração Littrow.

Enquanto o laser Littrow apresenta excesso de $40 \mathrm{~dB}$ no ruído da fase, encontramos valores para o ruído de amplitude do nosso novo laser entre 10 e $15 \mathrm{~dB}$ e do ruído de fase entre 11 e $27 d B$ acima do nível do ruído quântico padrão. Assim, conseguimos diminuir o ruído da quadratura fase por volta de $20 \mathrm{~dB}$, porém, também incrementamos o ruído de amplitude, fazendo com que o ruído das quadraturas esteja no nível de $11 \mathrm{~dB}$ acimo do nível do ruído quântico padrão. Este nível é compatível com laseres de estado sólido (Nd:YAG) e pode ser facilmente reduzido com ajuda de uma cavidade de filtro.

Palavras-chave: Laser, ruído de fase, ruído quântico padrão, cavidade, meio de ganho. 



\section{ABSTRACT}

Laser diodes are widely used in atomic physics in configurations of external cavity with a diffraction grating (Littrow or Littrow-Metcalf configuration), that allows us to tune its wavelength and filter their spectrum. Even with this control they present an excess noise about $\sim 40 \mathrm{~dB}$ above the standard quantum level,limiting their uses for quantum optics. Our goal in this project is to decrease the typical noise level of the diode laser, to reasonable values for future work with quantum optics. In order to do that we built a ring laser using a semiconductor chip as the gain medium.

We characterize the output power of the laser as a function of the injection current. We also introduce a mechanism for controlling the losses so that, we were able to characterize the output power by changing the controlled losses. We reach a maximum power of $\sim 25 \mathrm{~mW}$ at $0.8 \mathrm{~A}$, with the threshold current value $\sim 0.45 \mathrm{~A}$, and a maximum power of $\sim 10 \mathrm{~mW}$ (@ $0.8 A$ ) for $\sim 0.41 A$ of threshold current. In order to characterize its noise properties, we performed the ellipse rotation technique for different values of the injection current and controlled looses. Finally, we compare the quadrature noise of our new system with the noise of a diode laser in Littrow configuration.

While Littrow laser present excess of of $40 d B$ on the phase noise, we found noise levels for the amplitude noise of our new laser between 10 to $15 d B$ and its phase noise between 11 to $27 \mathrm{~dB}$ above the standard quantum level. So, we achieved a noise reduction of the phase quadrature in $20 \mathrm{~dB}$, but, we also increase the amplitude noise, obtaining a quadrature noise around $11 \mathrm{~dB}$ above the standard quantum limit. This level is compatible with solid state lasers (Nd:YAG) and can be easily reduced with the help of a filter cavity.

Keywords: Laser, phase noise, shot noise, cavity, gain media. 



\section{Lista de figuras}

Figura 1 - Comparação níveis de energia atômico, molecular e dos sólidos. . . . . 4

Figura 2 - Diagrama de bandas de um sólido. . . . . . . . . . . . 5

Figura 3 - Metais, Isolantes e semicondutores. . . . . . . . . . . . . 6

Figura 4 - Transições diretas e indiretas. . . . . . . . . . . . . . 7

Figura 5 - Concentração de portadoras a temperatura zero. . . . . . . . . . 8

Figura 6 - Concentrção de portadores semicondutor intrínseco. . . . . . . . . . 8

Figura 7 - Distribuição das portadores num semicondutor extrínseco. . . . . . . . 8

Figura 8 - Junção PN . . . . . . . . . . . . . . . . . . 11

Figura 9 - Diagrama de bandas para junção PN. . . . . . . . . . . . . . . 12

Figura 10 - Junção PN . . . . . . . . . . . . . . . . . . . . . . . 12

Figura 11 - Heterojunção. . . . . . . . . . . . . . . . . . . . . . . 13

Figura 12 - Estrutura do chip semicondutor. . . . . . . . . . . . . . . . . 14

Figura 13 - Sistema de dois níveis. . . . . . . . . . . . . . . . . . . . 19

Figura 14 - Esquema do sistema de três níveis. . . . . . . . . . . . . . . . . . 21

Figura 15 - Inversão de população para três e quatro níveis. . . . . . . . . . . . . . 22

Figura 16 - Perda da coerência na fase. . . . . . . . . . . . . . . . 25

Figura 17 - Parte Real e Imaginaria da Susceptibilidade Elétrica. . . . . . . . . . . 29

Figura 18 - Esquema Cavidade Fabry Perot . . . . . . . . . . . . . . . . . . 30

Figura 19 - Função de Airy. . . . . . . . . . . . . . . . . . . . . . . . . . 32

Figura 20 - Ganho em função da intensidade intracavidade. . . . . . . . . . . . . . 34

Figura 21 - Intensidade de saída da cavidade em função das perdas. . . . . . . . . . 35

Figura 22 - Puxamento de Frequência. . . . . . . . . . . . . . . 36

Figura 23 - Laser no instante inicial. . . . . . . . . . . . . . . . . . . . 37

Figura 24 - Seleção do espectro dentro da cavidade. . . . . . . . . . . . . . . . . . 37

Figura 25 - Diagrama de fasores para campo elétrico. . . . . . . . . . . . . . . 42

Figura 26 - Deteção Balanceada . . . . . . . . . . . . . . . . . . . . . . . 49

Figura 27 - Cavidade ótica para estudo da rotação de elipse. . . . . . . . . . . . . . 51

Figura 28 - Cavidade de Análises e dessintonia. . . . . . . . . . . . . . . 53

Figura 29 - Comportamento da portadora quando passa pela ressonância. . . . . . 54

Figura 30 - Correlação entre quadraturas, termo $\gamma \ldots \ldots$. . . . . . . . . 55

Figura 31 - Correlação entre quadraturas, termo $\delta \ldots \ldots \ldots$. . . . . . . 55 
Figura 32 - Elipse de ruído. . . . . . . . . . . . . . . . . . . . 55

Figura 33 - Espectro de ruído. . . . . . . . . . . . . . . . . 56

Figura 34 - Limite de frequência de análises. . . . . . . . . . . . . . . 57

Figura 35 - Montagem diodo em cavidade externa. . . . . . . . . . . . . . . . 62

Figura 36 - Geometria de feixes incidindo na rede de difração. . . . . . . . . . . . . 62

Figura 37 - Estrutura cavidade Littrow. . . . . . . . . . . . . . . . . . 63

Figura 38 - Montagem SDL. . . . . . . . . . . . . . . . . 64

Figura 39 - Prismas anormórficos . . . . . . . . . . . . . . . . . . . . 64

Figura 40 - Transmissão do etalon. . . . . . . . . . . . . . . . . . . . 65

Figura 41 - Esquema da Cavidade Fechada. . . . . . . . . . . . . . . . . . . 65

Figura 42 - Estabilidade da Cavidade . . . . . . . . . . . . . . . 66

Figura 43 - Cavidade de Análise . . . . . . . . . . . . . . . . . . . 67

Figura 44 - Problema trabalhando com resolução menor. . . . . . . . . . . . . . . . 68

Figura 45 - Problema trabalhando com frequência alta. . . . . . . . . . . . . . . 69

Figura 46 - Exemplo dados brutos Littrow . . . . . . . . . . . . . . . . 70

Figura 47 - Ajuste dados exemplo Littrow . . . . . . . . . . . . . . . . 71

Figura 48 - Potência nas saídas do chip semicondutor. . . . . . . . . . . . 76

Figura 49 - Estimativa da largura de linha do chip abaixo do limiar. . . . . . . . . 76

Figura 50 - Estimativa da largura de linha do chip acima do limar. . . . . . . . . . 76

Figura 51 - Resposta do chip frente ao feixe de bombeio, primeira montagem. . . . 77

Figura 52 - Montagem caracterização chip semicondutor. . . . . . . . . . . . 78

Figura 53 - Resposta do chip frente ao feixe de bombeio, montagem definitivo. . . . 79

Figura 54 - Comportamento do ganho em função do bombeio. . . . . . . . . . . . . 80

Figuras 55 - 60 - Saída da Cavidade em função da corrente de injeção . . . . . . . 80

Figuras 61 - 63 - Saída da Cavidade em função da polarização . . . . . . . . . . . 82

Figura 64 - Cavidade monomodo e multimodo. . . . . . . . . . . . . . . . . . . 84

Figura 65 - Meidção da largura de linha. . . . . . . . . . . . . . . . . . . . . . 85

Figura 66 - Largura de linha do laser. . . . . . . . . . . . . . . . . . . 85

Figura 67 - Sistema de rotação de elipse. . . . . . . . . . . . . . . . . 86

Figura 68 - Exemplos de problemas na medida do espectro de ruído. . . . . . . . 87

Figura 69 - Ruído das quadraturas em função da corrente de injeção cavidade fechada. 88

Figura 70 - Ruído das quadraturas em função da corrente de injeção cavidade aberta. 89

Figura 71 - Fator Q de Mandel normalizado em função potência do laser. .... . 91

Figura 72 - Ruído das quadraturas em função da corrente de injeção cavidade aberta. 92

Figuras 73 - 75 - Ruído das quadraturas em função das Perdas da Cavidade. . . . 93

Figura 76 - Comparação entre Ruído do diodo Littro e o SDL. . . . . . . . . . . . 95 


\section{Sumário}

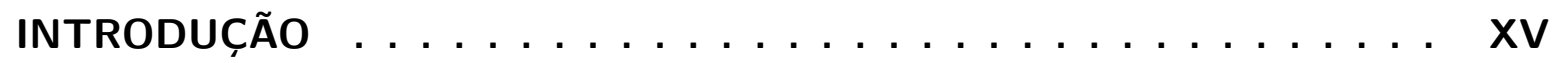

CONCEITOS TEÓRICOS 1

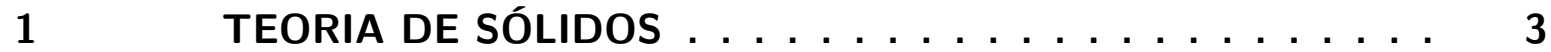

$1.1 \quad$ Níveis de energia num sólido . . . . . . . . . . . . . . . . . 3

1.1.1 Teorema de Bloch . . . . . . . . . . . . . . . . . 3

1.1.2 Excitação e decaimento entre níveis . . . . . . . . . . . . 6

1.2 Concentração de Portadores . . . . . . . . . . . . . 7

1.3 Junções . . . . . . . . . . . . . . . . 10

1.3.1 Junção PN . . . . . . . . . . . . . . . . . . 10

1.3.2 Heterojunção . . . . . . . . . . . . . . . . 13

1.3.2.1 Estrutura do Laser . . . . . . . . . . . . . . . . . . . . . 14

2 TEORIA DO LASER . . . . . . . . . . . . . . . 17

$2.1 \quad$ Amplificadores . . . . . . . . . . . . . . . . 18

2.1.1 Absorção e Emissão de Luz . . . . . . . . . . . . . . . . . . . . 18

2.1.2 Sistema de Três Níveis . . . . . . . . . . . . . . . . . . . 20

2.1.2.1 Interação da radiação com sistema de dois níveis . . . . . . . . . . . 23

2.1.2.2 Polarização e Susceptibilidade Dielétrica . . . . . . . . . . . . . . . . 27

$2.2 \quad$ Cavidade Vazia . . . . . . . . . . . . . . . . . . 29

$2.3 \quad$ Cavidade com Meio de Ganho . . . . . . . . . . . . . . . . . . 32

2.3.1 Condição de Limiar . . . . . . . . . . . . . . . . . . . . . . . . 33

2.3.2 Condição de Frequência . . . . . . . . . . . . . . . . . . 35

2.3.3 Distribuição Espectral . . . . . . . . . . . . . . . . . 36

$2.4 \quad$ Ruído do Laser Semicondutor . . . . . . . . . . . . . . . . . 38

3 DETEÇÃO DO RUÍDO . . . . . . . . . . . . . . . . . 41

3.1 Quadraturas do Campo Eletromagnético . . . . . . . . . . . 41

3.2 Ruído Quântico Padrão . . . . . . . . . . . . . . . . . . 44

3.2.1 Deteção Balanceada . . . . . . . . . . . . . . . . . 48

3.3 Deteção com Cavidade . . . . . . . . . . . . . 50

$3.4 \quad$ Elipse de Ruído . . . . . . . . . . . . . . . . . 54 
INSTRUMENTAÇÃO

4 INSTRUMENTAÇÃO . . . . . . . . . . . . . . 61

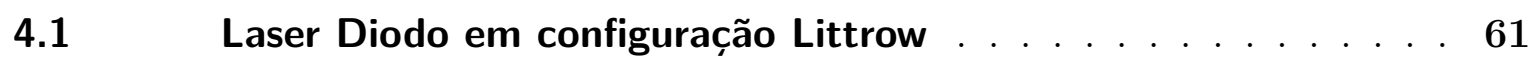

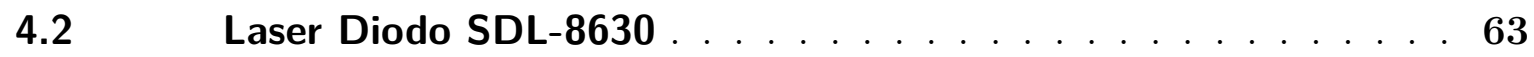

4.2 .1 Cavidade Fechada . . . . . . . . . . . . . . . . . 64

$4.3 \quad$ Cavidade de Análise $\ldots \ldots \ldots \ldots \ldots 6 \ldots$

$4.4 \quad$ Analisador de Espectro . . . . . . . . . . . . 67

DESENVOLVIMENTO EXPERIMENTAL E RESUL$\begin{array}{ll}\text { TADOS } & 73\end{array}$

5 MONTAGEM EXPERIMENTAL E RESULTADOS . . . . . . . 75

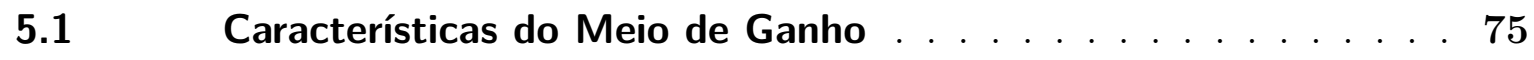

5.1.1 Resposta do chip frente ao feixe de bombeio . . . . . . . . . 76

5.1.1.1 Sentido Contrapropagante . . . . . . . . . . . . 76

5.1.1.2 Sentido Propagante . . . . . . . . . . . . . . . . 78

$5.2 \quad$ Cavidade Fechada $\ldots \ldots \ldots \ldots \ldots$

5.2.1 Saída da Cavidade em Função da Corrente de Injeção . . . . . . . . 80

5.2.2 Saída da Cavidade em função das perdas . . . . . . . . . . . . 82

5.2 .3 Efeito do Etalon na Cavidade . . . . . . . . . . . . . 83

$5.2 .4 \quad$ Largura de Linha . . . . . . . . . . . . . . . . . . . . 84

$5.3 \quad$ Ruído das Quadraturas . . . . . . . . . . . . . . 85

5.3.1 Ruído em Função da Corrente de Injeção . . . . . . . . . . . . . . . 87

5.3.2 Excesso de Ruído em Função da Potência do laser . . . . . . . . . . 90

5.3.3 Ruído em Função das Perdas da Cavidade . . . . . . . . . . . . . 93

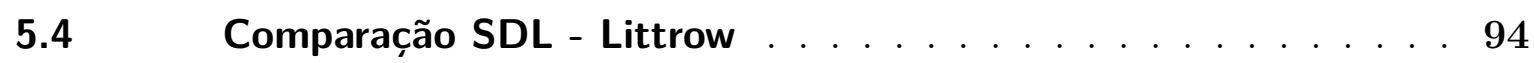

6 CONCLUSÕES E PERSPECTIVAS $\ldots \ldots \ldots \ldots \ldots$

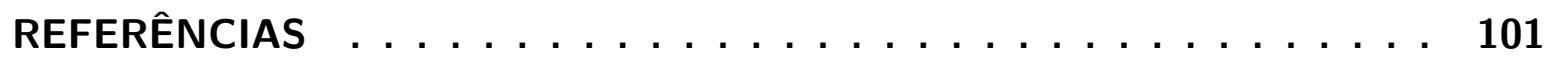




\section{Introdução}

Os sistemas óticos se mostram promissores para fazer testes de fundamentos da informação quântica. Ao mesmo tempo, estes sistemas apresentam resultados práticos e aplicáveis em maior escala como protocolos de criptografia quântica [1]. Uma das principais dificuldades no trabalho com estes sistemas está na fragilidade dos estados gerados e no aumento da complexidade da montagem, dado os recursos necessários para o isolamento do sistema, que contraria o propósito de escalabilidade.

No Laboratório de Manipulação Coerente de Átomos e Luz (LMCAL) temos bem estruturada a técnica para manipular estados emaranhados sintonizáveis, através de osciladores paramétricos óticos (OPO) usando meios não-lineares e cavides óticas [2]. Também empregamos os efeitos não lineares de sistemas atômicos como novas fontes de emaranhamento baseados na mesma estrutura do (OPO) [3], e estamos a procura da escalabilidade trabalhando com cavidades em chips semicondutores (micro-OPO) [4].

Todos estos fenômenos são gerados bombeando o meio com fontes de luz estáveis, com uma largura espectral estreita e de baixo ruído. Estas fontes de luz laser são compostas por um meio de ganho e uma cavidade de realimentação [5]. Para obter a amplificação da luz a condição denominada inversão de população deve ser garantida. Dependendo do tipo de meio de ganho, podemos criar essa condição por exemplo, por bombeio ótico coerente ou incoerente, usando reações químicas, descargas elétricas em gás ionizado, etc [6]. Para o laser de diodo, a inversão de população é obtida com a aplicação de uma corrente que insere portadores no semicondutor, diminuindo a diferença de potencial na região de depleção onde se recombinam os pares elétron-buraco com a emissão de fótons.

Como exemplo de aplicação temos o modelo Mephisto, da Innolight, baseado em um cristal de $N d: Y A G$, que fornece até $100 \mathrm{~mW}$ de potência no comprimento de onda $532 \mathrm{~nm}$, em um protocolo de teletransporte. No entando, mesmo este laser comercial com qualidade alta, possui um excesso de ruído apreciável e se faz necessário filtrar o campo através de uma cavidade que atua como filtro passa-banda, atenuando as frequências fora da ressonância e aumentando a dificuldade da montagem [7]. Também trabalhamos com laser Ti : Safira, sintonizável entre 700 a $1100 \mathrm{~nm}$ em operação monomodo, como bombeio em sistemas baseados em cristais ou átomos. Medidas do ruído feitas no nosso laboratório indicaram que este laser tem um ruído bem inferior ao do Mephisto, aproximando-se ao 
estado coerente para frequências de análise acima de $7 \mathrm{MHz}$, tornando-o um excelente candidato para aplicações em informação quântica. A grande desvantagem deste laser é o grande número de componentes óticos que compõem o sistema intra-cavidade para selecionar um modo de oscilação e o sistema de travamento de frequência [8], delicado por se tratar de cavidades usualmente grandes. Além disso, o custo de um laser destes pode alcançar a casa dos US $\$ 300.000,00$ incluíndo o laser de bombeio.

Outra fonte de luz muito usada em física atômica, o laser de diodo [9], está baseado em semicondutores e seu custo é bem menor $U S \$ 1.500,00$. O preço justifica que sejam mais largos espectralmente e que tenham potência menor, até $40 \mathrm{~mW}$ em $780 \mathrm{~nm}$. A largura de linha pode ser controlada elaborando um sistema de cavidade externa, formado por uma rede de difração e a reinjeção no sistema da primeira ordem do feixe difratado [10]. Por serem cavidades pequenas, a estabilização delas não é tão trabalhosa e facilmente podemos selecionar o modo de oscilação. O grande problema que vem com a economia é a qualidade, em termos de ruído. Mesmo com sistemas de travamento, o excesso de ruído na fase se encontra $40 d B$ acima do esperado para um estado coerente [11]. Para filtrar esse ruído precisaríamos de cavidades muito longas, difíceis de estabilizar, que acabariam atenuando fortemente o feixe [12].

Dado que no nosso laboratório temos ampla experiência trabalhando com laser de diodo, propomos trazer o ruído do diodo para níveis minimamente aceitáveis de ruído e assim obter fontes econômicas, sintonizáveis, úteis para física atômica e ótica quântica.

Este trabalho está dividido em três etapas. A primeira etapa contempla os conceitos teóricos necessários. Fazemos uma descrição geral dos semicondutores, centrados nas transições do sistema e no acoplamento com o campo eletromagnético. Passamos então ao estudo do laser, onde usamos a versão semi-clássica para estudar suas propriedades. O terceiro capítulo corresponde à descrição da técnica implementada para a medida do ruído da luz, a rotação de elipse.

A segunda etapa descreve a instrumentação usada no desenvolvimento deste projeto. A terceira e última etapa é a dos resultados da medida da potência e do ruído do laser e a discussão destes resultados. Por fim, concluímos este trabalho fazendo um resumo do aprendido, discutindo os principais resultados e apontaremos as perspectivas para o nosso novo laser. 
CONCEITOS TEÓRICOS 



\section{TEORIA DE SÓLIDOS}

Amplamente reconhecidos e estudados, os semicondutores são usados em sistemas óticos desde a industria até a pesquisa fundamental. Pela experiência do nosso laboratório trabalhando com eles em física atômica, decidimos fazer deles o núcleo central do nosso projeto e, por isso, temos um capítulo dedicado completamente para seu entendimento. Neste capítulo teremos uma descrição geral de como são formadas as bandas de energia nos sólidos para logo trabalhar explicitamente nos semicondutores, as transições possíveis, qual e como é a concentração dos portadores e finalmente uma introdução às junções p-n.

\subsection{Níveis de energia num sólido}

Lembremos que a solução do átomo de hidrogênio leva-nos a encontrar estados bem definidos com níveis de energia discretos [13]. A adição de um núcleo forma uma molécula de hidrogênio $\mathrm{H}_{2}^{+}$, e o sistema muda tal que as funções de onda dos elétrons vão se superpor, levando a ter uma mudança na energia do novo sistema tendo, por exemplo, no caso do estado base do íon, uma separação do nível fundamental em dois níveis que dependem fortemente da distância entre o elétron e os núcleos [14]. Poderia-se complicar o sistema adicionando átomos de hidrogênio o que levaria a aparição de novas separações em todos os níveis de energia, até por exemplo, considerar $10^{23}$ átomos, onde os subníveis de energia seriam tantos que não há como distinguir entre eles. Neste caso extremo, é possível considerar que o que antes era um nível discreto agora é uma banda contínua de energia separada de outras bandas por regiões proibídas denominadas gaps [15].

\subsubsection{Teorema de Bloch}

Seguindo a referência [16], descrevemos o modelo mais simples para estudar o comportamento de um elétron num cristal; um elétron livre sob a ação de um potencial 


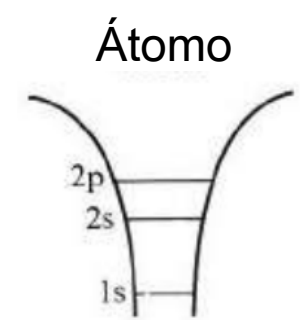

a)

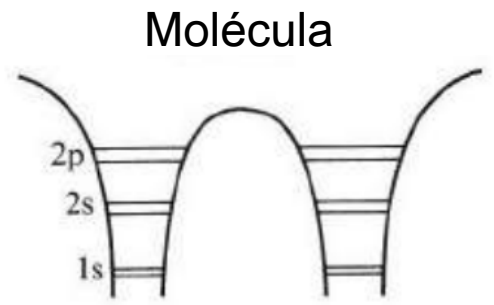

b)

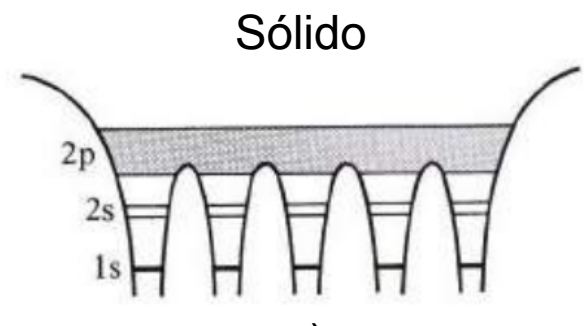

c)

Figura 1. A figura a) mostra os níveis de energía para só um átomo. Em b) vemos que foi acrecentado um nível pela consideração de um segundo átomo no sistema. Finalmente em c) vemos que o sistema com grande número de átomos, gera uma superposição dessa grande cantidade de novos niveis de energia. Figura tomada de [15].

periódico. Para estudar o sistema, consideremos a equação de Schrödinger independente do tempo I:

$$
\left[-\frac{\hbar}{2 m} \nabla^{2}+V(\mathbf{r})\right] \Psi(\mathbf{r})=E \Psi(\mathbf{r}),
$$

onde $E$ é a energia do elétron, $\Psi$ é a função de onda e $V(\mathbf{r})$ é o potencial sobre o elétron. Neste modelo, são feitas varias considerações [16]:

- Os íons formam uma rede perfeita e periódica. Isto implica que todos eles são equidistantes.

- Ignoramos a interação entre elétrons condutores por duas razões. A primeira é que no caso de ter dois elétrons com spin paralelo eles tentarão ficar longe um do outro e a segunda, por eles terem o mesmo sinal da carga vão se afastar por interação de Coulomb.

- Também ignoramos a interação coulombiana entre o elétron e os íons porque o campo dos outros elétrons e íons blindam o campo do íon em consideração, fazendo com que a interação seja de curto alcance.

A partir dessas considerações, o teorema de Bloch dá a solução para a equação de Schrödinger, Equação 1.1 ( $\Psi(\mathbf{r}))$, denominada a função de Bloch, que tem a forma:

$$
\Psi(\mathbf{r})=\mathrm{e}^{i \mathbf{k} \cdot \mathbf{r}} u_{n, \mathbf{k}}(\mathbf{r})
$$

onde $\mathrm{e}^{i \mathbf{k} \cdot \mathbf{r}}$ é uma onda plana indicando que o elétron se move como se fosse livre, $n$ é o nível de energia e $u_{\mathbf{k}}(\mathbf{r})$ é uma função que tem a mesma periodicidade da rede e modula a onda plana. Então temos uma função de onda que descreve o elétron pelo sólido todo, é não localizada e periódica.

\footnotetext{
I Consideramos um comportamento harmônico no tempo.
} 
Por outro lado, a energia do elétron no sistema periódico pode ser aproximada à energia do elétron livre considerando valores pequenos do vetor de onda $\mathbf{k}$ e mudando a massa do elétron por uma massa efetiva $m^{*}$ devido ao potencial periódico. Com isto em mente, a energia do elétron pode ser escrita como:

$$
E=\frac{\hbar^{2} k^{2}}{2 m^{*}}
$$

Se tomamos a Equação 1.2 e usamos a equação de Schrödinger (1.1), obtemos uma equação de autovalores e autovetores:

$$
\left[-\frac{\hbar}{2 m}(\nabla+i \mathbf{k})^{2}+V(\mathbf{r})\right] u_{n, \mathbf{k}}(\mathbf{r})=E_{n, \mathbf{k}} u_{n, \mathbf{k}}(\mathbf{r}),
$$

cujas soluções tem dependência com $\mathbf{k}$ sendo um parâmetro contínuo onde para cada $\mathbf{k}$ há um conjunto de soluções discretas $E_{n, \mathbf{k}}$.

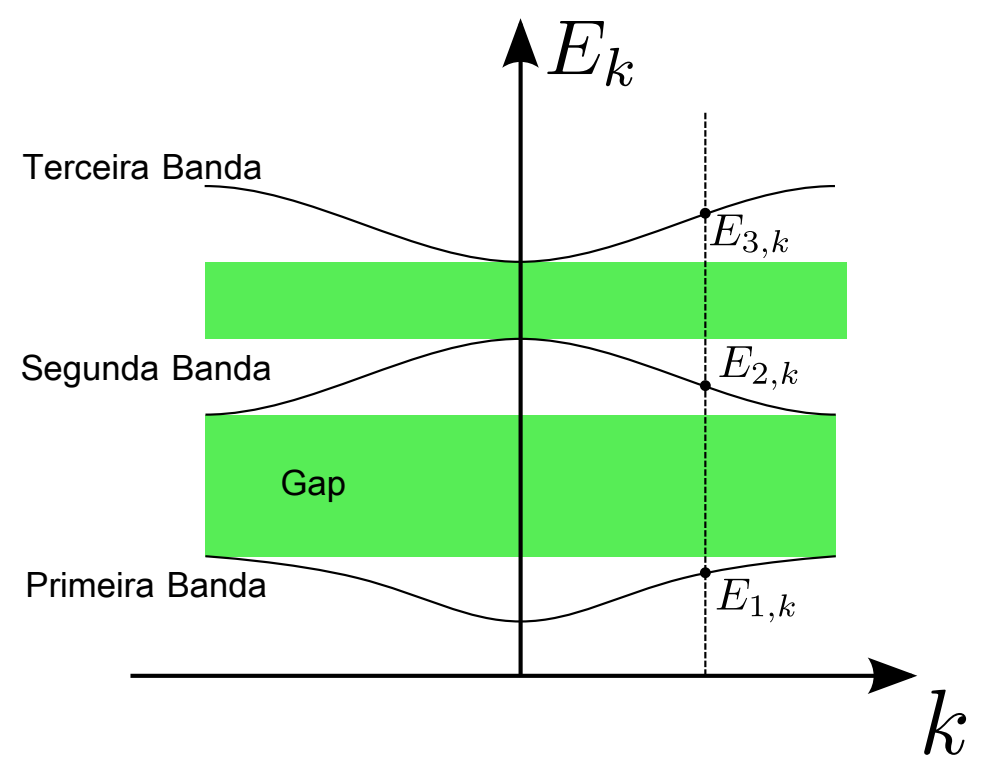

Figura 2. Exemplo do diagrama de bandas dos sólidos. Vemos o gap de energia entre as diferentes bandas e uma linha tracejada que amostra que para um valor específico do $k$ obtem-se autovalores discretos.

Cada sólido tem uma estrutura de bandas definida que determina a suas propriedades macroscópicas, ou seja se eles são condutores, isolantes ou semicondutores, e tem resposta diferente frente a um campo elétrico aplicado. Para que os elétrons possam se movimentar é preciso haver níveis energéticos livres. Por exemplo, quando uma banda de energia está incompleta ou quando o seguinte nível de energia está vazio e o campo externo for suficientemente forte para excitar um elétron, permitindo a sua movimentação livremente. Para esclarecer a ideia das bandas, temos na Figura 2 um exemplo de um diagrama de bandas. Vemos existe uma região proibida de energia, gap, que permite definir a banda de condução como aquela que está acima, e a banda de valência como aquela que está abaixo [17]. 
A diferença fundamental entre metais, isolantes e semicondutores está na região de energias proibidas. Em um isolante o número de elétrons é suficiente para encher completamente todos os níveis da banda de valência e o gap é grande, limitando a excitação de elétrons para banda de condução. No caso do condutor, as bandas de energia podem se superpor ou podem estar parcialmente cheias, portanto, os elétrons têm a capacidade de se movimentar livremente ao se aplicar um campo elétrico externo. Finalmente, os semicondutores quando estão a temperatura de $0 K$ são isolantes mas o gap de energia é menor do que o destes. Por exemplo, no caso do diamante ele apresenta um gap de $5 \mathrm{eV}$, sendo que o silício tem um gap de $1.1 \mathrm{eV}$. Nos semicondutores, a região de energia proibida é tão pequena que levar os elétrons para a banda de condução pode ser feito simplesmente deixando ele à temperatura ambiente. Em geral, podemos definir como semicondutores aqueles materiais que tem um gap de energia menor a $2 \mathrm{eV} \mathrm{[18].}$

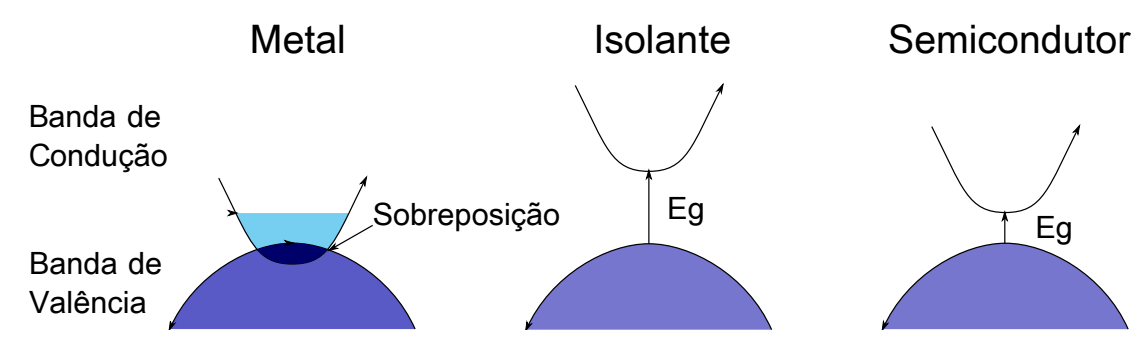

Figura 3. Exemplo de metais onde as bandas se sobrepoem. Vemos que os isolantes e os semicondutores, tem a banda de valência cheia (cor azul) enquanto a banda de condução está vazía.

\subsubsection{Excitação e decaimento entre níveis}

Imagine o caso de excitar um elétron da banda de valência, via ótica ou térmica. Quando o elétron vai para a banda de condução deixa livre um espaço na banda de valência denominado buraco, esta nova configuração é denominada par elétron buraco. O elétron pode voltar para a banda de valência recombinando-se com o buraco e liberando energia em forma de fótons ou de vibrações na rede (fônons). De acordo com a estrutura de bandas, o processo de relaxamento do estado pode diferir entre dois casos mostrados na Figura 4. Quando o sistema tem uma transição direta, o valor de energia mínimo da banda de condução e o valor máximo da banda de valência tem o mesmo momentum e a recombinação libera fótons. No caso dos sistemas indiretos o mínimo da banda de condução e o máximo da de valência estão situadas em diferentes valores do número de onda $k$ e a recombinação libera energia em forma de calor ou vibrações da rede.

Na manufatura de lasers semicondutores o sistema mais empregado é o aquele de transição direta pois aproveita melhor a recombinação e evita esquentar o semicondutor. ${ }^{\text {II }}$

II Alguns exemplos de semicondutores diretos são: GaN, GaAs e InP. Mencionamos também alguns semicondutores indiretos: Si, Ge e AlAs. 

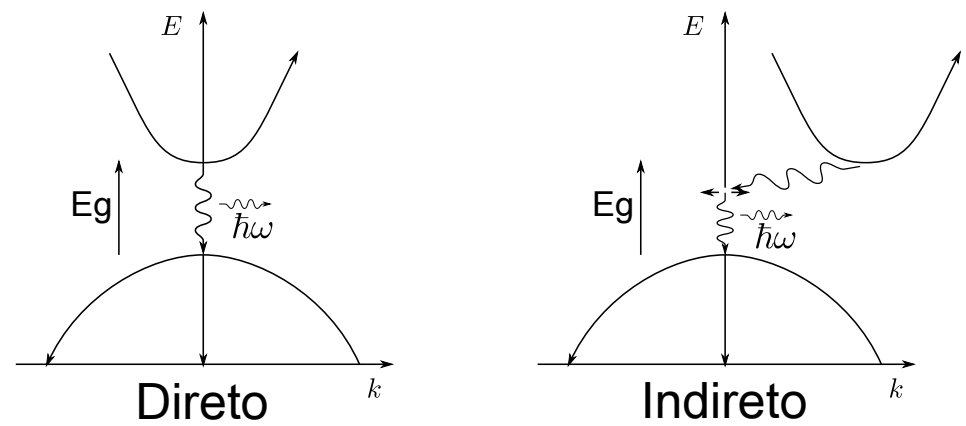

Figura 4. O sistema com transicões diretas libera um fóton quando o elétron se relaxa. No caso da transição indireta a energia liberada tem a forma de calor ou fónons.

\subsection{Concentração de Portadores}

Para conhecer as propriedades óticas do sistema necessitamos saber a densidade de buracos e elétrons, os quais chamaremos de portadores, nas bandas de condução e valência. Sabemos que em semicondutores podemos introduzir portadores, dopando o material gerando um excesso de buracos (semicondutore tipo p) ou de elétrons (semicondutores tipo $\mathbf{n}$ ). Como estamos trabalhando com um sistema de partículas idênticas que tem que obedecer o principio de exclusão de Pauli, vamos usar a distribuição de Fermi-Dirac para conhecer o concentração de portadores nas bandas de energia:

$$
f(E)=\frac{1}{\mathrm{e}^{\left(E-E_{F}\right) / k_{B} T}+1}
$$

tendo $k_{B}$ como a constante de Boltzmann, $E_{F}$ a energia de Fermi e $T$ a temperatura. Esta distribuição nos dá a probabilidade excitar de um elétron para um nível de energia livre $E$, dada uma temperatura $T$. A energia de Fermi representa o nível mais alto possível que um elétron teria num sistema a zero Kelvin, todos os níveis de energia abaixo de $E_{F}$ estão cheios e todos acima estão vazios (Ver Figura 5). Neste ponto, é necessário fazer uma explicação sobre a notação quando a temperatura do sistema for maior do que zero: se utiliza o termo energia de Fermi $\left(E_{F}\right)$ quando o sistema está a temperatura zero e quando for maior, definimos o nível de Fermi $\mu$, que é sinônimo do potencial químico no contexto de semicondutores, como a energia na qual o estado tem $50 \%$ de probabilidade de ser ocupado [16].

Vejamos o que acontece com os semicondutores intrínsecos quando a temperatura é maior do que zero. Neste caso alguns elétrons podem passar para a banda de condução criando buracos na banda de valência que logo se recombinariam. Este processo seria cíclico até obter o equilíbrio onde o processo de recombinação igualaria o processo de excitação térmica. Aqui, o número de elétrons nas duas bandas seria igual, como se representa na Figura 6.

É muito interessante comparar o diagrama dos semicondutores intrínsecos com os extrínsecos porque como já mencionamos, o semicondutor dopado cria bandas de energia no 


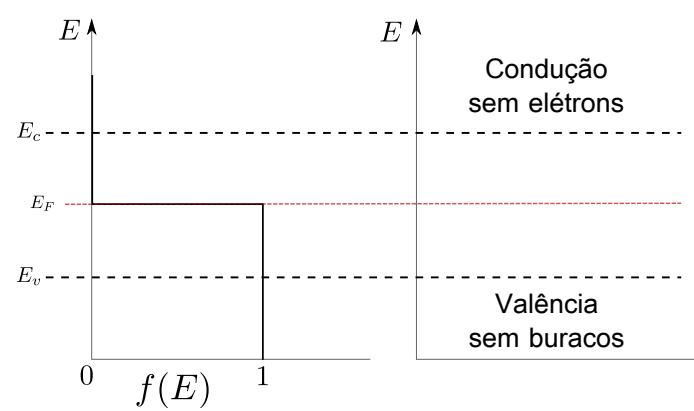

Figura 5. Com o sistema a temperatura zero, a banda de valência estaría completamente cheia e a banda de condução livre.

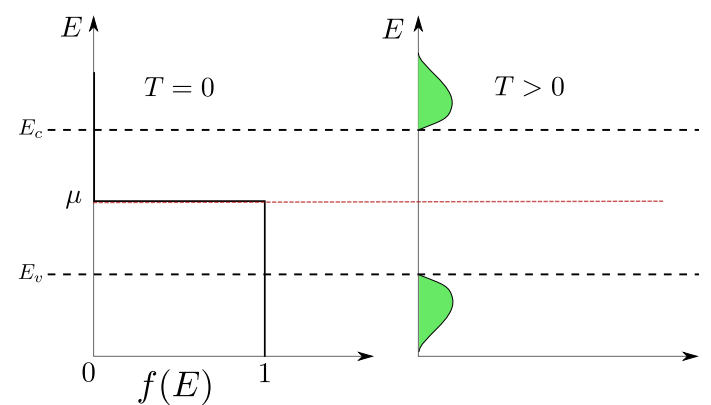

Figura 6. Nos semicondutores intrínsecos uma vez alcançado o equilibrio entre do sistema, teríamos igual número de elétrons e buracos nas bandas.

meio da região proibida perto da banda de condução (de valência) para os semicondutores tipo $\mathbf{n}(\mathbf{p})$. Dado que a concentração de elétrons (buracos) aumentou, a distribuição de Fermi-Dirac se desloca para acima (abaixo) o que se vê representado no deslocamento do nível de Fermi para acima (abaixo) do novo nível criado na banda de condução (valência).

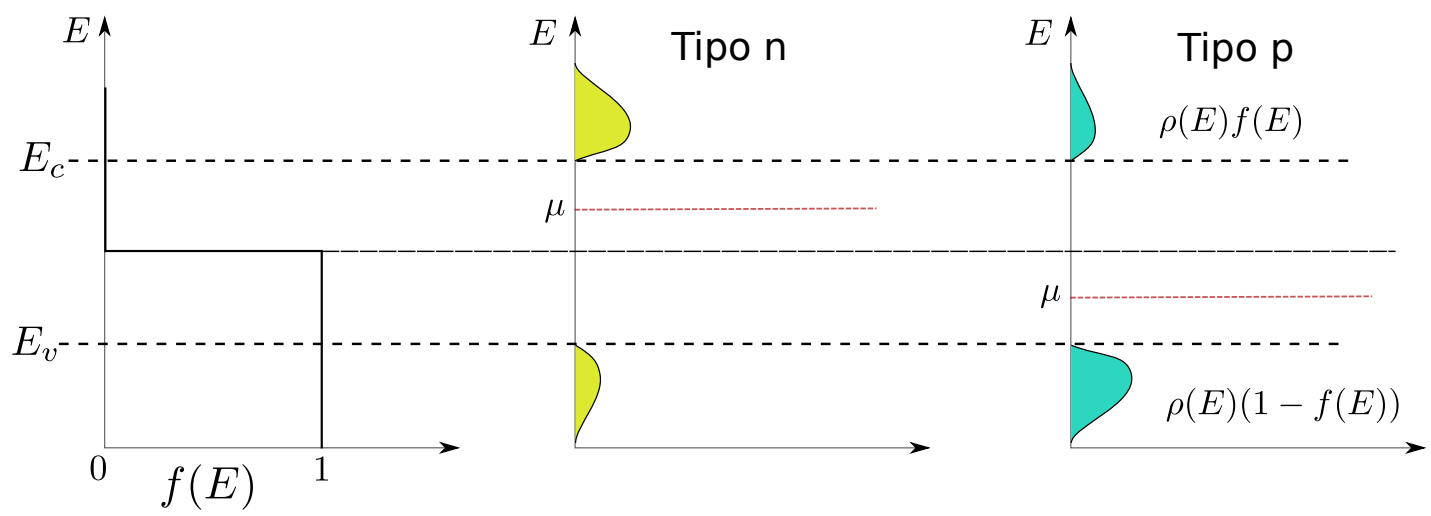

Figura 7. O nivel de Fermi é modificado conforme a concentração de portadores se tem nas bandas.

Finalmente podemos calcular o número de portadores nas duas bandas. A densidade de portadores nas bandas é:

$$
\begin{aligned}
n(E) & =\int_{E_{c}}^{E_{\max }} \rho_{c}(E) f(E) d E, \\
p(E) & =\int_{E_{\text {min }}}^{E_{v}} \rho_{p}(E)(1-f(E)) d E,
\end{aligned}
$$

onde $n(E)$ corresponde ao número de elétrons, $p(E)$ ao número de buracos, $E_{c}$ é a energia mínima da banda de condução, $E_{\max }$ é a energia máxima da banda de condução que podemos trocar por $\infty$ porque a distribuição de Fermi vai para zero para energias muito altas. $E_{m i n}$ é a energia mínima na banda de valência que igualmente trocamos por $-\infty$ e $E_{v}$ é a energia mais alta da banda de valência. $\rho_{c / v}$ é a densidade de estados por unidade de energia na banda de condução/valência e $f(E)$ é a distribuição de Fermi-Dirac. Neste 
ponto vamos considerar que estamos trabalhando com semicondutores não degenerados onde III

$$
\begin{aligned}
& E_{c}-\mu \gg k T, \\
& \mu-E_{v} \gg k T,
\end{aligned}
$$

Olhando as equações 1.9 vemos que $\mathrm{e}^{(E-\mu) / k t} \gg 1$, se levamos isto na distribuição de Fermi-Dirac (Equação 1.5), podemos desconsiderar a unidade que soma a exponencial, ficando com uma exponencial negativa $\left(\mathrm{e}^{-(E-\mu) / k T}\right)$ que corresponde à distribuição de Maxwell. Agora podemos escrever a densidade de portadores como:

$$
\begin{aligned}
& n(E)=\frac{1}{2}\left(\frac{2 m_{c} k T^{3 / 2}}{\pi \hbar} \mathrm{e}^{\left(\mu-E_{c}\right) / k T}\right), \\
& p(E)=\frac{1}{2}\left(\frac{2 m_{h} k T^{3 / 2}}{\pi \hbar} \mathrm{e}^{\left(E_{v}-\mu\right) / k T}\right),
\end{aligned}
$$

onde $m_{c / h}$ indica a massa efetiva dos elétrons/buracos, na banda de condução/valência. As equações 1.10 e 1.11 são válidas sem importar o tipo de semicondutor, só temos a restrição da Equação 1.9. Para poder calcular a densidade de portadores precisamos conhecer o valor do potencial químico $\mu$ do semicondutor. Para isso, notemos que o produto $n p$ não depende de $\mu$

$$
n p=\frac{1}{2^{4}}\left(\frac{2 k T}{\pi \hbar^{2}}\right)^{3}\left(m_{c} m_{h}\right)^{3 / 2} \mathrm{e}^{\left(E_{v}-E_{c}\right) / k T} .
$$

Esta relação indica que se tivermos uma temperatura constante, o produto entre densidades dos portadores é uma constante que independe da dopagem.

Calcular a densidade de portadores para os semicondutores intrínsecos ajuda a conhecermos a densidade no caso extrínseco. Sabemos que no caso intrínseco, os portadores são gerados aos pares e têm um processo no qual a excitação térmica iguala a recombinação elétron-buraco e portanto as densidades se mantém iguais $(n=p)$; isto nos ajuda a encontrar o valor do potencial químico

$$
\mu=\frac{E_{v}+E_{g}}{2}+\frac{3 k T}{4} \ln \left(\frac{m_{h}}{m_{c}}\right) .
$$

Chegamos então na densidade de portadores para semicondutores intrínsecos

$$
n_{i}=\frac{1}{2^{2}}\left(\frac{2 k T}{\hbar^{2}}\right)^{3 / 2} \mathrm{e}^{\left(E_{v}-E_{c}\right) / 2 k T}\left(m_{h} m_{c}\right)^{3 / 4},
$$

III Definimos os semicondutores não degenerados como aqueles que tem uma diferença de energia de $3 k T$ entre o potencial químico e qualquer uma das bandas [19]. 
onde o sub-índice $i$ refere-se a semicondutores intrínsecos. Lembremos agora da Equação 1.12 e vejamos que no caso intrínseco:

$$
n p=n_{i}^{2} .
$$

relação que por não ter dependência com o dopamento, permite que conhecida a densidade do semicondutor intrínseco, possa ser estimada a densidade do extrínseco. Na ?? e na ?? vimos que o dopamento cria novos níveis de energia (o doador e o aceitador) associados a átomos que são facilmente ionizáveis, consideramos então que a densidade de portadores nas bandas equivale ao número de elétrons ou buracos que o novo nível tem disponível IV

$$
\begin{aligned}
& n \approx N_{d} \\
& p \approx N_{a}
\end{aligned}
$$

sendo $N_{d}$ a densidade de elétrons no nível doador e $N_{a}$ a densidade de buracos no nível aceitador. Conhecida a densidade de cada novo nível e usando a Equação 1.15 encontramos a densidade de portadores em cada banda

$$
\begin{aligned}
n=\frac{n_{i}^{2}}{N_{a}} & \text { Semicondutor tipo } \mathbf{p}, \\
p=\frac{n_{i}^{2}}{N_{d}} & \text { Semicondutor tipo } \mathbf{n} .
\end{aligned}
$$

A primeira relação apresentada na Equação 1.18a funciona quando o dopamento gerou semicondutor tipo $\mathbf{n}$ e predominam os elétrons na banda de condução. $\mathrm{O}$ valor da densidade dos buracos na banda de valência $\mathbf{p}$ é menor do que o valor dos elétrons na banda de condução, como se representa na Figura 7. Quando for um semicondutor tipo p a densidade de elétrons na banda de condução é menor do que a densidade de buracos na banda de valência.

\subsection{Junções}

Vimos como é que os semicondutores trabalham, a concentração de portadores o a suas transições, agora vamos estudar uma das aplicações mais interessantes que são as junções pn e as heterojunções.

\subsubsection{Junção PN}

A junção PN é uma estrutura muito versátil que podemos encontrar como célula solar, diodo, fotodiodos e vários outros usos. Consiste em um semicondutor que tem um IV Aqui estamos supondo que a energia de ionização é suficiente para que todos os elétrons mudem de banda. 


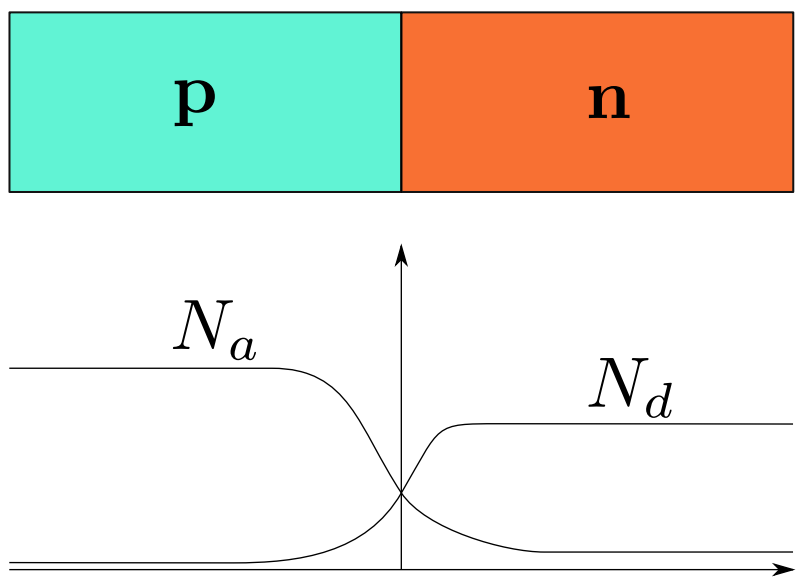

Figura 8. Denominamos junção à parte onde as duas regiões se encontram. O processo de dopamento em cada região do semicondutor pode gerar diferente número de portadores.

tratamento dopante tal que uma parte dele fica sendo tipo $\mathbf{n}$ e a outra tipo p. Vamos estudar esta estrutura de uma forma descritiva que permita ter uma noção geral do funcionamento dele.

Vamos considerar o semicondutor depois de ter sido modificado para ter os dois dopantes nele. Para cada elétron (buraco) existe um íon de carga oposta de onde o elétron (buraco) saiu. O equilibrio do sistema se atinge quando a distribuição dos portadores for homogênea pelo material todo [15] . Procurando o equilibrio, os elétrons vão tentar passar pela junção até a região $\mathbf{p}$ deixando íons positivos na região $\mathbf{n}$; na recombinação com os buracos da região p vão criar íons negativos. Devido ao intercambio de portadores a região $\mathbf{p}$ ficará caregada negativamente e a região tipo $\mathbf{n}$ fica caregada positivamente, criando uma diferencia de potencial entre as regiões denominado potencial de contato $(\phi)$, diminuindo fortemente o trânsito de portadores e criando uma diferença de energia entre regiões igual a $e \phi$, como se ilustra na Figura 9.

Quando se aplica uma voltagem $V_{o}$ no sentido da polarização direta como indicado pela Figura 10, a diferença de potencial entre as duas regiões diminuiu por $e V_{o}$, vamos entender isto por partes. Quando o terminal negativo está ligado ao lado n, elétrons vão invadir este lado e vão se recombinar com os íons positivos que tem na junção além de atrair aos buracos que estão na região p. Uma vez que a maioria dos ions positivos estejam neutros, os elétrons podem passar à região $\mathbf{p}$ onde alguns deles vão se recombinar com os buracos em excesso existente na região. Isso fará com que sejam atraídos pelo terminal positivo. De forma similar acontece com os buracos. Teremos assim, elétrons indo para a junção desde a região $\mathbf{p}$ e buracos indo para junção desde a região $\mathbf{n}$ com recombinação na interface. 
$\mathbf{p}$

$\mathbf{n}$
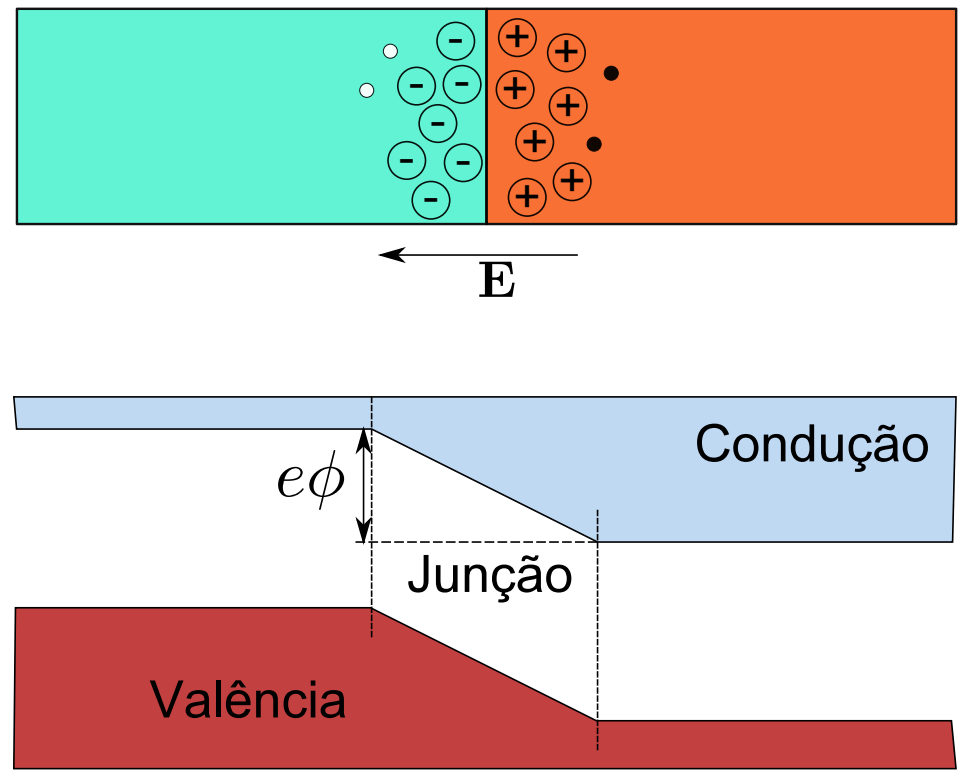

Figura 9. No equilibrio, a recombinação das portadoras gera ions que a sua vez geram um campo elétrico que limita o passo de portadores. A região da junção não tem cargas livres devido ao campo elétrico criado pelos íons.
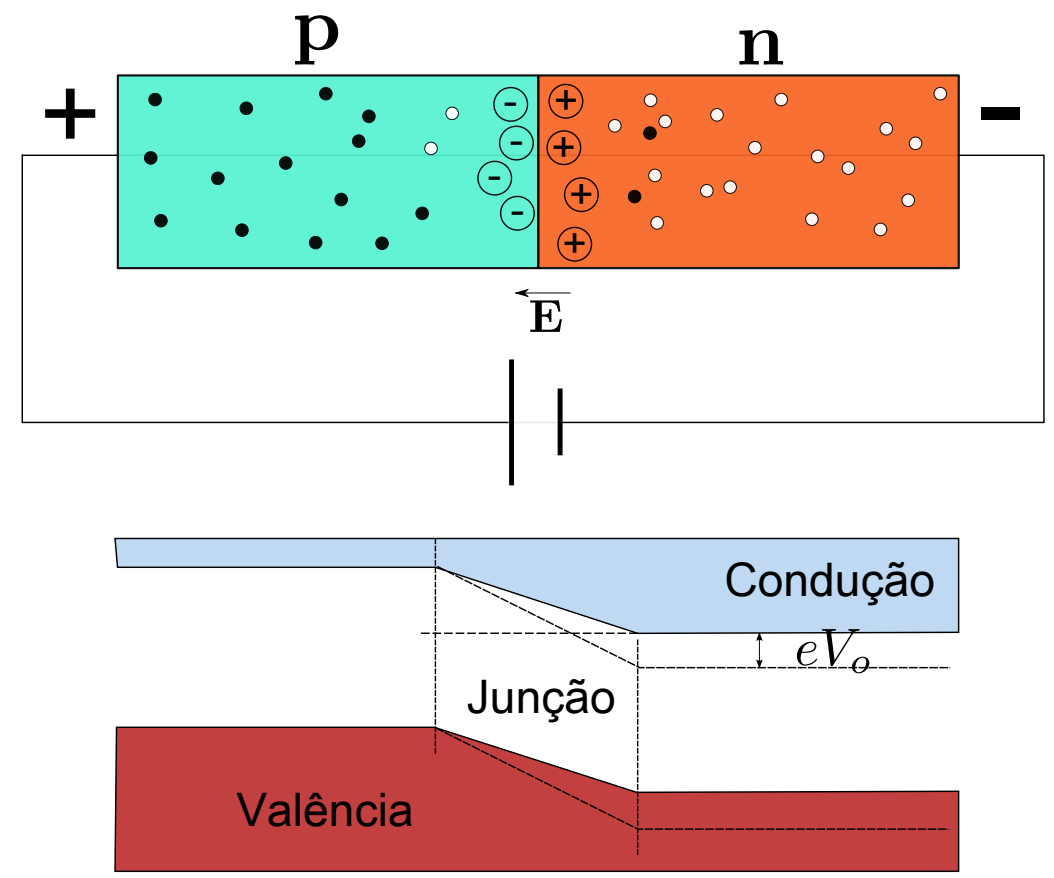

Figura 10. O esquema do semicondutor mostra que o campo elétrico diminui devido à recombinação dos novos elétrons/buracos com os íons antes presentes. No diagrama de bandas, a linha cortada se refere ao sistema em equilibrio e vemos o aumento da energia na região $\mathbf{n}$ pela voltagem aplicada. Vemos que o terminal positivo vai na região $\mathbf{p}$ e o negativo na região $\mathbf{n}$, esta configuração se denomina de polarização direta. 
$\mathbf{p}$

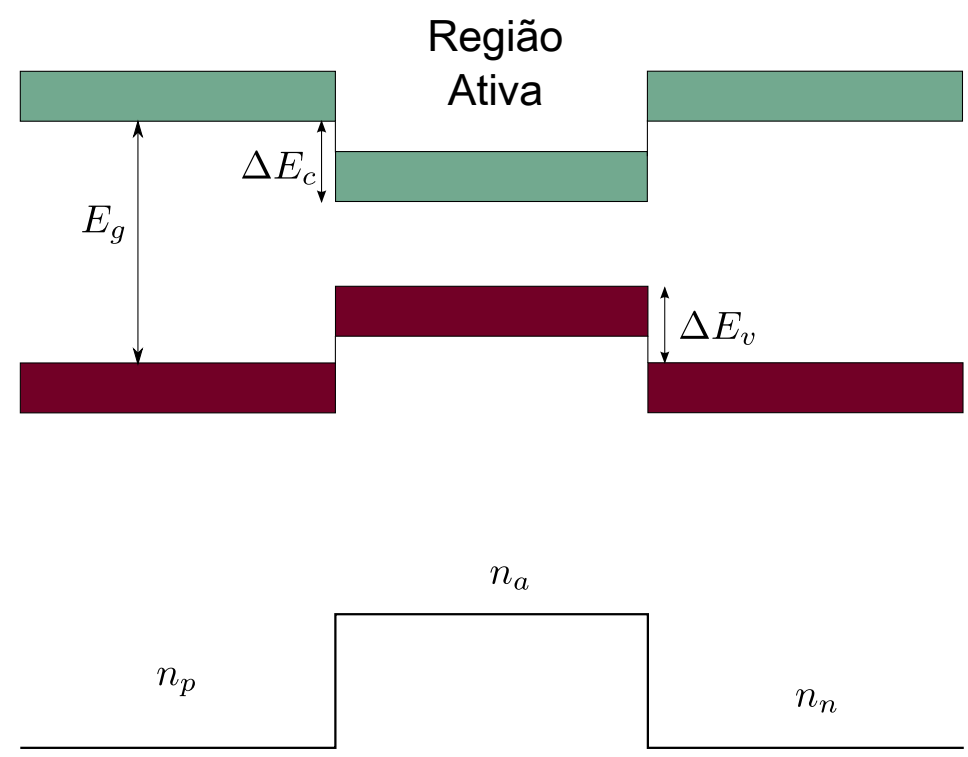

Figura 11. Como exemplo de uma hetereojunção, propomos uma estrutura ppn. Na região de junção são criados offsets de energia que quando tem uma injeção de corrente em polarização direta, atúam como barreiras de potencial para evitar o escape de portadores. Também tem o efeito dos índices de refração dos maeriais usados, sendo o da região ativa o maior e que aumenta ainda mais quando o gap de energia diminui. Por tudo isso a eficiência na amplificação da luz é melhorada.

\subsubsection{Heterojunção}

Uma junção feita de diferentes materiais recebe o nome de heterojunção. Esta nova estrutura é muito útil em sistema óticos pois gera descontinuidades nas bandas, isto é, barreiras de potencial localizadas que definem plenamente uma região que chamamos de região ativa, onde os portadores vão se recombinar. Além disso, aproveitando o índice de refração de diferentes materiais, é possível criar estruturas fotônicas para o confinamento ou o direcionamento da luz. Estas vantagens fazem com que as heteroestruturas sejam os sistemas por excelência para criação de laser.

Nas interfaces da junção são gerados deslocamentos nas energias das bandas $\left(\Delta E_{c / v}\right)$. Quando aplicamos voltagem na polarização direta os buracos e os elétrons vão se encontrar na região ativa e sabemos pelo explicado na junção $P N$ que a diferença de energia entre regiões diminui. Na maioria de semicondutores o índice de refração aumenta conforme o "band gap"diminui, portanto a região ativa vai ter um índice de refração maior que nas vizinhanças e a luz é confinada nesta região melhorando a eficiência de recombinação elétron-buraco na geração de luz [20]. 


\subsubsection{Estrutura do Laser}

A Figura 12 mostra a estrutura usual do chip de um laser semicondutor. Ele esta formado por uma heterojunção, com duas camadas dopadas (p e n) e uma camada não dopada (intrínseco). A região ativa é onde o efeito do laser vai acontecer. Quando a corrente em polarização direta é injetada no sistema, a luz sai na direção $z$. Os dois extremos do chip na direção $z$ funcionam como espelhos e retornam alguma porcentagem da luz amplificada, gerando uma onda estacionaria na direção longitudinal [21].

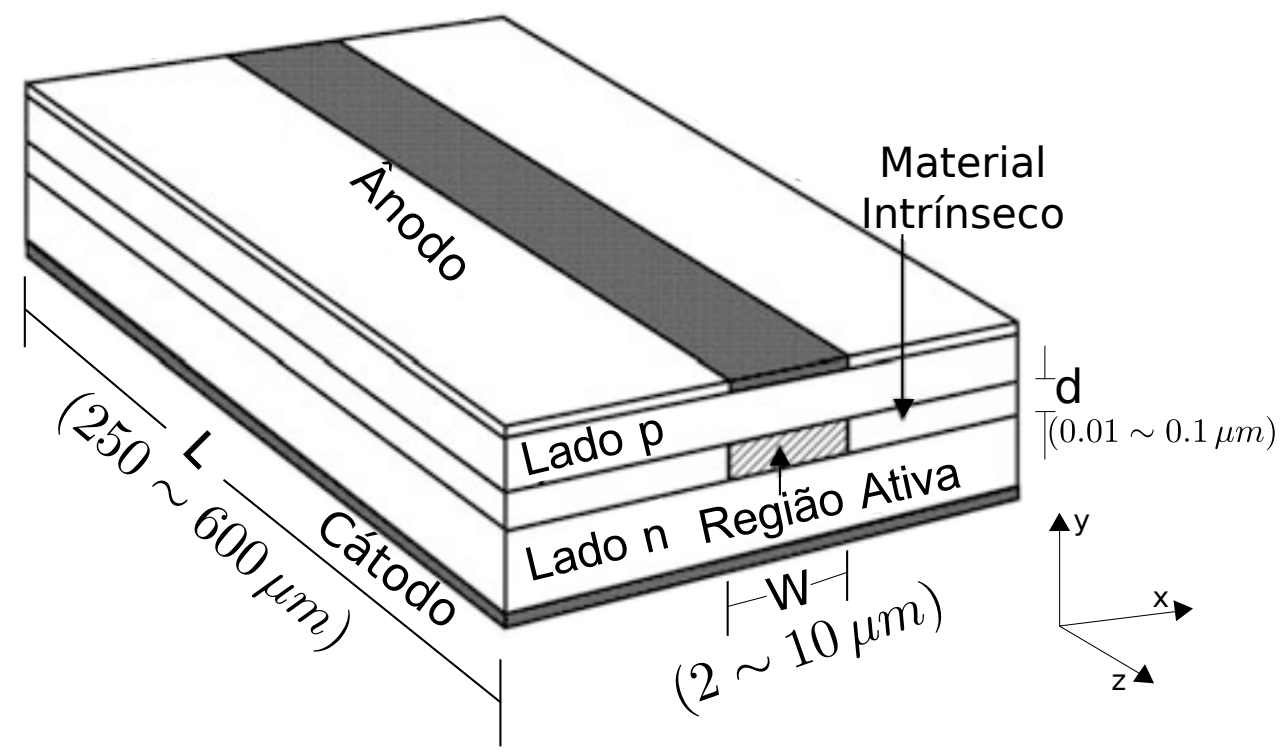

Figura 12. Estrutura típica do semicondutor. Vemos que corresponde a uma hetero-junção com uma região $\mathbf{p}$, uma $\mathbf{n}$ e no meio uma camada de material intrínseco.

Existe um grande número de condições para escolher os elementos que vão compor o laser. A primeira condição é que os materiais devem ter uma transição direta entre bandas pois isto melhora a eficiência da emissão. Por exemplo, o GaAs com um gap de $1,52 \mathrm{eV}$ a $0 \mathrm{~K}$ é amplamente implementado nestes sistemas e em geral os semicondutores que estão entre as colunas IIIA e $V A$ da tabela periódica. Semicondutores como o Ge ou o $S i$ são péssimos candidatos para o laser por eles terem transições indiretas.

Um aspecto importante é o substrato onde o laser é feito. A diferença entre constantes de rede entre substrato e semicondutor tem que ser no máximo $0.1 \%$ pois um valor maior levaria à que a densidade de defeitos da rede aumente, mudando levemente as propriedades como "band gap", degradando a emissão laser. Claramente dependendo do comprimento de onda o "band gap"é estabelecido, assim, semicondutores dopados como o $A l_{x} G a_{1-x} A s$ podem ser construídos e emitir em uma fxia de 0,7 a 0,9 $9 \mathrm{~m}$. Este semicondutor pode ser produzido sobre um sustrato de GaAs [22]. 


\section{Resumo do capítulo}

Finalizando este capítulo estamos na capacidade de explicar como são as transições no semicondutor, como dopar o semicondutor ajuda na criação da diferença de população e porquê a junções $\mathbf{P N}$ e heterojunções são preferidos na hora de construir lasers.

Agora estamos interessados em entender o que acontece quando colocamos o semicondutor no meio de dois espelhos para a realimentação ótica podendo estes refletores serem as próprias faces do semicondutor. Esse tema será explicado no capítulo seguinte. 

Um laser é uma estrutura que gera e amplifica radiação de forma coerente, isto é, com comprimento de onda e fase igual entre os fótons absorvidos e os emitidos, empregando a emissão estimulada de radiação. Desde a invenção do laser por Maiman [23] um número crescente de aplicações desta fonte de luz tem sido encontrada. Por exemplo, o nosso sistema de telecomunicações se baseia neles. Básicamente, um laser esta composto por três componentes:

$\diamond$ Uma região ativa que tem como tarefa amplificar a luz incidente.

$\diamond$ Um bombeio que leva os átomos do nível fundamental para níveis superiores.

$\diamond$ Uma cavidade ótica que reinjeta no sistema parte da luz amplificada, deixando sair uma fração da mesma e, por sua vez, seleciona os modos que vão viver dentro da cavidade.

Neste capítulo, vamos explicar estes três componentes do laser. Começaremos estudando o meio amplificador partindo do sistema de dois níveis, passando pela descrição do origem da largura natural e pela interação da radiação sobre o sistema de dois níveis onde usaremos a eletrodinâmica clássica para introduzir as propriedades do material amplificador. Passamos assim a estudar o sistema de três níveis para entender o conceito de inversão de população e como funciona o bombeio.

Vamos então para a última parte do laser, a cavidade vazia. Nesta parte introduzimos os conceitos de largura de banda, finesse e intervalo espectral livre. Finalizamos o capítulo estudando o sistema completo, cavidade junto com meio de ganho e fazemos uma breve menção do ruído ao laser semicondutor. 


\subsection{Amplificadores}

Começamos a tarefa única e fortemente necessária de entender como é o sistema de amplificação no laser. O meio de ganho ou região ativa, como é denominada esta estrutura, tem a tarefa fundamental de amplificar a luz incidente de forma coerente o que significa, que tenham a mesma frequência e fase do que os fótons do feixe incidente.

\subsubsection{Absorção e Emissão de Luz}

Pensemos em um sistema de dois níveis, atômico, molecular ou sólido. Sabemos que os estados de menor energia são os mais estáveis e portanto os sistemas físicos tendem a ficar nesse estado e por consequência, um elétron excitado vai tentar, por algum meio e em algum tempo $\tau$, voltar para seu estado de mínima energia. Isto é conhecido como emissão espontânea, sendo caracterizado por ser um processo aleatório na direção e na fase do fóton emitido (Figura 13 a). O elétron excitado tem duas possibilidades para decair, ele pode se relaxar emitindo um fóton, o que se denomina relaxamento radiativo, ou ele pode se relaxar liberando sua energia em forma de calor ou como vibrações em uma rede (fônons), o que denominamos relaxamento não radiativo [6]. No caso de laser semicondutores idealmente se procura por um processo nativamente radiativo para aumentar a eficiência de emissão.

Como feito por Einstein [24], o sistema de dois níveis permite ter uma boa apreciação dos processo radiativos. Cada nível tem energias $E_{2}$ e $E_{1}$, com $E_{2}>E_{1}$, com densidade de população $N_{2}$ e $N_{1}$, respectivamente. No processo espontâneo, a taxa de decaimento dos átomos excitados para o nível inferior deve ser proporcional ao número de átomos que estejam no nível excitado e deve ser igual à taxa com que o nível $E_{1}$ é preenchido. Desse modo,

$$
\left[\frac{d N_{2}(t)}{d t}\right]_{e s p}=\left[-\frac{d N_{1}(t)}{d t}\right]_{e s p}=-A_{21} N_{2}(t),
$$

onde $A_{21}$ é a probabilidade de transição espontânea. A solução da Equação 2.1 é uma exponencial decrescente, o que justifica que a população do nível $E_{2}$ caia rapidamente com uma taxa $1 / A_{21}$.

Consideremos que agora enviamos luz para o sistema. Se um fóton incidente tem a mesma energia da transição, $\hbar \omega=E_{2}-E_{1}$, ele poderá ser absorvido por um átomo no nível $E_{1}$ e levará um elétron para o nível $E_{2}$. Este processo é conhecido como absorção estimulada representado na Figura 13 c). A taxa de absorção é proporcional ao número de fótons incidentes com energia $\hbar \omega(n(t))$, vezes a população $N_{1}$

$$
\left[\frac{d N_{2}(t)}{d t}\right]_{a b}=B_{12} n(t) N_{1}(t)
$$


sendo $B_{12}$ a probabilidade de absorção estimulada. Os fótons incidentes também podem estimular a transição do elétron do nível $E_{2}$ para o nível $E_{1}$ emitindo um fóton de energia $\hbar \omega$, com a mesma fase e direção que os fótons incidentes. Já poderíamos imaginar que o nome do processo é emissão estimulada e a sua equação de taxa é:

$$
\left[\frac{d N_{2}(t)}{d t}\right]_{e s t}=-B_{21} n(t) N_{2}(t) .
$$

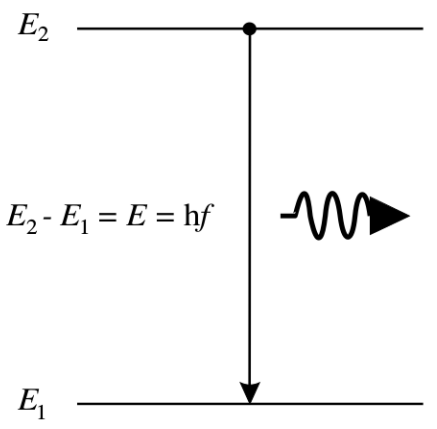

a)

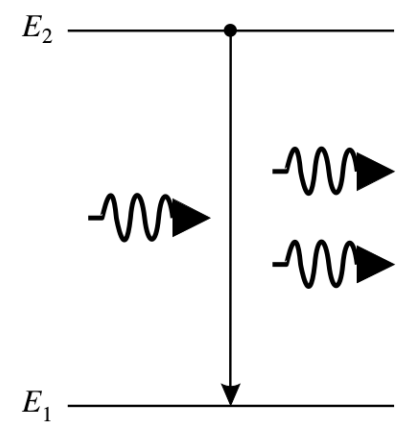

b)

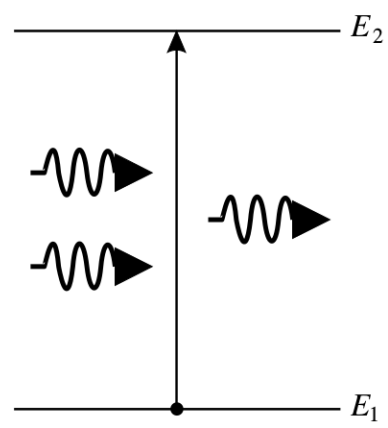

C)

Figura 13. Processos radiativos no sistema de dois niveis. Em a) vemos a emissão espontânea, em b) vemos a emissâo estimulada e em $\boldsymbol{c}$ ) a absorção. Figura tomada de [25] .

A taxa total de transferência corresponde à soma das equações de taxa

$$
\frac{d N_{2}(t)}{d t}=-\frac{d N_{1}(t)}{d t}=\left[B_{12} N_{1}(t)-B_{21} N_{2}(t)\right] n(t)-A_{21} N_{2}(t)
$$

Neste ponto vamos considerar que o feixe incidente é muito forte de tal forma que a emissão espontânea é muito fraca frente aos processo estimulados. Esta aproximação terá sentido mais para frente, onde consideraremos que o meio de ganho será inserido dentro de uma cavidade, o que gerará grande retorno da intensidade da luz,

$$
\frac{d N_{2}(t)}{d t}=-\frac{d N_{1}(t)}{d t}=\left[B_{12} N_{1}(t)-B_{21} N_{2}(t)\right] n(t)
$$

A equação Equação 2.5 corresponde à taxa de elétrons que são excitados quando absorvem um fóton do campo incidente. A mesma quantidade de energia tem que ser retirada do campo incidente

$$
\frac{d n(t)}{d t}=-\left[B_{12} N_{1}(t)-B_{21} N_{2}(t)\right] n(t)
$$

com $n(t)$ a densidade de fótons do campo incidente. Considerando um sistema não degenerado, a razão de transferência entre os processos estimulados é a mesma, ou seja $B_{12}=B_{21}=B[6]^{\mathrm{I}}$. Vemos então que a densidade de fótons do feixe incidente pode

I Em geral, um sistema que apresenta degenerescência poderia ter diferentes taxas de transferência entre estados, mas aqui consideramos sistemas não-degenerados. 
decair ou aumentar conforme a variação de portadores. Se o sinal externo aplicado em um sistema cuja maioria de átomos está no nível fundamental $\left(N_{1}>N_{2}\right)$, a diferença de população será positiva e a Equação 2.6 negativa indicando que o fluxo de fótons está diminuindo devido às transições para o nível superior. Se estivermos em um regime onde $N_{2}$ é maior que $N_{1}$, a intensidade do feixe incidente seria incrementada obtendo assim uma amplificação proporcional à diferença de população. Esta condição é chamada de inversão de população.

Não levemos a impressão errada que podemos construir um laser com apenas dois níveis. Até agora usamos o sistema de dois níveis como ferramenta teórica para mostrar que a inversão de população é uma condição necessária para o laser. Mas lembremos que em um sistema termodinâmico de dois níveis que atinge o equilíbrio, o nível com energia menor sempre tem uma probabilidade maior de ser ocupado do que o nível de energia superior segundo a distribuição de Maxwell-Boltzmann

$$
\frac{N_{2}}{N_{1}}=\mathrm{e}^{-\frac{\left(E_{2}-E_{1}\right)}{\kappa_{B} T}}
$$

Mesmo considerando o sistema fora do equilíbrio, não é possível ter uma inversão de população no sistema de dois níveis, pois além das transições estimuladas temos a emissão espontânea.

\subsubsection{Sistema de Três Níveis}

A forma mais simples para inverter a população é um sistema de três níveis. Serve como um modelo útil, aplicável por exemplo, para o laser de rubi, o primeiro laser. Como veremos mais a frente, no capítulo 5, o nosso sistema apresenta configurações onde absorve fótons ao invés de amplificar. Por isso vamos estudar o sistema de três níveis para entender como é a inversão de população nestes sistemas. A Figura 14 esquematiza o sistema de três níveis. Os termos $\gamma_{i j}$ representam as taxas de transição entre os níveis $i$ e $j$. Vemos o bombeio $B$ que gera transições estimuladas entre o nível 1 e 3 , onde $B=B_{31}=B_{13}$. Queremos ter o efeito de laser entre os níveis 2 e 1 e para isso a inversão de população deve se dar entre eles o que gera condições sobre o tempo que um átomo pode permanecer em um estado.

Vamos desenvolver as equações de taxa, que basicamente correspondem ao fluxo de átomos que entram e saem de um nível por unidade de tempo.

$$
\begin{aligned}
\frac{d N_{3}}{d t} & =B N_{1}-B N_{3}-\gamma_{31} N_{3}-\gamma_{32} N_{3} \\
\frac{d N_{2}}{d t} & =\gamma_{32} N_{3}-\gamma_{21} N_{2} .
\end{aligned}
$$




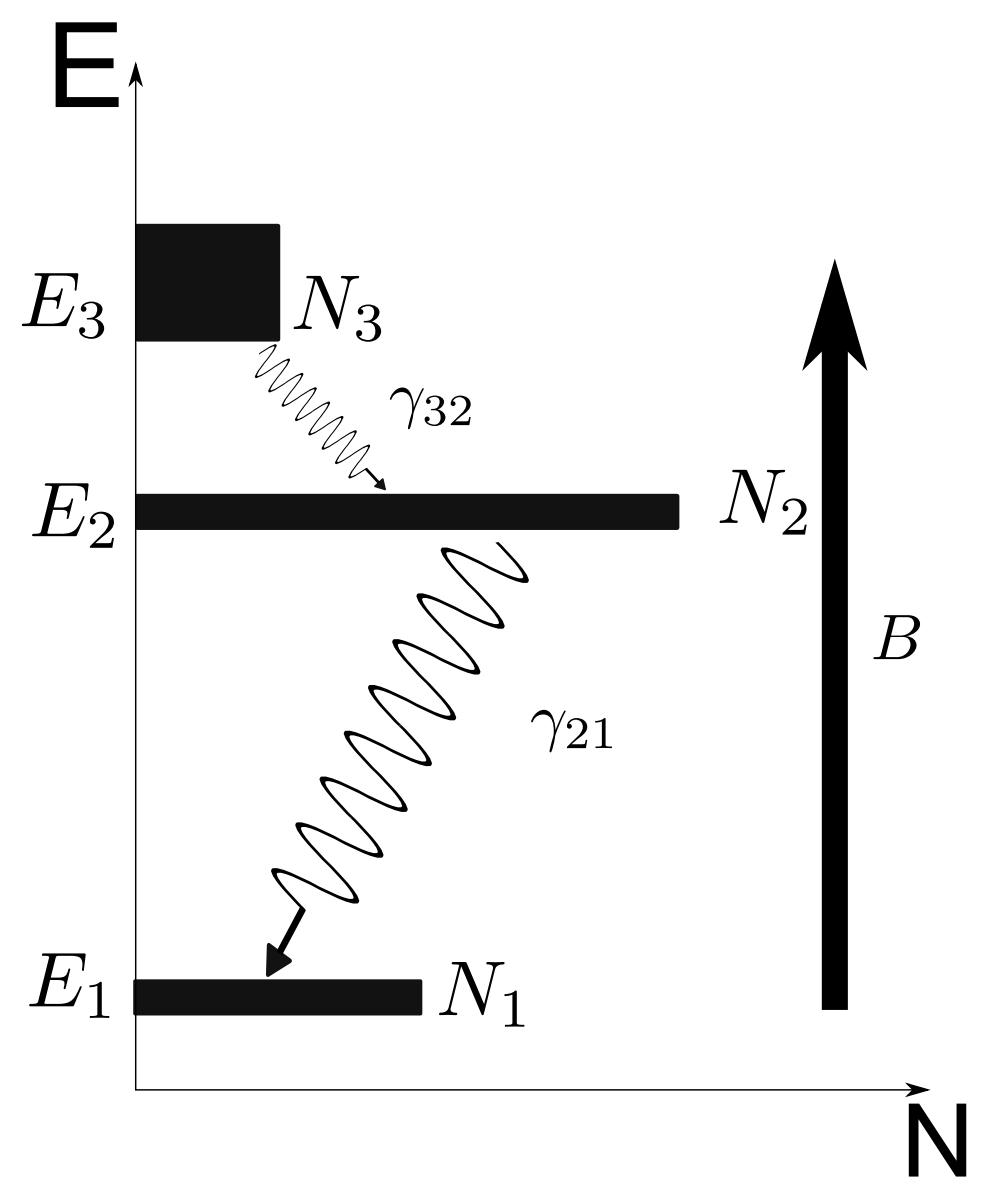

Figura 14. Esquema do sistema de três níveis. Supomos que as transições entre o nível 3 e o 1 tem uma probabilidade muito baixa de acontecer; denotamos o mecanismo de bombeio como B.

Para o nível base não precisamos equação de taxa porque ele está relacionado com os outros dois mediante a conservação do número de átomos $N=N_{1}+N_{2}+N_{3}$. Considerando o sistema quando atinge o equilíbrio:

$$
\begin{aligned}
B\left(N_{1}-N_{3}\right)-\gamma_{3} N_{3} & =0 ; \quad \gamma_{3}=\gamma_{31}+\gamma_{32} \\
\gamma_{32} N_{3}-\gamma_{21} N_{2} & =0
\end{aligned}
$$

Neste ponto vamos estudar a diferença entre as populações 2 e 1.

$$
\begin{aligned}
N_{2}-N_{1} & =N_{2}-N_{3}-\frac{\gamma_{3} N_{3}}{B} \\
& =N_{2}-\frac{\gamma_{21}}{\gamma_{32}} N_{2}-\frac{\gamma_{3} \gamma_{21}}{\gamma_{32} B} N_{2} .
\end{aligned}
$$

O termo $\gamma_{3}$ pode se simplificar, se pensamos que a probabilidade de uma transição entre o nível 3 e 1 é baixa comparada com a transição entre 3 e $2\left(\gamma_{32} \gg \gamma_{31}\right)$ o que é 
válido se consideramos que a transição entre 3 e 1 é muito estreita, portanto $\gamma_{3} \approx \gamma_{32}$ e obtemos:

$$
\frac{\Delta N}{N}=\frac{N_{2}-N_{1}}{N}=\frac{\gamma_{32} B-\gamma_{21} B-\gamma_{21} \gamma_{32}}{2 \gamma_{21} B+\gamma_{21} \gamma_{32}}
$$

Vemos que $\Delta N>0$ se

$$
\begin{aligned}
B & \geq \frac{\gamma_{32} \gamma_{21}}{\gamma_{32}-\gamma_{21}} \\
\gamma_{32} & >\gamma_{21}
\end{aligned}
$$

esta condição é conhecida como a inversão de população. Assim, átomos no nível 3 de energia tem que decair rapidamente para o nível 2, aqueles que estejam no nível 2 tem que ficar mais tempo neste nível antes de passar para o 1, onde pela ação do bombeio, serão excitados rapidamente para o nível 3. Este processo gera um nível 2 superlotado comparado com os seus vizinhos, garantindo a inversão de população. Com estas considerações podemos considerar a Equação 2.11 normalizada pelo número total da átomos como:

$$
\frac{\Delta N}{N} \propto \frac{a B-b}{2 e B+b}+c
$$

Representamos esta relação na Figura 15 onde vemos que um sistema de três níveis pode apresentar absorção se o bombeio não for suficiente forte.

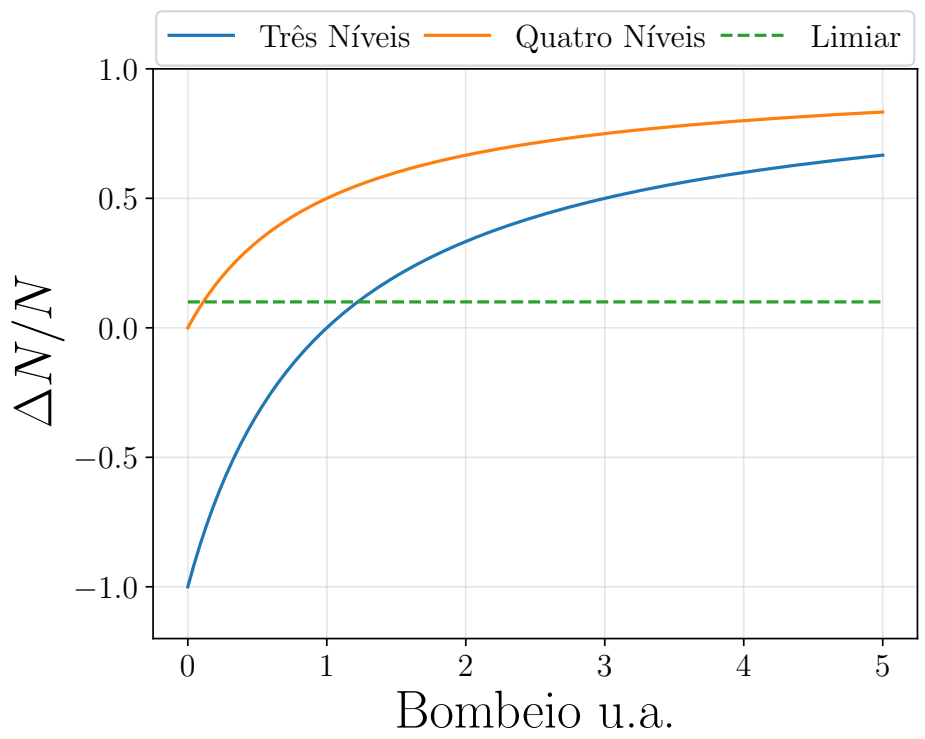

Figura 15. Inversão de população normalizado em função do bombeio $\mathbf{B}$ para o sistema de três e quatro níveis. Vemos que um sistema de três níveis pode apresentar absorção enquanto o sistema de quatro níveis não. A linha pontilhada representa o limiar de oscilação. 
Um sistema de quatro níveis funciona para descrever sistemas como o $N d: Y A G$ e o Ti : Safira. Uma análise parecida com a desenvolvida nesta seção nos leva a concluir que a diferença de população do sistema de quatro níveis é da forma [6]

$$
\frac{\Delta N}{N} \propto \frac{a B}{h+f B}
$$

onde vemos que em um sistema de quatro níveis sempre temos inversão de população. Por isto é que os sistemas de quatro níveis são procurados para construir laseres, já que o bombeio necessário para obter amplificação é menor do que o bombeio no sistema de três níveis.

\subsubsection{Interação da radiação com sistema de dois níveis}

Estamos interessados nos efeitos da luz no sistema amplificador assim como o papel da população na absorção e refração da luz. Este estudo será feito usando o formalismo da matriz densidade [13] dado que o passo para o tratamento do laser semicondutor na teoria quântica é feito usando este conceito [21]. Para isso, tomemos um sistema de dois níveis que é bombeado com um feixe de luz. O Hamiltoniano do sistema é

$$
\begin{aligned}
H & =H_{o}+H_{I}, \\
H_{o} & =\hbar \omega_{o} \sigma_{z}, \\
H_{I} & =-\mu E(t),
\end{aligned}
$$

$H_{o}$ correspondendo ao hamiltoniano do sistema de dois níveis, $\sigma_{z}$ à matriz de Pauli que representa os dois estados possíveis do átomo, $H_{I}$ ao hamiltoniano de interação, $\mu=-e r$ ao momento de dipolo elétrico de só um átomo do sistema alinhado na polarização do campo incidente. A princípio poderíamos considerar o campo incidente como uma onda plana $E(r, t)=E_{o} \mathrm{e}^{i(k r-\omega t)} \operatorname{com} k=2 \pi / \lambda$ e $\lambda$ o comprimento de onda. Porém, podemos desprezar o termo $\mathrm{e}^{i k r}$ se considerarmos que o comprimento de onda da luz é muito maior do que o tamanho do átomo e, portanto, $k r \ll 1$ o que permite expandir a exponencial ao redor de zero e ficar só com o primeiro termo, deixando o campo elétrico como $E(t)=E_{o} \mathrm{e}^{-i \omega t}$. Isto é conhecido como aproximação de dipolo elétrico.

O nosso propósito é conhecer o momento de dipolo de um ensamble $\langle\mu\rangle$ induzido pelo campo incidente, que em termos da matriz densidade é dado por [5]:

$$
\begin{aligned}
\langle\hat{\mu}\rangle & =\operatorname{Tr}[\hat{\rho} \hat{\mu}], \\
& =\left(\rho_{21}+\rho_{12}\right) \mu,
\end{aligned}
$$

onde foi considerado que $\mu_{11}=\mu_{22}=0$ pela paridade ${ }^{\mathrm{II}}$ e $\mu_{12}=\mu_{21}=\mu$. [26].

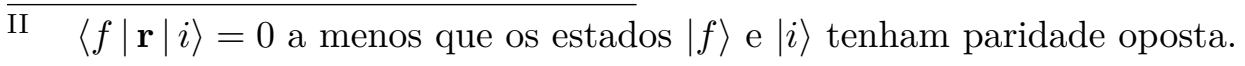


A evolução temporal da matriz densidade é:

$$
\frac{\partial \rho}{\partial t}=\frac{-i}{\hbar}[H, \rho]
$$

Se considerarmos que a matriz densidade está escrita na base de autoestados do hamiltoniano de dois níveis $\left(H_{o}\left|\Psi_{i}\right\rangle=E_{i}\left|\Psi_{i}\right\rangle\right)$ e tomamos cada uma das componentes resultantes da Equação 2.18 obtemos:

$$
\frac{\partial \rho_{21}}{\partial t}=-i \omega_{o} \rho_{21}+\frac{i \mu}{\hbar} E(t)
$$

$\operatorname{com} \omega_{o}=\left(E_{2}-E_{1}\right) / \hbar$

$$
\frac{\partial \rho_{22}}{\partial t}=\frac{-i \mu E(t)}{\hbar}\left(\rho_{21}-\rho_{21}^{\star}\right)
$$

Sabendo que na matriz densidade $\operatorname{Tr}[\rho]=1$, ou seja

$$
\rho_{11}+\rho_{22}=1
$$

podemos obter a seguinte equação:

$$
\frac{\partial\left(\rho_{11}-\rho_{22}\right)}{\partial t}=\frac{2 i \mu E(t)}{\hbar}\left(\rho_{21}-\rho_{21}^{\star}\right)
$$

As equações da matriz densidade até agora apresentadas não tem informação nenhuma do termo de emissão espontânea ${ }^{\text {III }}$, então vamos acrescentar nas equações anteriores os seguintes termos:

as $\Gamma$ é o fator de decaimento espontâneo entre as populações. Este termo garante que no caso de desligar o campo incidente, a população irá para o equilíbrio.

\& $\gamma$ é um termo associado à perda da coerência na fase do sistema via colisões. Pensemos em um sistema de dipolos que oscilam na mesma frequência como ilustrado na Figura 16. Suponha que depois de um tempo os dipolos podem sofrer colisões elásticas entre eles o que não reduz a amplitude da oscilação mas muda a fase de cada dipolo. Essa defasagem gera uma mudança na amplitude do momento de dipolo total $\mu_{T o t}(t)$. Essas colisões aleatórias podem cancelar o momento de dipolo mesmo sem processos radiativos.

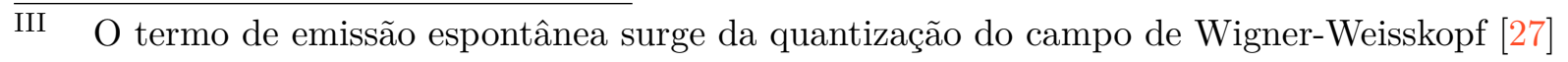




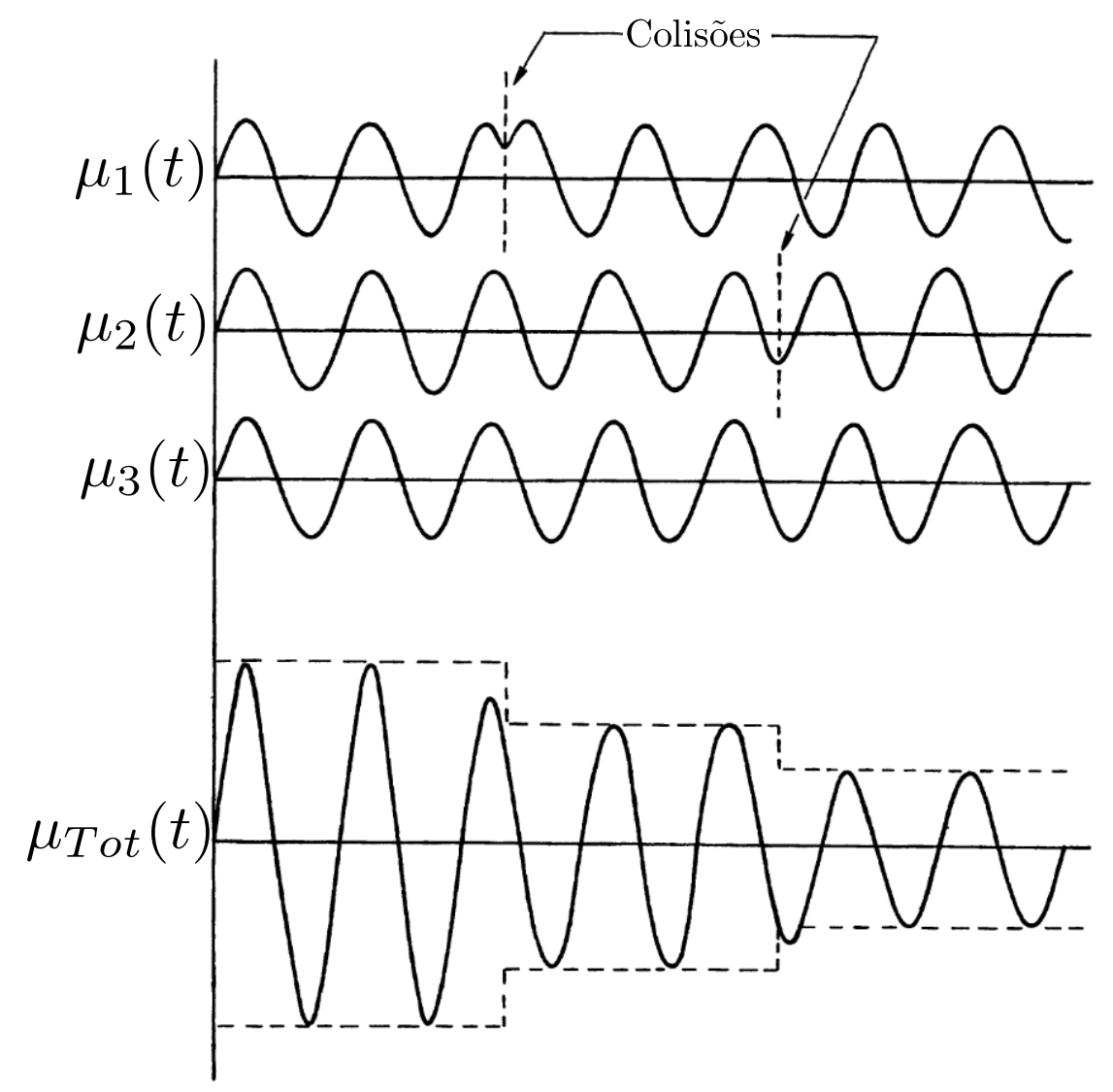

Figura 16. Colisões entre dipolos mudam a fase de cada dipolo o que pode dimiuir o momento de dipolo total [6] .

Assim, a Equação 2.19 e Equação 2.22 ficam:

$$
\begin{aligned}
\frac{\partial \rho_{21}}{\partial t} & =-i \omega_{o} \rho_{21}+\frac{i \mu}{\hbar} E(t)-\gamma \rho_{21} \\
\frac{\partial\left(\rho_{11}-\rho_{22}\right)}{\partial t} & =\frac{2 i \mu E(t)}{\hbar}\left(\rho_{21}-\rho_{21}^{\star}\right)-\Gamma\left[\left(\rho_{11}-\rho_{22}\right)-\left(\rho_{11}-\rho_{22}\right)_{o}\right]
\end{aligned}
$$

onde $\left(\rho_{11}-\rho_{22}\right)_{o}$ corresponde à diferença de população quando o campo incidente é zero.

Vamos mudar a base para um sistema rotante $\rho=\tilde{\rho} \mathrm{e}^{-i \omega t}$, onde $\tilde{\rho}$ varia lentamente com o tempo. Também consideramos o caso especial quando o campo incidente é harmônico

$$
\begin{aligned}
\mathbf{E}(t)= & \operatorname{Re}\left(\mathbf{E}_{\mathbf{o}} \mathrm{e}^{i \omega t}\right) \\
& \frac{\mathbf{E}_{\mathbf{o}}}{2}\left(\mathrm{e}^{i \omega t}+\mathrm{e}^{-i \omega t}\right)
\end{aligned}
$$


Assim, as equações 2.23a e 2.23b ficam:

$$
\begin{aligned}
\frac{\partial \tilde{\rho}_{21}}{\partial t}= & i\left(\omega-\omega_{o}\right) \tilde{\rho}_{21}+\frac{i \mu E_{o}}{2 \hbar}\left(\mathrm{e}^{i 2 \omega t}+1\right)\left(\rho_{11}-\rho_{22}\right)-\gamma \tilde{\rho}_{21} \\
\frac{\partial\left(\rho_{11}-\rho_{22}\right)}{\partial t}= & \frac{i \mu E_{o}}{\hbar}\left[\tilde{\rho}_{21}\left(1-\mathrm{e}^{-i 2 \omega t}\right)+\tilde{\rho}_{21}^{\star}\left(\mathrm{e}^{i 2 \omega t}-1\right)\right] \\
& -\Gamma\left[\left(\rho_{11}-\rho_{22}\right)-\left(\rho_{11}-\rho_{22}\right)_{o}\right] .
\end{aligned}
$$

Como estamos considerando que $\omega \approx \omega_{o}$, as exponenciais com termos $2 \omega$ podem ser desprezadas pois oscilam rapidamente comparados com os termos $\omega$ e numa média temporal o seu efeito é nulo. Essa aproximação é chamada de aproximação de onda girante, resultando em

$$
\begin{aligned}
\frac{\partial \tilde{\rho}_{21}}{\partial t} & =i\left(\omega-\omega_{o}\right) \tilde{\rho}_{21}+\frac{i \mu E_{o}}{2 \hbar}\left(\rho_{11}-\rho_{22}\right)-\gamma \tilde{\rho}_{21}, \\
\frac{\partial\left(\rho_{11}-\rho_{22}\right)}{\partial t} & =\frac{i \mu E_{o}}{\hbar}\left(\tilde{\rho}_{21}+\tilde{\rho}_{21}^{\star}\right)-\Gamma\left[\left(\rho_{11}-\rho_{22}\right)-\left(\rho_{11}-\rho_{22}\right)_{o}\right] .
\end{aligned}
$$

Para obter a solução no estado estacionário, basta igualar as equações 2.26a e 2.26b a zero:

$$
\begin{aligned}
\gamma \tilde{\rho}_{21} & =i\left(\omega-\omega_{o}\right) \tilde{\rho}_{21}+\frac{i \mu E_{o}}{2 \hbar}\left(\rho_{11}-\rho_{22}\right), \\
\frac{i \mu E_{o}}{\hbar}\left(\tilde{\rho}_{21}+\tilde{\rho}_{21}^{\star}\right) & =\Gamma\left[\left(\rho_{11}-\rho_{22}\right)-\left(\rho_{11}-\rho_{22}\right)_{o}\right] .
\end{aligned}
$$

Agora podemos manipular as equações fazendo somas e subtrações entre a Equação 2.27a e seus complexos conjugados, e junto com a Equação 2.27b vamos obter o seguinte:

$$
\begin{gathered}
\left(\rho_{22}-\rho_{11}\right)=\frac{\left[1+\left(\frac{\omega-\omega_{o}}{\gamma}\right)^{2}\right]\left(\rho_{22}-\rho_{11}\right)_{o}}{\left[1+\left(\frac{\omega-\omega_{o}}{\gamma}\right)^{2}\right]+\frac{\Omega^{2}}{\Gamma \gamma}}, \\
\operatorname{Re}\left(\tilde{\rho}_{21}\right)=\frac{\frac{\left(\omega-\omega_{o}\right) \Omega}{2 \gamma^{2}}\left(\rho_{22}-\rho_{11}\right)_{o}}{\left[1+\left(\frac{\omega-\omega_{o}}{\gamma}\right)^{2}\right]+\frac{\Omega^{2}}{\Gamma \gamma}} \\
\operatorname{Im}\left(\tilde{\rho}_{21}\right)=\frac{\frac{-\Omega}{2 \gamma}\left(\rho_{22}-\rho_{11}\right)_{o}}{\left[1+\left(\frac{\omega-\omega_{o}}{\gamma}\right)^{2}\right]+\frac{\Omega^{2}}{\Gamma \gamma}}
\end{gathered}
$$

onde $\Omega=\frac{\mu E_{o}}{\hbar}$ é a frequência de Rabi que corresponde a um ciclo onde o sistema de dois níveis absorve e emite luz pelo processo estimulado. Lembremos que estamos procurando é o valor da media do ensamble $\langle\mu\rangle$ que tem a forma: 


$$
\begin{aligned}
\langle\hat{\mu}\rangle & =\mu\left(\rho_{12}+\rho_{21}\right) \\
& =\mu\left(\tilde{\rho}_{21}^{\star} \mathrm{e}^{i \omega t}+\tilde{\rho}_{21} \mathrm{e}^{-i \omega t}\right) \\
& =2 \mu\left[\operatorname{Re}\left(\tilde{\rho}_{21}\right) \cos (\omega t)+\operatorname{Im}\left(\tilde{\rho}_{21}\right) \sin (\omega t)\right] .
\end{aligned}
$$

A polarização macroscópica é:

$$
\operatorname{Re}(P)=N\langle\hat{\mu}\rangle
$$

onde $N$ é a densidade de átomos, e usando as relações 2.29, 2.30 e 2.31 a polarização fica:

$$
\operatorname{Re}(P)=N \mu\left[\frac{\frac{\left(\omega_{o}-\omega\right) \Omega}{\gamma^{2}} \cos (\omega t)-\frac{\Omega}{\gamma} \sin (\omega t)}{\left[1+\left(\frac{\omega-\omega_{o}}{\gamma}\right)^{2}\right]+\frac{\Omega^{2}}{\Gamma \gamma}}\right]\left(\rho_{22}-\rho_{11}\right)_{o}
$$

Por outro lado, a diferença de população por unidade de volume é obtida multiplicando a Equação 2.28 por $N$, assim:

$$
\Delta N=\frac{\left[1+\left(\frac{\omega-\omega_{o}}{\gamma}\right)^{2}\right] \Delta N_{o}}{\left[1+\left(\frac{\omega-\omega_{o}}{\gamma}\right)^{2}\right]+\frac{\Omega^{2}}{\Gamma \gamma}},
$$

com $\Delta N_{o}=N\left(\rho_{22}-\rho_{11}\right)_{o}$ que corresponde à diferença de população do sistema sem campo aplicado e em equilíbrio. Vejamos que o termo $\Omega^{2}$ é proporcional à intensidade incidente I. Quando a intensidade do bombeio é muito grande, os processos estimulados tanto de emissão como de absorção, serão tão fortes que a diferença de população tende para zero. Esta condição é conhecida como saturação. Como consequência teremos o alargamento da largura de linha do sistema, fenômeno que estudaremos na seção 2.3.

\subsubsection{Polarização e Susceptibilidade Dielétrica}

Para conectar isto com a susceptibilidade dielétrica, evoquemos os conhecimentos de eletrodinâmica. $\mathrm{O}$ vetor de deslocamento elétrico é proporcional ao campo elétrico dentro do material e polarização:

$$
\mathbf{D}=\epsilon_{o} \mathbf{E}+\mathbf{P},
$$

onde o vetor de polarização é escrito como [28],

$$
\mathbf{P}=\epsilon_{o} \chi(\omega) \mathbf{E}
$$

e obtemos uma expressão para o vetor deslocamento dada por:

$$
\mathbf{D}=\varepsilon(\omega) \mathbf{E}
$$


Por outro lado, imaginemos o que aconteceria com uma onda plana que viaja em direção $z$ com vetor de onda $\kappa=\omega \sqrt{\varepsilon(\omega) \mu}$ :

$$
\begin{aligned}
\mathbf{E}(t) & =\operatorname{Re}\left[\mathbf{E}_{\mathbf{o}} \mathrm{e}^{i(\omega t-\kappa z)}\right] \\
\kappa & =\omega \sqrt{\mu \epsilon_{o}[1+\chi(\omega)]}
\end{aligned}
$$

Considerando que $|\chi| \ll 1$, podemos expandir a raiz e obter:

$$
\kappa \approx k_{o}\left(1+\frac{\chi(\omega)}{2}\right)
$$

com $k_{o}=\omega / c$, onde consideramos um material dielétrico $\left(\mu=\mu_{o}\right)$. Além disso, consideremos que a susceptibilidade é complexa $\chi=\chi^{\prime}-i \chi^{\prime \prime}$. O campo elétrico tomará a seguinte forma:

$$
\begin{aligned}
\mathbf{E}(t) & =\operatorname{Re}\left[\mathbf{E}_{\mathbf{o}} \mathrm{e}^{i \omega t} \mathrm{e}^{-i k_{o}\left(1+\chi^{\prime} / 2\right) z} \mathrm{e}^{-k_{o} \chi^{\prime \prime} z / 2}\right] \\
& =\operatorname{Re}\left[\mathbf{E}_{\mathbf{o}} \mathrm{e}^{i \omega t} \mathrm{e}^{-i\left(k_{o}+\Delta k\right) z} \mathrm{e}^{\mathrm{g}(\omega) z}\right]
\end{aligned}
$$

onde

$$
\Delta k=\frac{\chi^{\prime} k_{o}}{2}
$$

corresponde a um deslocamento na fase da onda e

$$
g(\omega)=-\frac{\chi^{\prime \prime} k_{o}}{2}
$$

relaciona-se com a amplificação da luz e é conhecido como o coeficiente de ganho.

Falta agora conhecer os valores das componentes da susceptibilidade. A polarização do sistema corresponde a:

$$
\mathbf{P}(t)=\operatorname{Re}\left(\mathbf{P} \mathrm{e}^{i \omega t}\right),
$$

onde usando a Equação 2.32 junto com a Equação 2.36 encontramos que:

$$
\begin{aligned}
N\langle\hat{\mu}\rangle & =\operatorname{Re}\left(\mathbf{E}_{\mathbf{o}} \epsilon_{o} \chi \mathrm{e}^{i \omega t}\right) \\
& =\mathbf{E}_{\mathbf{o}} \epsilon_{o}\left(\chi^{\prime} \cos (\omega t)+\chi^{\prime \prime} \sin (\omega t)\right),
\end{aligned}
$$

e usando a Equação 2.33, concluimos a forma das componentes da susceptibilidade:

$$
\chi^{\prime}=\frac{\Delta N \mu^{2} \pi}{\gamma_{o} \epsilon_{o} \hbar}\left(\omega_{o}-\omega\right) \mathcal{L}(\omega)
$$




$$
\chi^{\prime \prime}=-\frac{2 \pi \Delta N \mu^{2}}{\epsilon_{o} \hbar} \mathcal{L}(\omega)
$$

onde $2 \gamma=\gamma_{o}, \mathcal{L}(\omega)$ é a função Lorentziana, centrada em $\omega_{o}$ e com largura a meia altura $\gamma_{o}$.

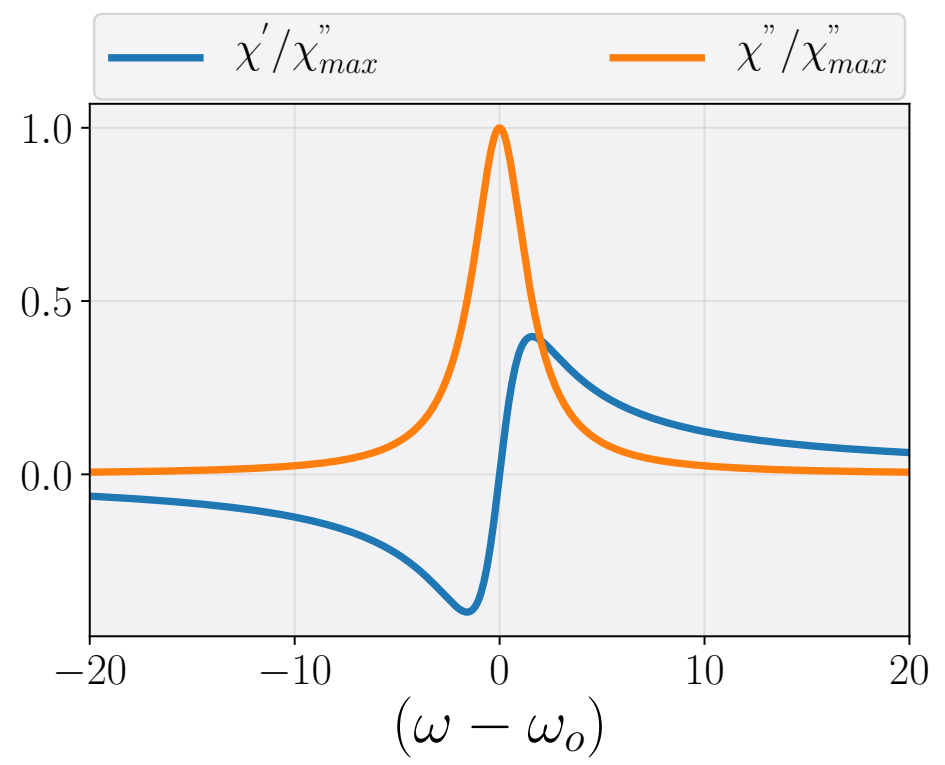

Figura 17. Parte Real e Imaginaria da Susceptibilidade Elétrica.

Finalmente cabe lembrar a relação entre o índice de refração n e a susceptibilidade do meio. Pela eletrodinâmica sabemos que $\mathrm{n}=\sqrt{(\varepsilon \mu) /\left(\epsilon_{o} \mu_{o}\right)}$, levando em consideração que o material é dielétrico da Equação 2.39 encontramos que:

$$
\mathrm{n}_{r e}-i \mathrm{n}_{i m}=1+\frac{\chi^{\prime}(\omega)}{2}-i \frac{\chi^{\prime \prime}}{2}
$$

Com esta última expressão acoplamos o índice de refração, uma propriedade do material, com a diferença de população do laser, mediante a susceptibilidade. Note que as propriedades do material mudam se o material estiver absorvendo $(\Delta N<0)$ ou amplificando a luz $(\Delta N>0)$. Comparando com o sistema de dois níveis, Equação 2.7, vemos que nesse sistema sempre vamos ter $\Delta N<0$.

\subsection{Cavidade Vazia}

Como foi dito no começo do capítulo, o laser é composto por três componentes essenciais. Nesta seção vamos tratar o terceiro e último deles, a cavidade de retroalimentação. Fazemos o estudo da cavidade vazia para introduzir a notação usada e logo passamos à cavidade com meio de ganho. 
Consideremos uma cavidade vazia de espelhos planos, cada espelho com refletividade $R_{1}$ e $R_{2}$. Dentro da cavidade temos uma onda plana, monocromática de frequência $\omega$ e comprimento de onda $\lambda$ :

$$
\mathbf{E}(\mathbf{r}, t)=\operatorname{Re}\left[\mathbf{E}_{\mathbf{o}} \mathrm{e}^{i(-\omega t+k z)}\right]
$$

onde $\left(E_{o}\right)$ é uma amplitude complexa.

Queremos estudar o que acontece com o campo transmitido e refletido pela cavidade e para isso detalhemos a Figura 18. O campo incidente de amplitude $E_{o}$ quando chega no primeiro espelho tem uma parte refletida e uma transmitida. A amplitude transmitida $\left(E_{o} t_{1}\right)$ será menor que a amplitude inicial. A onda se propaga até atingir o segundo espelho onde novamente tem uma parte transmitida e uma refletida. A linha vermelha indica o caminho extra que percorre o primeiro feixe refletido comparado com o primeiro feixe transmitido, o que corresponde à fase ganha pela diferença de caminho ótico entre dois feixes no mesmo frente de onda e cuja relação é:

$$
\phi=\frac{4 \pi}{\lambda} d \cos \left(\theta_{1}\right)
$$

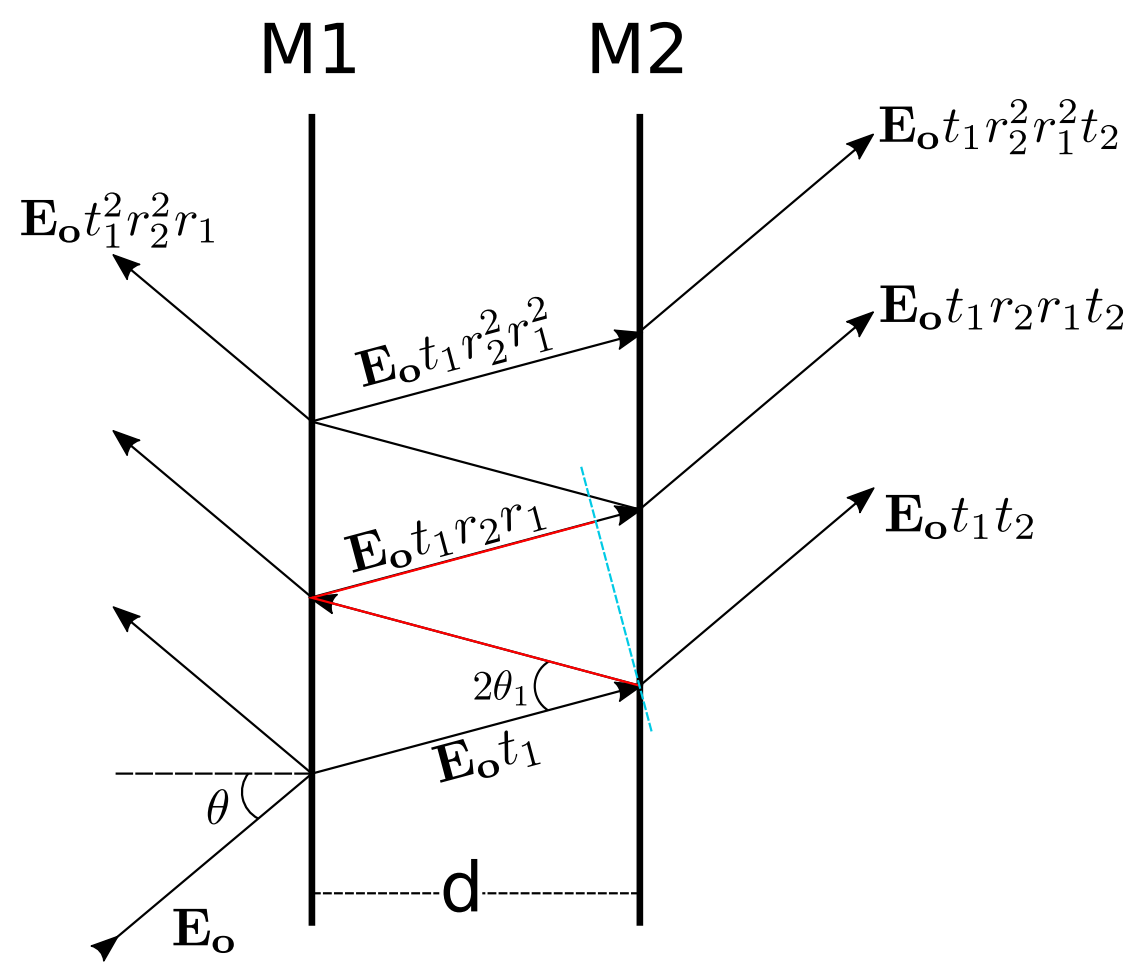

Figura 18. Esquema de uma cavidade Fabry Perot.

O feixe total transmitido pela cavidade será a soma de todos e cada um dos feixes em cada passo descrito, assim: 


$$
\begin{aligned}
\mathbf{E}_{\mathbf{t}} & =\mathbf{E}_{\mathbf{o}} t_{1} t_{2}+\mathbf{E}_{\mathbf{o}} t_{1} t_{2} r_{1} r_{2} \mathrm{e}^{i \phi}+\mathbf{E}_{\mathbf{o}} t_{1} t_{2} r_{1}^{2} r_{2}^{2} \mathrm{e}^{i 2 \phi}+\mathbf{E}_{\mathbf{o}} t_{1} t_{2} r_{1}^{3} r_{2}^{3} \mathrm{e}^{i 3 \phi}+\cdots, \\
& =\mathbf{E}_{\mathbf{o}} t_{1} t_{2} \sum_{n=0}^{\infty} r_{1}^{n} r_{2}^{n} \mathrm{e}^{i n \phi}, \\
& =\mathbf{E}_{\mathbf{o}} t_{1} t_{2} \frac{1}{1-r_{1} r_{2} \mathrm{e}^{i \phi}} .
\end{aligned}
$$

De forma similar, podemos encontrar a expressão para o campo refletido:

$$
\mathbf{E}_{\mathbf{r}}=\mathbf{E}_{\mathbf{o}}\left[-r_{1}+\frac{r_{2} t_{1}^{2} \mathrm{e}^{i \phi}}{1-r_{1} r_{2} \mathrm{e}^{i \phi}}\right]
$$

O sinal negativo do primeiro esta associado com uma mudança de $\pi$ da fase do feixe incidente em relação ao primeiro refletido. A intensidade transmitida é:

$$
I_{t}=\frac{\left|\mathbf{E}_{\mathbf{o}}\right|^{2}\left|t_{1}\right|^{2}\left|t_{2}\right|^{2}}{\left|1-r_{1} r_{2} \mathrm{e}^{i \phi}\right|^{2}}
$$

Dado que as reflexões geram uma mudança de fase, nos permitimos escrever $r_{j}=\left|r_{j}\right| \mathrm{e}^{i \phi_{r} / 2}$ e definimos a fase $\Phi=\phi+\phi_{r}$. Com isto a intensidade fica:

$$
I_{t}=\frac{I_{o}\left|t_{1}\right|^{2}\left|t_{2}\right|^{2}}{\left(1-\left|r_{1}\right|\left|r_{2}\right|\right)^{2}} \frac{1}{1+\left(\frac{2 \sqrt{\left|r_{1}\right|\left|r_{2}\right|}}{1-\left|r_{1}\right|\left|r_{2}\right|}\right)^{2} \sin ^{2}(\Phi / 2)},
$$

onde $I_{o}=\left|\mathbf{E}_{\mathbf{o}}\right|^{2}$. Definimos a finesse como $\mathcal{F}=\frac{\pi \sqrt{\left|r_{1}\right|\left|r_{2}\right|}}{1-\left|r_{1}\right|\left|r_{2}\right|}$. Ela indica quão estreito é o pico de transmissão e é uma medida da habilidade para resolver as frequências que entram na cavidade. A intensidade escrita em termos da finesse é:

$$
I_{t}=\frac{I_{o}\left|t_{1}\right|^{2}\left|t_{2}\right|^{2}}{\left(1-\left|r_{1}\right|\left|r_{2}\right|\right)^{2}} \frac{1}{1+\left(\frac{2 \mathcal{F}}{\pi}\right)^{2} \sin ^{2}(\Phi / 2)} .
$$

Justo como indica a Figura 19, os máximos da transmissão acontecem quando $\Phi=2 n \pi$ ou seja:

$$
n \pi=\frac{4 \pi}{\lambda} d \cos \left(\theta_{1}\right)+\phi_{r}
$$

A fase que a onda ganha pela reflexão por um dielétrico dado que o feixe passa de um meio mais denso para um menos denso é igual a zero $\left(\phi_{r}=0\right)$. Agora consideremos uma incidência normal $\left(\theta=\theta_{1}=0\right)$ que permite conhecer a frequência onde o máximo aparece:

$$
\nu_{\max }=\frac{n v}{2 d},
$$

onde $v$ é a velocidade da luz no meio. Se tomarmos agora a diferença entre dois máximos consecutivos: 


$$
\begin{aligned}
\Delta \nu_{\max } & =\frac{v}{2 d}[(n+1)-n], \\
& =\frac{v}{2 d},
\end{aligned}
$$

vemos que dois máximos da mesma frequência estão separados igualmente. Pensemos em uma cavidade que pode ser varrida em frequência, por exemplo com um PZT em um dos espelhos. A figura que veríamos seria equivalente à Figura 19, onde vemos que temos um pico de ressonância $\Phi / 2=0$, uma região de frequências fora da ressonância com a cavidade, novamente uma ressonância em $\Phi / 2=\pi$. Este padrão se repete conforme varremos em frequência. A distância entre os picos é conhecida como Intervalo Espectral Livre ou FSR (Free Spectral Range). Cada um desses picos tem uma largura a meia altura largura a meia altura que é relacionada com a finesse e o FSR como:

$$
\delta \nu_{c}=\frac{F S R}{\mathcal{F}}
$$

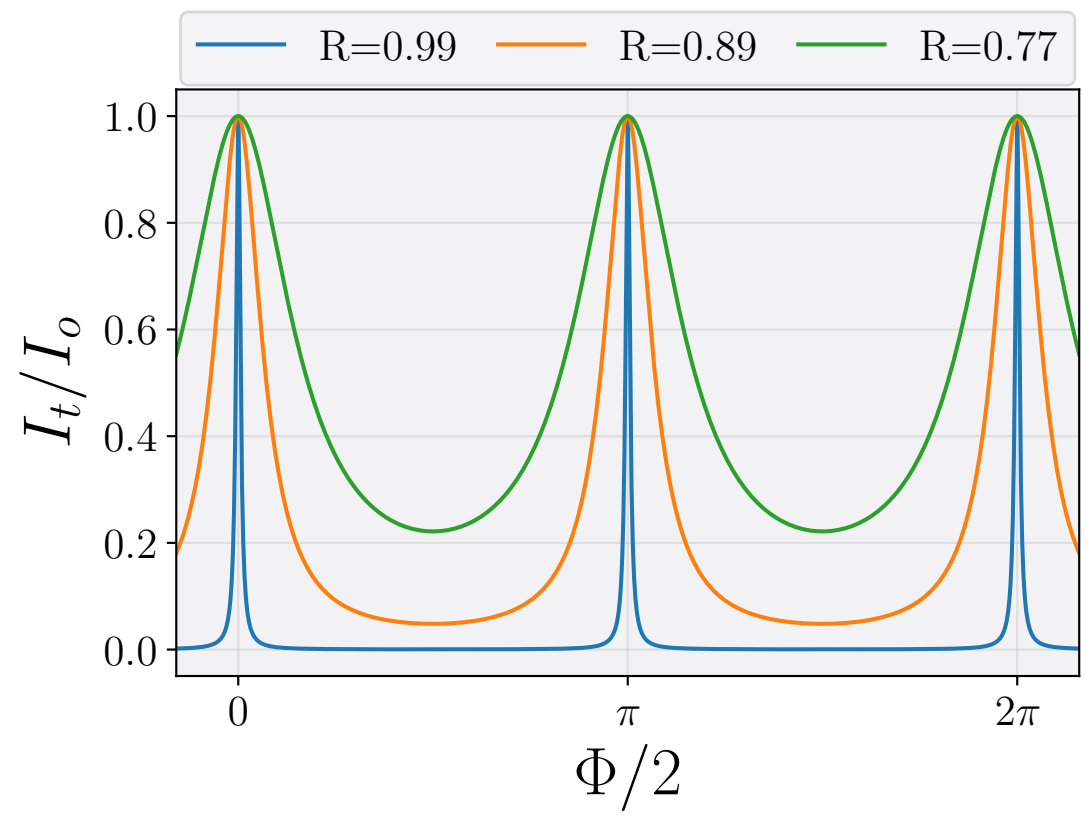

Figura 19. Intensidade transmitida pela Fabry Perot correspondendo com a função de Airy, para diferentes valores de refletividade dos espelhos. Nesta figura consideramos que $R=|r|^{2}$ $e\left|r_{1}\right|=\left|r_{2}\right|$.

\subsection{Cavidade com Meio de Ganho}

Finalmente vamos estudar o sistema completo. Conhecemos como funciona o meio de ganho, como funciona a cavidade vazia. Agora posicionemos dentro dos dois espelhos o meio de ganho e estudemos o que acontece. 


\subsubsection{Condição de Limiar}

Cada vez que o feixe passa pelo meio de ganho ele é amplificado e sempre que percorre o caminho de volta ao amplificador ele diminui a sua intensidade devido à atenuação nos espelhos, transmitindo parte da potência (perda útil) ou espalhando luz. A condição para ter oscilação é que o feixe inicial seja igual ao feixe final, levando a um regime estacionário. Usando a Equação 2.40 podemos escrever uma equação matemática para isto, agora levando em conta as perdas espúrias da cavidade tais como absorção ou dispersão:

$$
\frac{E_{\text {final }}(z=2 d)}{E_{\text {inicial }}(z=0)}=R_{1} R_{2} \mathrm{e}^{g(\omega) 2 d} \mathrm{e}^{-\alpha 2 d}=1,
$$

onde $\alpha$ é o termo de perdas espúrias. Deixando em evidência o coeficiente de ganho $g(\omega)$ :

$$
\mathrm{g}(\omega)=\alpha+\frac{1}{2 d} \ln \left(\frac{1}{R_{1} R_{2}}\right)
$$

esta relação é conhecida como condição de limiar e indica que para ter oscilação da luz, a amplificação do sistema tem que ser pelo menos igual ao conjunto as perdas presentes no sistema.

Podemos calcular, a partir do coeficiente de ganho, qual a inversão de população no limiar. Vamos escrever o termo à direita da Equação 2.60 como $\alpha_{r}$, com isto, podemos escrever $g(\omega)$ em termos da diferença de população usando a Equação 2.46 para obter:

$$
\Delta N_{l}=\frac{\epsilon_{o} \hbar}{\mu^{2} \pi k_{o} \mathcal{L}(\omega)} \alpha_{r}
$$

com $\Delta N_{l}=N_{2}-N_{1}$. Por esta relação podemos ver que caso as perdas da cavidade sejam grandes, é necessário uma maior potência para manter a inversão de população, justo como visto na Equação 2.12.

Podemos também reescrever o coeficiente de ganho $g(\omega)$ em termos da intensidade de saturação e para isso basta organizar o ganho em termo da diferença de população sem campo incidente, assim:

$$
g(\omega)=-\frac{k_{o} \Delta N_{o} \mu^{2} \pi \mathcal{L}(\omega)}{2 \hbar \epsilon_{o}} \frac{1}{1+I_{o} / I_{s}(\omega)}
$$

com $I_{s}(\omega)=\frac{\hbar^{2} \Gamma}{\pi \mu^{2} \mathcal{L}(\omega)}$, corresponde à intensidade de saturação, isto é, a intensidade intracavidade na qual o ganho cai pela metade. $I_{o}$ é a intensidade intracavidade. A Figura 20 mostra a relação entre ganho e intensidade intracavidade onde observamos que efetivamente, o ganho diminui conforme a intensidade interna aumenta. Mais para frente aprofundaremos este conceito. 


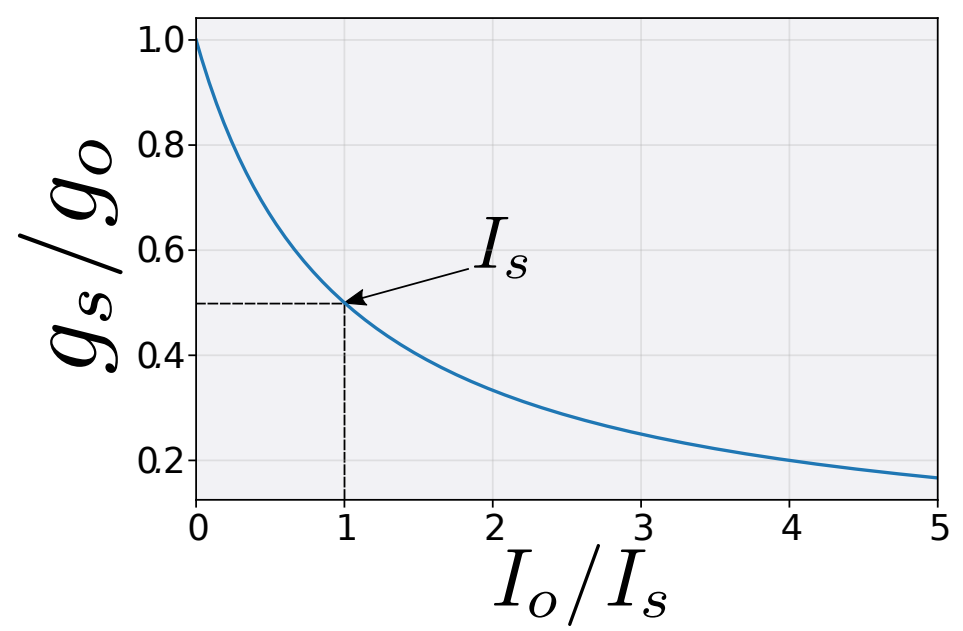

Figura 20. Ganho normaliozado pelo ganho sem campo intracavidade em função da intensidade intracavidade normalizado pela corrente de saturação, para uma frequência $\omega$.

Neste ponto vale definir o ganho do sistema como a razão entre a potência de saída do sistema e a potência de entrada:

$$
G(\omega)=\left|\frac{E_{\text {final }}(z=2 d)}{E_{\text {inicial }}(z=0)}\right|^{2} .
$$

Note que usando a Equação 2.59 e a Equação 2.62, podemos escrever o ganho como:

$$
\ln [G(\omega)]=4 d(g(\omega)-\alpha) \approx-4 d \pi k_{o} \Delta N \mu^{2} \mathcal{L}(\omega)
$$

onde consideramos que as perdas são muito menores do que o coeficiente de ganho. Portanto, vemos que o ganho depende da diferença de população do sistema e claramente é função do bombeio; o ganho tem o mesmo comportamento ilustrado na Figura 15.

Finalmente queremos conhecer qual a intensidade que circula e que sai da cavidade. Voltemos na Equação 2.60 e definamos as perdas após uma volta como três contribuições $\delta$ da seguinte forma:

$$
2 d g(\omega)=2 d \alpha+\ln \left(\frac{1}{R_{1} R_{2}}\right)=\delta_{o}+\delta_{1}+\delta_{2}
$$

com $\delta_{o}$ perdas espúrias, $\delta_{1}$ e delta 2 perdas nos espelhos da cavidade. Usando a Equação 5.1, podemos conhecer a potência que circula dentro da cavidade após uma volta $(2 d)$ quando o sistema está saturado que é dado pela expressão:

$$
I_{\text {circ }}=I_{s}(\omega)\left[\frac{g_{o}}{\delta_{o}+\delta_{1}+\delta_{2}}-1\right]
$$


onde $g_{o}=\frac{-k_{o} \Delta N_{o} \pi \mu^{2} \mathcal{L}(\omega)}{\epsilon_{o} \hbar}$ é o coeficiente de ganho fora da saturação. O campo de saída do laser será o campo que circula vezes as perdas que correspondem à interação com o exterior, ou seja:

$$
\begin{aligned}
I_{\text {circ }} & =\left(\delta_{1}+\delta_{2}\right) I_{\text {out }}=\delta_{e} I_{\text {out }} . \\
I_{\text {out }} & =\delta_{e}\left[\frac{k I_{\text {diodo }}}{\delta_{o}+\delta_{e}}-1\right] I_{s}(\omega)
\end{aligned}
$$

sendo $\delta_{e}=\delta_{1}+\delta_{2}$. A Figura 21 ilustra o comportamento da saída da cavidade em função das perdas pelos espelhos. Vemos que a intensidade tem uma intensidade máxima e logo começa a diminuir conforme as perdas superam a amplificação do sistema.

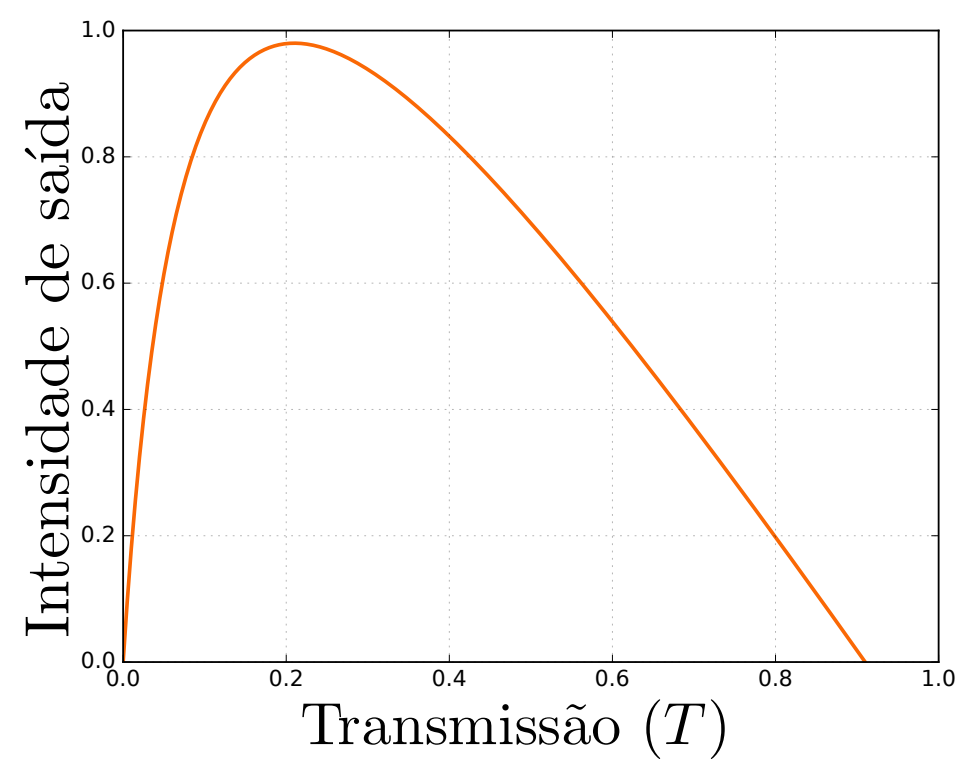

Figura 21. Intensidade de saída da cavidade em função das perdas.

\subsubsection{Condição de Frequência}

Também temos uma outra condição sobre o feixe intracavidade. Após uma volta, a fase que o feixe ganha deve mudar em múltiplos de $2 \pi$, ou seja a fase final deve ser a mesma do que a inicial. Lembrando novamente a Equação 2.40 e pegando só a parte que corresponde à mudança da fase, conseguimos que:

$$
\left(k_{o}+\Delta k\right) 2 d=2 \pi q ; \quad q=1,2,3, \cdots
$$

Podemos usar a Equação 2.40 para reescrever $\Delta k$ em termos da susceptibilidade, também, segundo as Equação 2.45 e Equação 2.46, $\chi^{\prime}=\left(\omega_{o}-\omega\right) \chi^{\prime \prime} / 2 \gamma_{o}$. Finalmente podemos escrever o vetor de onda em termos de frequências e encontrar:

$$
\omega+\frac{2 c\left(\omega-\omega_{o}\right)}{\gamma_{o}} g(\omega)=\omega_{q}
$$


onde $\omega_{q}$ é a frequência da cavidade sem meio de ganho justo como na Equação 2.56, $\omega_{o}$ é a frequência de transição do meio de ganho, $\gamma_{o}$ é a largura da emissão do meio de ganho. A Equação 2.70 mostra que colocar o meio de ganho dentro da cavidade desloca a frequência da cavidade um pouco em direção da frequência da transição do meio. Este fenômeno é denominado puxamento de frequência [29].

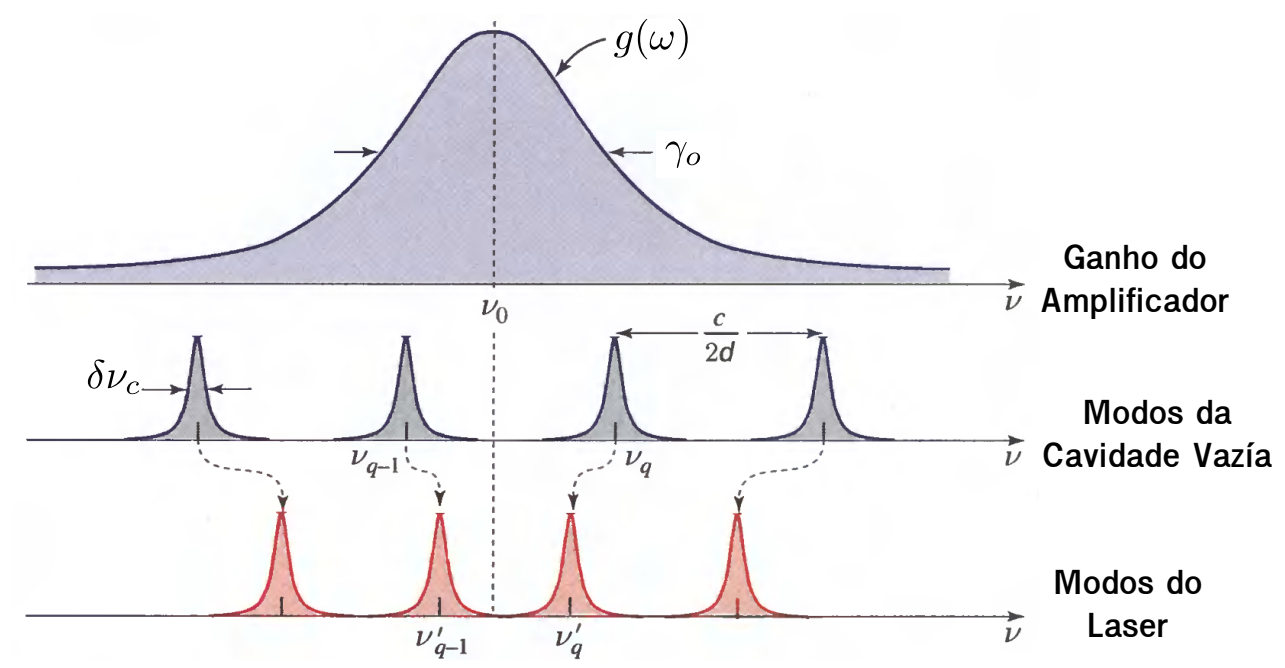

Figura 22. Acima vemos o ganho do amplificador, logo segue os modos da cavidade vazía e finalmente os modos de oscilação do laser. Vemos como os modos da cavidade estão um pouco mais próximos à frequência do sistema amplificador. Isto é conhecido como puxamento de frequência. Figura tomada de [30] .

\subsubsection{Distribuição Espectral}

A distribuição espectral do laser estará definida pelas condições das seções anteriores. Para entender como funciona isto vejamos a Figura 23. A condição de ter ganho maior do que as perdas da cavidade só é atingida por algumas frequências da cavidade, cortando várias outras que estão fora. Vemos agora que só os modos que oscilam conforme a condição de frequência 2.70 vão sobreviver quando o alargamento é homogêneo.

A modo de resumo pensemos no processo completo. Suponha que temos um meio onde temos uma grande inversão de população, por exemplo, bloqueando espelho da cavidade e ligando o bombeio do meio de ganho. Agora liberamos a cavidade para ela oscilar livremente. A principio, o feixe será amplificado fortemente dada a grande inversão de população, ele reflete nos espelhos e tem algumas perdas espúrias antes de voltar para o meio de ganho. Ao mesmo tempo o meio de ganho que perdeu população do nível $N_{2}$ pela emissão estimulada, recuperou algo da sua população devido ao bombeio, mas não recupera a população inicial, e perdeu outro tanto pela emissão espontânea. Quando o feixe chega de novo no meio de ganho, ele é amplificado novamente, não tanto como antes e apresenta perdas percorrendo a cavidade. Este processo vai continuar, diminuindo a população do nível 2, diminuindo a amplificação do feixe como se ilustra na Figura 24, perdendo intensidade pelos processos espúrios até atingir um estado estacionário conhecido 


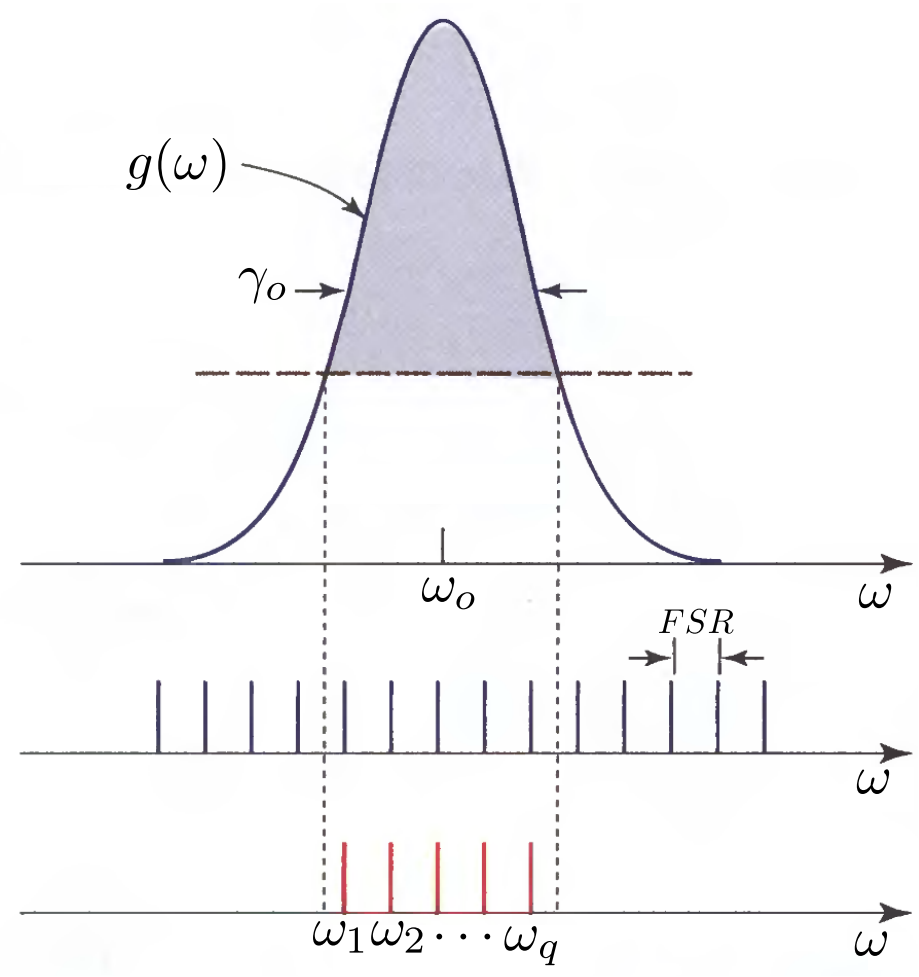

Figura 23. As frequências que cumplem as condições de oscilação sobrevivem e permanecem dentro da cavidade. Figura tomada de [30] .

como saturação. É neste ponto em que o bombeio e a emissão estimulada são tais que o feixe é amplificado, iguala as perdas $\left(\alpha_{r}\right)$ e ainda mantêm a diferença de população efetiva que permite ter laser [31]. Este mecanismo também seleciona o modo que sobrevive na cavidade. Dado que a região de ganho que é maior do que as perdas diminui, também as frequências que acompanham essas regiões deixam de oscilar. No final, só uma pequena região do espectro de ganho ao redor da sua frequência central $\omega_{o}$ cumprirá a condição do ganho e será a frequência de emissão do laser.
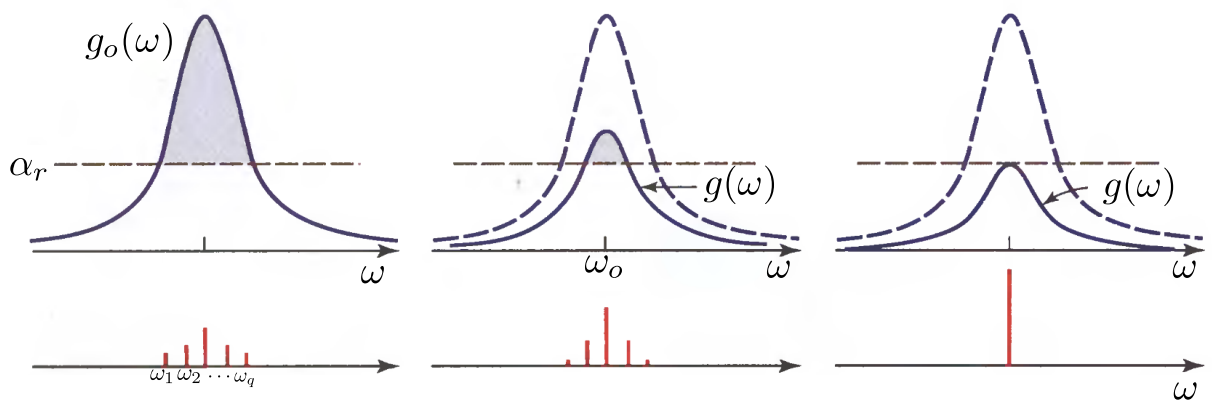

Figura 24. Conforme a potência intracavidade aumenta, o ganho diminui e as regiôes que tem ganho maior do que as perdas também diminuem selecionando a frequência ganhadora para permanecer na cavidade. Figura tomada de [30] . 


\subsection{Ruído do Laser Semicondutor}

Nesta última seção, saímos da descrição do laser e vamos mencionar os mecanismos que geram ruído no laser semicondutor. Suponha que temos um laser extremadamente estável e que conseguimos isolar-le de qualquer efeito ou ruído externo, tendo somente perdas nos espelhos e a emissão espontânea. Em cada volta do laser uma componente aleatória é aderida tanto na amplitude como na fase. No caso da amplitude, essas flutuações são amortecidas porque para manter o laser, o estado estacionário do sistema define o ganho do laser que por sua vez define uma potência (Equação 2.60). No caso da fase, ela não tem alguma forma de restauração e portanto ela segue sendo aleatória. Isto gera um limite inferior na largura de banda do laser dado pela relação do Schawlow-Townes [32-35]:

$$
\Delta \nu_{\text {Laser }}=\frac{4 \pi \hbar \omega\left(\delta \nu_{c}\right)^{2}}{P_{o}}
$$

onde $\Delta \nu_{\text {laser }}$ é a largura total a meia altura, $\delta \nu_{c}$ é a largura total a meia altura do ressonador e $P_{o}$ é a potência de saída do laser.

Isto funciona bem para o caso do laser de gás ou cristais, mas não funciona para lasers semicondutores, caso no qual, para um sistema de AlGaAs, foram reportadas larguras de linha até 50 vezes maiores do que a Equação 2.71 pode descrever [36]. Vamos tentar explicar fenomenologicamente a sua causa.

O ruído da emissão espontânea é bastante infeccioso no sistema semicondutor porque ele contamina tudo o que for possível. Começando a contaminação pela amplitude, esta começa a se estabilizar devido à referência na saturação do ganho mas no caminho, transpasa ruído para as populações. Estas flutuações nas portadoras podem ser entendidas como pequenas variações de energia dos elétrons dentro da mesma banda (absorção de portadoras livres [21]). Variações nas populações estão diretamente ligadas com variação do índice de refração do semicondutor o que por sua vez se traduz em uma flutuação no ganho e na fase do semicondutor. As flutuações na fase são flutuações no vetor de onda então estamos estimulando também um deslocamento do vetor de onda ao redor da transição direta o que leva à emissão de fônons para voltar no vetor de onda certo. Isto esquenta o material o que pode mudar o índice de refração do material e finalmente, mudar a fase. Todas essas novas interações no semicondutor dão a entender que existe um acoplamento entre as flutuações da amplitude com as flutuações da fase as quais podem ser caracterizadas pelo fator de Henry $\left(\alpha_{E}\right)$, denominado assim por ser ele quem conseguiu explicar este alargamento de linha. Estas flutuações estão relacionadas como $[37,38]$ :

$$
\alpha_{E}=\frac{\Delta \mathrm{n}_{r e}}{\Delta \mathrm{n}_{i m}}
$$


Com isto a Equação 2.71 é modificada como segue:

$$
\Delta \nu_{\text {Laser }}=\frac{\pi \hbar \omega\left(\delta \nu_{c}\right)^{2}}{P_{o}}\left(1+\alpha_{E}^{2}\right)
$$

O fator de Henry relaciona a parte real e imaginária do índice de refração que no fundo, pela Equação 2.47, a Equação 2.46 e a Equação 2.45, relaciona a mudança do ganho com a mudança na fase.

\section{Resumo do capítulo}

Neste capítulo estudamos como o laser funciona. Essa descrição foi feita compreendendo cada componente do laser para logo juntar tudo para formar o laser. O sistema de três níveis permite entender a diferença de população e explica como é possível que sistemas laser possam apresentar absorção. Também é importante lembrar que o índice de refração modifica a fase e o ganho do que passa pelo material e que ele é proporcional à diferença de população. Portanto uma flutuação na população gera flutuações na fase e/ou na amplificação do meio. Essa correlação é explicada pelo fator de Henry (Equação 2.72).

O seguinte capítulo explica a teoria da técnica implementada para realizar as medições do nosso sistema. 



\section{Deteção do Ruído}

Neste capítulo vamos descrever o processo de medição do ruído mediante uma cavidade denominada Rotação de elipse. Iniciamos pela definição das quadraturas do campo elétrico com uma perspectiva clássica que pode ser generalizada facilmente para o caso quântico e damos um exemplo de como as flutuações em frequência e amplitude geram ruído em frequências fora da frequência central. Continuamos fazendo uma pequena introdução da quantização do campo com a principal ideia de chegar na descrição do ruído quântico padrão como limite para as medidas. Descrevemos a deteção balanceada e como ela permite extrair a informação das flutuações do campo. Finalmente estabelecemos a notação usada pelo nosso grupo e descrevemos o processo completo da deteção do ruído com cavidade. Dado que a teoria está quase completamente desenvolvida nos trabalhos anteriores do nosso grupo [7,39], deixaremos a parte teórica de lado e estaremos centrados na parte fenomenológica sempre incluindo as equações pertinentes .

\subsection{Quadraturas do Campo Eletromagnético}

Consideremos um campo eletromagnético monomodo ${ }^{\mathrm{I}}$ escrito da seguinte forma:

$$
E(t)=\alpha(t) \mathrm{e}^{-i \omega_{0} t}+\alpha^{*}(t) \mathrm{e}^{i \omega_{o} t}=\operatorname{Re}[\mathcal{E}(t)] / 2,
$$

$\operatorname{com} \mathcal{E}(t)=\alpha(t) \mathrm{e}^{-i \omega_{o} t}, \alpha(t)=|\alpha(t)| \mathrm{e}^{i \varphi}$ uma amplitude complexa lentamente variável, $\omega_{o}$ a frequência central da luz e a fase $\varphi$ representando uma fase arbitrária. Expandindo as exponenciais podemos escrever o campo elétrico em função de dois termos em quadratura [40]:

$$
E(t)=X(t) \cos \left(\omega_{o} t\right)+Y(t) \sin \left(\omega_{o} t\right),
$$

I Monomodo se refere a uma única frequência, polarização e modo espacial. 
em que $X(t) \propto|\alpha(t)| \cos (\varphi)$ e $Y(t) \propto|\alpha(t)| \sin (\varphi)$. Em situações físicas reais, o campo está sujeito a flutuações que podem ser originadas por efeitos tanto clássicos como quânticos, um diagrama de Fresnel permite representar claramente estas grandezas (Figura 25) O módulo do fasor corresponde à amplitude do campo $|\alpha|$ e a fase está definida como $\varphi=\arctan (Y / X)$.

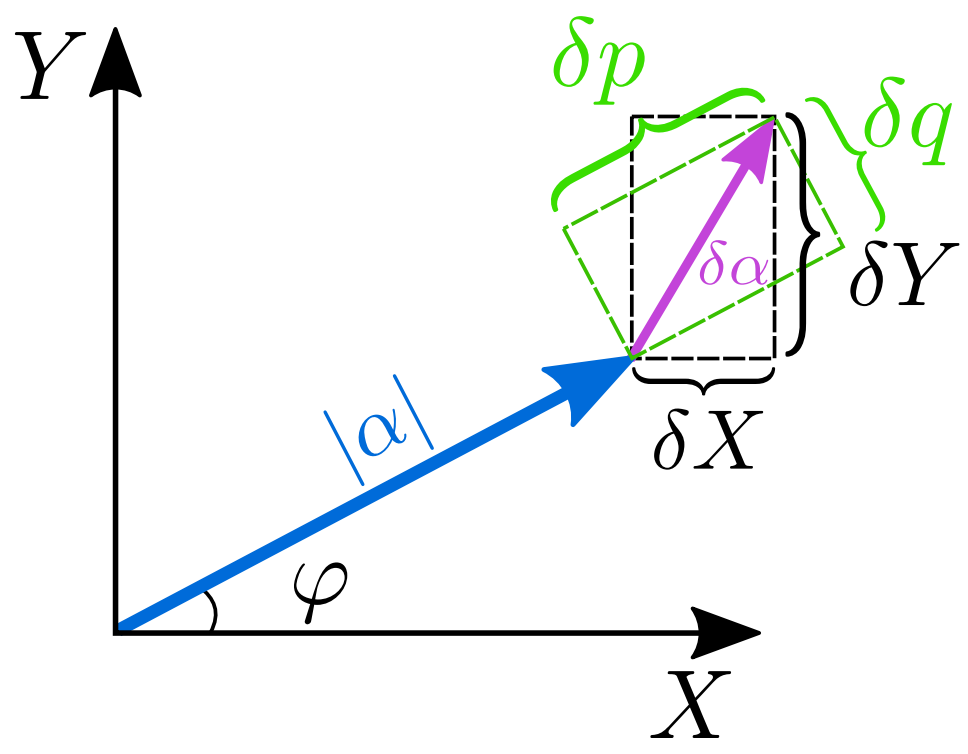

Figura 25. Representação do campo e das flutuações do mesmo num diagrama de fasores. Vemos o valor médio do campo $|\alpha|$ e a sua flutuação $\delta \alpha$.

De forma geral podemos escrever as quadraturas $X$ e $Y$ como [40]:

$$
\begin{aligned}
X_{\theta} & =\alpha(t) \mathrm{e}^{-i \theta}+\alpha^{*}(t) \mathrm{e}^{i \theta}, \\
Y_{\theta} & =-i\left[\alpha(t) \mathrm{e}^{-i \theta}-\alpha^{*}(t) \mathrm{e}^{i \theta}\right],
\end{aligned}
$$

onde $\theta$ serve como uma referência de fase que permite girar as quadraturas com relação à fase do campo $\varphi$. Por exemplo, se $\theta=\varphi, X_{\varphi}$ estará alinhado na direção da amplitude do campo elétrico.

No nosso sistema, estamos trabalhando com um grande fluxo de fótons, tanto que os detetores não tem uma resposta suficientemente rápida para distinguir cada um deles. Podemos portanto escrever a intensidade do feixe como um valor estacionário bem definido $\langle I\rangle$ acompanhado de flutuações rápidas $\delta I(t)$,

$$
I(t)=\langle I\rangle+\delta I(t)
$$

termo que tem que ser igual ao produto da amplitude do campo vezes o seu complexo conjugado. Adicionamos na amplitude complexa o termo de flutuação tal que:

$$
\alpha(t)=\bar{\alpha}+\delta \alpha(t)
$$


onde $\bar{\alpha}=|\alpha| \mathrm{e}^{i \varphi}$. Reescrevemos a intensidade do campo como:

$$
\begin{aligned}
I(t) & =\alpha(t) \alpha^{*}(t) \\
& =|\alpha|^{2}+|\alpha|\left[\delta \alpha^{*}(t) \mathrm{e}^{-i \varphi}+\delta \alpha(t) \mathrm{e}^{i \varphi}\right]+\delta \alpha^{*}(t) \delta \alpha(t) .
\end{aligned}
$$

Podemos desprezar o termo $\delta \alpha^{*}(t) \delta \alpha(t)$ já que assumimos um feixe intenso $\left(\alpha_{o} \gg|\delta \alpha(t)|\right)$. A amplitude quadrada do campo elétrico corresponde à intensidade média $\langle I\rangle=|\alpha|^{2}$, e o termo faltante é associado com as flutuações de intensidade:

$$
\begin{aligned}
\delta I(t) & =\bar{\alpha}^{*} \delta \alpha(t)+\bar{\alpha} \delta \alpha^{*}(t), \\
& =|\alpha|\left[\mathrm{e}^{-i \varphi} \delta \alpha(t)+\mathrm{e}^{i \varphi} \delta \alpha^{*}(t)\right], \quad \text { que pela Equação 3.3, } \\
& =|\alpha| X_{\varphi}(t) .
\end{aligned}
$$

A Figura 25 e a Equação 3.8 revelam que a flutuação da intensidade é dada pela flutuação de amplitude $\alpha$, por isso denominamos essa quadratura como quadratura amplitude e a denotamos como $p$, assim:

$$
\delta p(t)=\mathrm{e}^{-i \varphi} \delta \alpha(t)+\mathrm{e}^{i \varphi} \delta \alpha^{*}(t)
$$

tal que $\delta p=\delta I(t) /|\alpha|$. Também vemos que uma pequena flutuação da fase de $\alpha$ gera flutuações na direção ortogonal a $p$ e denominamos essa quadratura como de fase $(q)$ :

$$
\delta q(t)=-i\left[\mathrm{e}^{-i \varphi} \delta \alpha(t)-\mathrm{e}^{i \varphi} \delta \alpha^{*}(t)\right]
$$

Em resumo, flutuações em fase com a amplitude média geram flutuações da amplitude e, flutuações em quadratura resultam em flutuações da fase do campo.

Consideremos o comportamento das flutuações no domínio da frequência:

$$
\begin{aligned}
\delta \alpha(\nu) & =\int_{-\infty}^{\infty} \mathrm{e}^{i 2 \pi \nu t} \delta \alpha(t) d t, \\
{[\delta \alpha(\nu)]^{*} } & =\int_{-\infty}^{\infty} \mathrm{e}^{-i 2 \pi \nu t} \delta \alpha^{*}(t) d t, \\
& =\int_{-\infty}^{\infty} \mathrm{e}^{i 2 \pi(-\nu) t}[\delta \alpha(t)]^{*} d t, \\
& =\delta \alpha^{*}(-\nu),
\end{aligned}
$$

esta última linha só para deixar clara a notação. 
As flutuações da amplitude e fase no domínio de frequência são:

$$
\begin{gathered}
\delta p(\nu)=\mathrm{e}^{-i \varphi} \delta \alpha(\nu)+\mathrm{e}^{i \varphi} \delta \alpha^{*}(-\nu), \\
\delta q(\nu)=-i\left[\mathrm{e}^{-i \varphi} \delta \alpha(\nu)-\mathrm{e}^{i \varphi} \delta \alpha^{*}(-\nu)\right] .
\end{gathered}
$$

Praticamente toda a energia está concentrada na região da frequência central do feixe $\omega_{o}$, tomaremos esta referência como zero $(\nu=0)$ e a denominaremos como portadora. As frequências $\nu \neq 0$ ao redor da portadora, que chamamos bandas laterais, estão contaminadas pelo ruído clássico ou quântico que possa apresentar o sistema e criam alguns fótons nessa vasta região de frequências. Podemos entender isto estudando o que acontece com um feixe quando é modulado na sua amplitude numa fração $M$ [41]:

$$
E(t)=\alpha(t) \mathrm{e}^{-i \omega_{o} t}=|\alpha|\left[(1-M)+M \cos \left(\Omega_{A M} t\right)\right] \mathrm{e}^{-i \omega_{o} t} .
$$

Podemos escrever o coseno em termos de exponenciais:

$$
E(t)=|\alpha|\left[(1-M) \mathrm{e}^{-i \omega_{o} t}+\frac{M}{2}\left(\mathrm{e}^{-i\left(\omega_{o}+\Omega_{A M}\right) t}+\mathrm{e}^{-i\left(\omega_{o}-\Omega_{A M}\right) t}\right)\right],
$$

então, a modulação da amplitude na frequência $\Omega_{A M}$ gera componentes de frequências fora de $\omega_{o}$, as bandas laterais, em $\omega_{o} \pm \Omega_{A M}$.

Uma modulação em frequências do tipo:

$$
E(t)=|\alpha| \mathrm{e}^{-i M \cos \left(\Omega_{F M} t\right)} \mathrm{e}^{-i \omega_{o} t}
$$

onde $M \ll 1$. Podemos expandir em series de Taylor e levar em conta só os dois primeiros termos para obter:

$$
E(t)=|\alpha| \mathrm{e}^{-i \omega_{o} t}+i \frac{|\alpha| M}{2}\left[\mathrm{e}^{-i\left(\omega_{o}+\Omega_{F M}\right) t}+\mathrm{e}^{i\left(\omega_{o}-\Omega_{F M}\right) t}\right] .
$$

Efetivamente, uma modulação de frequência ou de amplitude do campo é representada pelo surgimento de bandas laterais de amplitude proporcional à portadora. A diferença esta no fato de que as bandas que aparecem na modulação de amplitude continuam sobre a portadora central, enquanto a modulação de fase aparece com uma defasagem de $\pi / 2$, no eixo ortogonal respeito à portadora.

\subsection{Ruído Quântico Padrão}

Para discutir sobre o conceito do ruído quântico padrão, temos que estudar o campo quantizado, o estado de vácuo e como ele se relaciona com o estado coerente. Após isso, 
falaremos do mecanismo para conhecer experimentalmente o ruído quântico e como usar ele como referência nas medidas.

Considerando um campo eletromagnético dentro de uma cavidade vazia, com paredes perfeitamente refletoras (condição de periodicidade) e sem nenhum tipo de fonte, as equações de Maxwell tem a forma:

$$
\begin{array}{ll}
\nabla \times \mathbf{E}(\mathbf{r}, t)=-\frac{\partial \mathbf{B}(\mathbf{r}, t)}{\partial t}, & \nabla \cdot \mathbf{E}(\mathbf{r}, t)=0, \\
\nabla \times \mathbf{B}(\mathbf{r}, t)=\frac{1}{c^{2}} \frac{\partial \mathbf{E}(\mathbf{r}, t)}{\partial t}, & \nabla \cdot \mathbf{B}(\mathbf{r}, t)=0 .
\end{array}
$$

Considerando o gauge de Coulomb, temos:

$$
\begin{aligned}
& \mathbf{E}(\mathbf{r}, t)=-\frac{\partial \mathbf{A}(\mathbf{r}, t)}{\partial t}, \\
& \mathbf{B}=\nabla \times \mathbf{A}(\mathbf{r}, t)
\end{aligned}
$$

Escrevendo o vetor potencial na base de ondas planas, podemos expressar os campos elétrico e magnético como [35, 42, 43]:

$$
\begin{array}{r}
\mathbf{E}(\mathbf{r}, t)=\frac{1}{\sqrt{\varepsilon_{o} L^{3}}} \sum_{\mathbf{k}} \sum_{s} i \omega_{\mathbf{k} s}\left[u_{\mathbf{k} s}(t) \hat{\epsilon}_{\mathbf{k} s} \mathrm{e}^{i \mathbf{k} \cdot \mathbf{r}}+u_{\mathbf{k} s}^{*}(t) \hat{\epsilon}_{\mathbf{k} s}^{*} \mathrm{e}^{-i \mathbf{k} \cdot \mathbf{r}}\right], \\
\mathbf{B}(\mathbf{r}, t)=\frac{1}{\sqrt{\varepsilon_{o} L^{3}}} \sum_{\mathbf{k}} \sum_{s}\left[u_{\mathbf{k} s}(t)\left(\mathbf{k} \times \hat{\epsilon}_{\mathbf{k} s}\right) \mathrm{e}^{i \mathbf{k} \cdot \mathbf{r}}-u_{\mathbf{k} s}^{*}(t)\left(\mathbf{k} \times \hat{\epsilon}_{\mathbf{k} s}^{*}\right) \mathrm{e}^{-i \mathbf{k} \cdot \mathbf{r}}\right],
\end{array}
$$

onde $L^{3}$ é o volume da caixa onde temos o campo, $u_{\mathbf{k} s}(t)$ é a amplitude complexa do campo, $\hat{\epsilon}_{\mathbf{k} s}$ uma base que define a direção da polarização do campo que depende da componente $s$ e dos diferentes modos $\mathbf{k}$ existentes.

Se calculamos a energia do campo eletromagnético, encontraremos que pode se escrever como:

$$
H=\frac{1}{2} \sum_{\mathbf{k}} \sum_{s}\left[p_{\mathbf{k} s}^{2}(t)+\omega_{\mathbf{k} s}^{2} q_{\mathbf{k} s}^{2}(t)\right]
$$

onde $p$ e $q$ são variáveis canonicamente conjugadas, definidas como

$$
\begin{aligned}
& q_{\mathbf{k} s}(t)=u_{\mathbf{k} s}(t)+u_{\mathbf{k} s}^{*}(t), \\
& p_{\mathbf{k} s}(t)=-i \omega_{\mathbf{k} s}\left[u_{\mathbf{k} s}(t)-u_{\mathbf{k} s}^{*}(t)\right] .
\end{aligned}
$$

Veja que se definimos $u_{\mathbf{k} s}(t)=|\alpha| \mathrm{e}^{-i \varphi}$, as equações 3.24 e 3.25 são iguais às equações 3.3 e 3.4 respectivamente. Aproveitamos para nomear elas como os seus homólogos clássicos, $p$ 
como a quadratura amplitude e $q$ como a quadratura fase [35]. Para obter o Hamiltoniano quântico, basta associar um operador a cada variável clássica, assim:

$$
H=\frac{1}{2} \sum_{\mathbf{k}} \sum_{s}\left[\hat{p}_{\mathbf{k} s}^{2}(t)+\omega_{\mathbf{k} s}^{2} \hat{q}_{\mathbf{k} s}^{2}(t)\right]
$$

com as regras de comutação

$$
\begin{array}{r}
{\left[\hat{q}_{\mathbf{k} s}(t), \hat{p}_{\mathbf{k}^{\prime} s^{\prime}}(t)\right]=i \hbar \delta_{\mathbf{k}, \mathbf{k}^{\prime}}^{3} \delta_{s, s^{\prime}},} \\
{\left[\hat{q}_{\mathbf{k} s}(t), \hat{q}_{\mathbf{k}^{\prime} s^{\prime}}(t)\right]=0,} \\
{\left[\hat{p}_{\mathbf{k} s}(t), \hat{p}_{\mathbf{k}^{\prime} s^{\prime}}(t)\right]=0 .}
\end{array}
$$

Seguindo o procedimento para o oscilador harmônico, definimos o operador de criação e aniquilação:

$$
\begin{aligned}
& \hat{a}_{\mathbf{k} s}^{\dagger}(t)=\frac{1}{\left(2 \hbar \omega_{\mathbf{k} s}\right)^{\frac{1}{2}}}\left(\omega_{\mathbf{k} s} \hat{q}_{\mathbf{k} s}(t)-i \hat{p}_{\mathbf{k} s}(t)\right), \\
& \hat{a}_{\mathbf{k} s}(t)=\frac{1}{\left(2 \hbar \omega_{\mathbf{k} s}\right)^{\frac{1}{2}}}\left(\omega_{\mathbf{k} s} \hat{q}_{\mathbf{k} s}(t)+i \hat{p}_{\mathbf{k} s}(t)\right),
\end{aligned}
$$

chegando finalmente à expressão do hamiltoniano do oscilador harmônico

$$
\hat{H}=\hbar \omega_{\mathbf{k} s} \sum_{\mathbf{k}} \sum_{s}\left[\hat{a}_{\mathbf{k} s}^{\dagger}(t) \hat{a}_{\mathbf{k} s}(t)+\frac{1}{2}\right]
$$

com $\hat{a}^{\dagger} \hat{a}$ igual ao operador número $\hat{N}$ [42]. Este hamiltoniano corresponde à energia contida por cada $\mathbf{k}$ oscilador harmônico associado ao modo $\mathbf{k} s$ que está na cavidade e cumpre a equação de autovalores:

$$
\hat{H}|n\rangle=\hbar \omega(N+1 / 2)|n\rangle,
$$

onde denominamos o autoestado $|n\rangle$ como estado número [42]. Os campos elétrico e magnético podem ser escritos em função dos novos operadores de criação e aniquilação e adquirem a forma:

$$
\begin{aligned}
& \mathbf{E}(\mathbf{r}, t)=\frac{1}{L^{\frac{3}{2}}} \sum_{\mathbf{k}} \sum_{s} \sqrt{\frac{\hbar \omega_{\mathbf{k} s}}{2 \varepsilon_{o}}}\left[i \hat{a}_{\mathbf{k} s} \hat{\epsilon}_{\mathbf{k} s} \mathrm{e}^{i\left(\mathbf{k} \cdot \mathbf{r}-\omega_{\mathbf{k} s} t\right)}-i \hat{a}_{\mathbf{k} s}^{\dagger} \hat{\epsilon}_{\mathbf{k} s}^{*} \mathrm{e}^{-i\left(\mathbf{k} \cdot \mathbf{r}-\omega_{\mathbf{k} s} t\right)}\right] \\
& \mathbf{B}(\mathbf{r}, t)=\frac{1}{L^{\frac{3}{2}}} \sum_{\mathbf{k}} \sum_{s} \sqrt{\frac{\hbar}{2 \omega_{\mathbf{k} s} \varepsilon_{o}}}\left[i \hat{a}_{\mathbf{k} s}\left(\mathbf{k} \times \hat{\epsilon}_{\mathbf{k} s}\right) \mathrm{e}^{i\left(\mathbf{k} \cdot \mathbf{r}-\omega_{\mathbf{k} s} t\right)}-i \hat{a}_{\mathbf{k} s}^{\dagger}\left(\mathbf{k} \times \hat{\epsilon}_{\mathbf{k} s}^{*}\right) \mathrm{e}^{-i\left(\mathbf{k} \cdot \mathbf{r}-\omega_{\mathbf{k} s} t\right)}\right]
\end{aligned}
$$


O produto do desvio padrão entre as quadraturas $\hat{p}$ e $\hat{q}$, calculados na base do estado número, leva a uma relação similar ao principio de incerteza de Heisenberg:

$$
\Delta \hat{q}_{\mathbf{k} s} \Delta \hat{p}_{\mathbf{k} s}=\hbar\left(n_{\mathbf{k} s}+\frac{1}{2}\right) .
$$

É interessante observar que mesmo na ausência de excitações do campo eletromagnético, a energia não vai para zero, ela é igual a $\hbar \omega / 2$. Isto é associado com as flutuações aleatórias de um campo denominado campo do vácuo. Vemos isto mais claramente se calculamos a variância do campo elétrico na base de estados número para $n=0$ :

$$
\langle 0|\mathbf{E}| 0\rangle^{2}=\frac{1}{2 \varepsilon_{o} L^{3}} \sum_{\mathbf{k} s} \hbar \omega_{\mathbf{k} s}
$$

Do mesmo modo, vemos que o desvio padrão para este tipo de campo é igual a $\hbar / 2$. Estados que cumprem a igualdade são denominados estados de mínima incerteza [44].

Existem estados quânticos diferentes do vácuo que também são de mínima incerteza e são uma equivalência quântica de uma onda monocromática chamados estados coerentes e estão definidos como autoestados do operador de aniquilação [44]:

$$
\hat{a}|\alpha\rangle=\alpha|\alpha\rangle, \quad|\alpha\rangle=\mathrm{e}^{-\frac{|\alpha|^{2}}{2}} \sum_{n=0}^{\infty} \frac{\alpha^{n}}{\sqrt{n}}|n\rangle,
$$

sendo $\alpha$ complexo. Se calculamos a variância do número de fótons na base de estados coerentes encontramos que:

$$
\Delta^{2} n=\langle\hat{n}\rangle=|\alpha|^{2},
$$

relação característica de um processo com distribuição Poissoniana. Por outro lado, se queremos calcular a probabilidade de achar $n$ fótons em um estado $|\alpha\rangle$ encontramos uma distribuição poissoniana:

$$
P(n)=\mathrm{e}^{-|\alpha|^{2}} \sum_{n} \frac{|\alpha|^{2}}{n !},
$$

o que indica que o intervalo de tempo de deteção de fótons é completamente aleatório, e que não existe correlação entre a medidas feitas em tempos diferentes. Podemos corroborar que o produto do desvio padrão das quadraturas, calculadas na base de estados coerentes são iguais a $\hbar / 2$.

Para estudar uma última propriedade dos estados coerentes podemos calcular a variância do campo elétrico na base de estados coerentes e encontrar que:

$$
\Delta^{2} \mathbf{E}=\frac{1}{2 \varepsilon_{o} L^{3}} \sum_{\mathbf{k} s} \hbar \omega_{\mathbf{k} s}
$$


Em um estado coerente a amplitude das flutuações do campo elétrico é uma constante e é igual às flutuações do vácuo (Equação 3.34). Essas flutuações que acabamos de calcular, são denominadas como Ruído Quântico Padrão (RQP) ou Shot Noise.

O shot noise é uma característica intrínseca à natureza quântica da luz, ao fato de ela estar composta por fótons. Ele impõe um limite inferior na precisão para resolver uma medida com fontes clássicas e serve como referência para as medidas de ruído no laboratório [45].

\subsubsection{Deteção Balanceada}

Nesta seção vamos a explicar como empregamos o shot noise como referência das medidas e como extraímos a informação das flutuações usando a técnica de deteção balanceada.

Consideremos dois campos $\mathbf{E}_{\mathbf{1}}$ e $\mathbf{E}_{\mathbf{2}}$ que incidem em um divisor de feixes (Figura 26) onde se geram dois feixes $\mathbf{E}_{\mathbf{3}}$ e $\mathbf{E}_{\mathbf{4}}$ relacionados entre si pela equação [41]:

$$
\left(\begin{array}{l}
E_{3} \\
E_{4}
\end{array}\right)=\left(\begin{array}{ll}
\mathbf{r} & \mathbf{t} \\
\mathbf{t} & \mathbf{r}
\end{array}\right)\left(\begin{array}{l}
E_{1} \\
E_{2}
\end{array}\right),
$$

onde $\mathbf{r}$ e t são os coeficientes complexos de reflexão e transmissão. Exigindo conservação de energia temos que

$$
\left|E_{1}\right|^{2}+\left|E_{2}\right|^{2}=\left|E_{3}\right|^{2}+\left|E_{4}\right|^{2}
$$

que condiciona os coeficientes $\mathbf{r}$ e $\mathbf{t}$ como

$$
\begin{aligned}
& |\mathbf{r}|^{2}+|\mathbf{t}|^{2}=1 \\
& \mathbf{r t}^{*}+\mathbf{r}^{*} \mathbf{t}=0 .
\end{aligned}
$$

Usando conservação da energia e escrevendo os coeficientes como fasores $\left(\mathbf{r}=|r| \mathrm{e}^{i \phi}\right)$ e associando para cada campo elétrico $E$ um operador de aniquilação $\hat{a}$, podemos chegar em:

$$
\left(\begin{array}{l}
\hat{a}_{3} \\
\hat{a}_{4}
\end{array}\right)=\left(\begin{array}{cc}
|r| & -|t| \\
|t| & |r|
\end{array}\right)\left(\begin{array}{l}
\hat{a}_{1} \\
\hat{a}_{2}
\end{array}\right)
$$

onde aproveitamos a quantização canônica para associar para cada campo clássico $E_{i}$ um operador de aniquilação $\hat{a}_{i}$. 


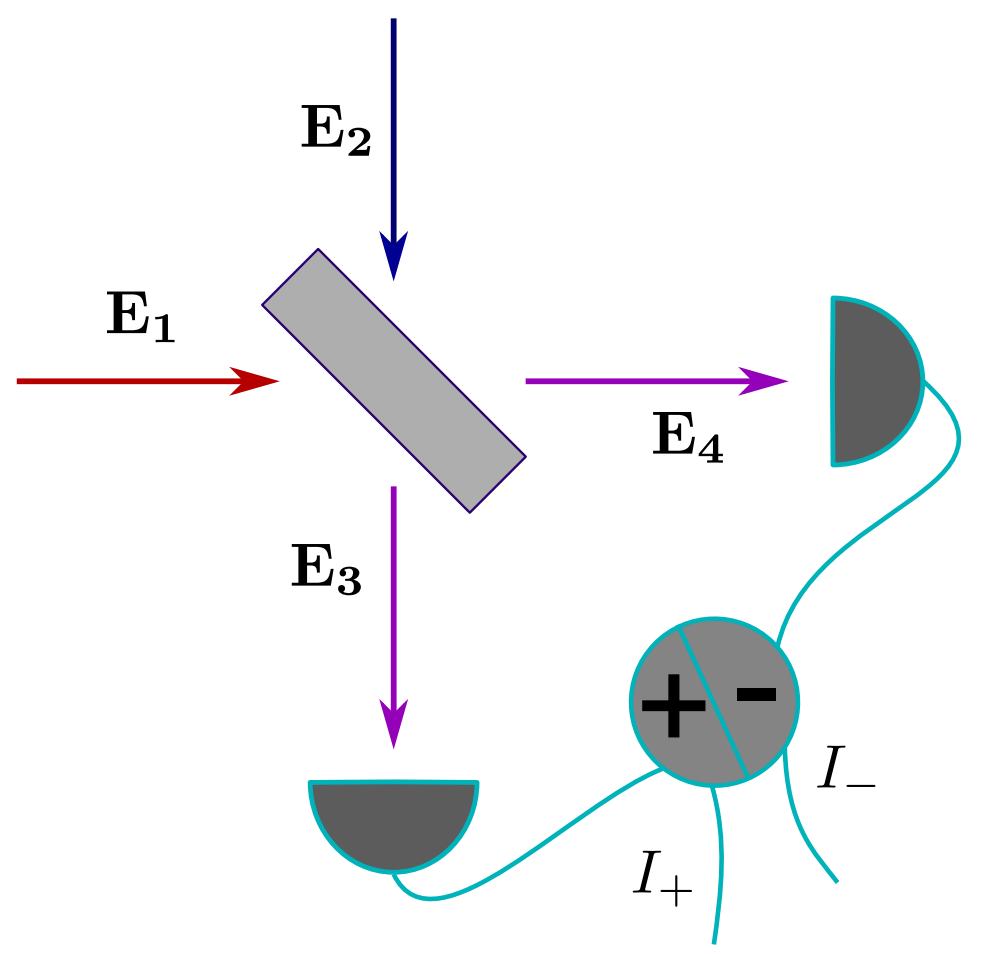

Figura 26. Esquema da deteção balanceada. Uma vez os campos passam pelo divisor de feixes, são medidos pelos detetores e vão para um sistema eletrónico que faz a soma ou a substração.

A deteção dos campos nos fotodiodos (Figura 26) será governada pelo operador número em cada um deles, assim:

$$
\hat{I}_{3}=Z \hat{a}_{3}^{\dagger} \hat{a}_{3}, \quad \hat{I}_{4}=Z \hat{a}_{4}^{\dagger} \hat{a}_{4},
$$

onde $Z$ é um fator de ganho dos detetores. O seguinte passo é fazer a soma e a subtração, no caso balanceado $|r|^{2}=|t|^{2}=1 / 2$.

Os nossos detetores tem a capacidade de separar as componentes de baixa frequências $D C$ de aquelas de alta frequência $H F$. O sinal que sofre o processo de soma e subtração é o sinal $H F$. Portanto temos que calcular a variância da soma e substração das fotocorrentes. Considerando que o feixe $\hat{a}_{2}$ é coerente e tem amplitude complexa $\alpha_{2}=\left|\alpha_{2}\right| \mathrm{e}^{-i \varphi}$ enquanto $\hat{a}_{1}$ é um feixe qualquer, vemos que

$$
\begin{aligned}
\Delta^{2} I_{-} & =Z^{2}\left\langle\hat{n}_{1}\right\rangle+Z^{2}\left[\left\langle X_{\varphi}^{2}\right\rangle-\left\langle X_{\varphi}\right\rangle^{2}\right] \\
& =Z^{2}\left(\left\langle I_{1}\right\rangle+\left\langle I_{2}\right\rangle+\Delta^{2} X_{\varphi}\right)
\end{aligned}
$$

onde $X_{\varphi}$ é a quadratura generalizada (Equação 3.3) do campo $\hat{a}_{1}$. O caso da soma tem como resultado

$$
\Delta^{2} I_{+}=Z^{2}\left(\left\langle\Delta^{2} \hat{n}_{1}\right\rangle+\left\langle I_{2}\right\rangle\right)
$$


Dado o caso de ter uma entrada de vácuo no porto $\hat{a}_{2}$, a variância na subtração muda para

$$
\Delta^{2} I_{-}=Z\left\langle I_{1}\right\rangle
$$

Lembramos que para um estado coerente a variância é igual ao valor médio do campo. Podemos concluir que a subtração das fotocorrentes mede aquele limite inferior nas medidas. Reconhecemos este último termo novamente como o ruído quântico padrão.

No caso da soma, temos a expressão:

$$
\Delta^{2} I_{+}=Z^{2}\left(\left\langle\Delta^{2} \hat{n}_{1}\right\rangle\right)
$$

que corresponde ao ruído de intensidade do campo $\hat{a}_{1}$, em outras palavras, o sinal completo que um dos detetores mediria.

Se pensamos em uma situação clássica, estaríamos inclinamos a concluir que o sinal de dois feixes da mesma intensidade ao ser subtraindo daria zero, mas a mecânica quântica novamente joga com os preconceitos clássicos e mostra que tem um sinal remanescente, o shot noise.

Finalmente podemos entender como usamos o ruído quântico padrão como referência. As medidas de ruído tomadas são comparadas com o ruído quântico padrão, calculando a razão

$$
\Delta^{2} I_{+} / \Delta^{2} I_{-}=\Delta^{2} \hat{n_{1}} / I_{1}
$$

onde estamos tomando o ruído total do campo dado pela soma $\hat{a}_{4}+\hat{a}_{3}$, e estamos normalizando pelo RQP. Este processo serve como referência dado que se a razão for igual a 1 , estaremos falando de um estado coerente. Se for maior que 1 estamos trabalhando com um feixe com excesso de ruído e se for menor do que 1, temos compressão de ruído $[46]$.

\subsection{Deteção com Cavidade}

A seção anterior explicou a existência de bandas laterais e introduz o conceito de ruído quântico padrão. A análise semiclássica que vamos a desenvolver daqui para frente permanece válido no caso quântico, onde associamos a cada amplitude $\alpha(\nu)$ e $\alpha(-\nu)$ um operador nas bandas laterais $\hat{a}_{\nu}$ e $\hat{a}_{-\nu}$. Com isso em mente, podemos descrever o processo de rotação de elipse. Veremos como é feita a leitura das bandas laterais e como entender a estrutura do espectro de ruído com a referência do ruído quântico padrão.

Se queremos obter informação da fase de uma onda, temos que ter a possibilidade de transformar fase em intensidade. Um exemplo claro e simples de como isto é possível é 
o interferômetro de Mach-Zehnder. Quando a diferença de fase entre os dois caminhos é proporcional a $n \pi$ a luz segue só um caminho. No caso de ter uma diferença de fase de $\pi / 2$, o feixe é dividido com a mesma intensidade nas duas saídas. Efetivamente mediante a intensidade do feixe podemos extrair informação da fase.

Suponha que por algum meio físico, temos a capacidade de modificar a portadora ou as bandas laterais com uma fase $\theta$ controlada. Comecemos com a banda lateral em $\nu$ e usemos a Equação 3.13:

$$
\begin{aligned}
\delta p^{\prime}(\nu) & =\mathrm{e}^{i \theta} \mathrm{e}^{-i \varphi} \delta \alpha(\nu)+\mathrm{e}^{i \varphi} \delta \alpha^{*}(-\nu), \\
& =\mathrm{e}^{i \theta / 2}\left[\mathrm{e}^{-i(\varphi-\theta / 2)} \delta \alpha(\nu)+\mathrm{e}^{i(\varphi-\theta / 2)} \delta \alpha^{*}(-\nu)\right] .
\end{aligned}
$$

Ignorando a fase global, quando $\theta= \pm \pi$ a quadratura representada seria fase. Agora modifiquemos a fase da portadora $\varphi \rightarrow \varphi+\theta$,

$$
\delta p^{\prime}(\nu)=\mathrm{e}^{-i(\theta+\varphi)} \delta \alpha(\nu)+\mathrm{e}^{i(\theta+\varphi)} \delta \alpha^{*}(-\nu),
$$

portanto, variando a fase $\theta$ entre 0 e $2 \pi$, podemos fazer a leitura das diferentes quadraturas, igualando a quadratura fase para valores de $\theta=\pi / 2$ e $\theta=3 \pi / 2$.

Um sistema que permite gerar essa variação contínua da fase relativa entre o feixe incidente e o refletido é uma cavidade ótica vazia. Consideremos um feixe incidindo numa cavidade linear com espelhos de coeficiente de reflexão $R_{1}$ altamente refletor e $R_{2}<1$ representado perdas espúrias e que acoplam o campo intracavidade ao vácuo $\alpha_{v}$.

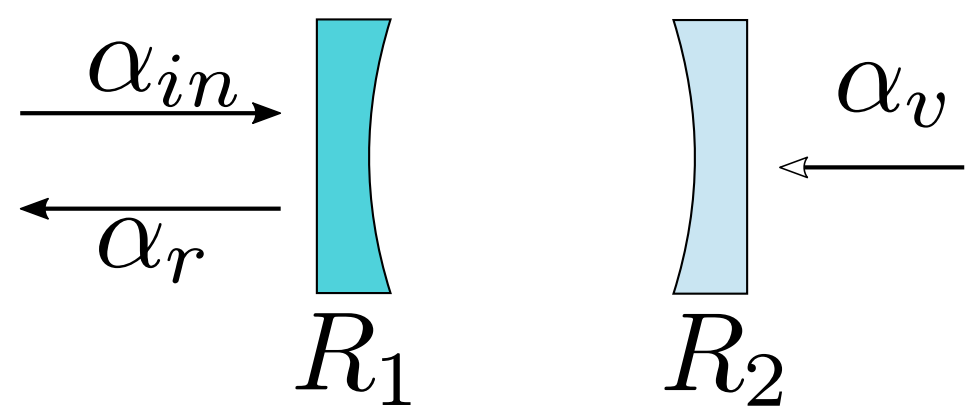

Figura 27. Sistema base para estudar a influência da cavidade sobre o feixe refletido. A amplitude $\alpha_{v}$ é conhecida como vácuo e leva em conta as perdas espúrias do sistema.

Os coeficientes de reflexão e transmissão da cavidade são [40]:

$$
\begin{aligned}
& r(\varpi)=\frac{r_{1}-r_{2} \mathrm{e}^{i 2 \varpi / \mathcal{F}}}{1-r_{1} r_{2} \mathrm{e}^{i 2 \varpi / \mathcal{F}},} \\
& t(\varpi)=\frac{t_{1} t_{2} \mathrm{e}^{i \varpi / \mathcal{F}}}{1-r_{1} r_{2} \mathrm{e}^{i 2 \varpi / \mathcal{F}}},
\end{aligned}
$$


sendo $\mathcal{F}$ a finesse da cavidade definida na Equação 2.54 .

O feixe refletido $\alpha_{r}$ se relaciona com o campo incidente e com o vácuo como:

$$
\alpha_{r}\left(\nu^{\prime}\right)=r\left(\Delta+\nu^{\prime}\right) \alpha_{i n}\left(\nu^{\prime}\right)+t\left(\Delta+\nu^{\prime}\right) \alpha_{v}\left(\nu^{\prime}\right),
$$

com $\nu^{\prime}$ a frequência de análise normalizada pela largura de banda da cavidade, que basicamente indica para qual frequência queremos medir o ruído,

$$
\nu^{\prime}=\frac{\nu}{\delta \nu_{c}}
$$

e $\Delta$ a dessintonia entre a portadora e a ressonância da cavidade relativa a sua largura de banda [39]:

$$
\Delta=\frac{\left(\nu_{o}-\nu_{c}\right)}{\delta \nu_{c}}
$$

Se aplicamos a Equação 3.52 sobre a portadora e consideramos o valor médio temos:

$$
\bar{\alpha}_{r}(0)=r(\Delta) \bar{\alpha}_{i n}(0)
$$

onde $\bar{\alpha}_{i n}(0)=\left|\alpha_{i n}\right| \mathrm{e}^{i \varphi_{i n}}$ e consideramos que o valor médio do vácuo é nulo. Apliquemos novamente a equação 3.52 nas bandas laterais

$$
\begin{gathered}
\delta \alpha_{r}\left(\nu^{\prime}\right)=r\left(\Delta+\nu^{\prime}\right) \delta \alpha_{i n}\left(\nu^{\prime}\right)+t\left(\Delta+\nu^{\prime}\right) \delta \alpha_{v}\left(\nu^{\prime}\right), \\
\delta \alpha_{r}^{*}\left(-\nu^{\prime}\right)=r\left(\Delta-\nu^{\prime}\right) \delta \alpha_{i n}^{*}\left(-\nu^{\prime}\right)+t^{*}\left(\Delta-\nu^{\prime}\right) \delta \alpha_{v}^{*}\left(-\nu^{\prime}\right) .
\end{gathered}
$$

Estas relações deixam ver que o feixe refletido, seja banda lateral ou portadora, muda a sua amplitude devido a $r(\Delta)$ e é defasado em $\theta_{r}$ :

$$
\mathrm{e}^{i \theta_{r}}=r(\Delta) /|r(\Delta)|
$$

O efeito da cavidade sobre a quadratura $p$ do campo refletido tem contribuições das quadraturas incidentes e do acoplamento da cavidade com o vácuo, de onde encontramos a relação [39]:

$$
\begin{aligned}
\delta p_{r}\left(\nu^{\prime}\right)= & g_{p}\left(\Delta, \nu^{\prime}\right) \delta p_{i n}\left(\nu^{\prime}\right)+i g_{q}\left(\Delta, \nu^{\prime}\right) \delta q_{i n}\left(\Delta, \nu^{\prime}\right) \\
& +g_{v p}\left(\Delta, \nu^{\prime}\right) \delta v_{p}\left(\nu^{\prime}\right)+i g_{v q}\left(\Delta, \nu^{\prime}\right) \delta v_{q}\left(\nu^{\prime}\right),
\end{aligned}
$$

onde $\delta v_{j}$ são as flutuações do vácuo e 


$$
\begin{aligned}
2 g_{p} & =\mathrm{e}^{-i \theta_{r}(\Delta)} r\left(\Delta+\nu^{\prime}\right)+\mathrm{e}^{i \theta_{r}(\Delta)} r^{*}\left(\Delta-\nu^{\prime}\right), \\
2 g_{q} & =\mathrm{e}^{-i \theta_{r}(\Delta)} r\left(\Delta+\nu^{\prime}\right)-\mathrm{e}^{i \theta_{r}(\Delta)} r^{*}\left(\Delta-\nu^{\prime}\right), \\
2 g_{v p} & =\mathrm{e}^{-i \theta_{r}(\Delta)} t\left(\Delta+\nu^{\prime}\right)+\mathrm{e}^{i \theta_{r}(\Delta)} t^{*}\left(\Delta-\nu^{\prime}\right), \\
2 g_{v q} & =\mathrm{e}^{-i \theta_{r}(\Delta)} t\left(\Delta+\nu^{\prime}\right)-\mathrm{e}^{i \theta_{r}(\Delta)} t^{*}\left(\Delta-\nu^{\prime}\right) .
\end{aligned}
$$

Os coeficientes $g_{p, q}$ tem a dependência do $p_{r}$ com as quadraturas de entrada, enquanto $g_{v p, v q}$ são a contribuições de vácuo.

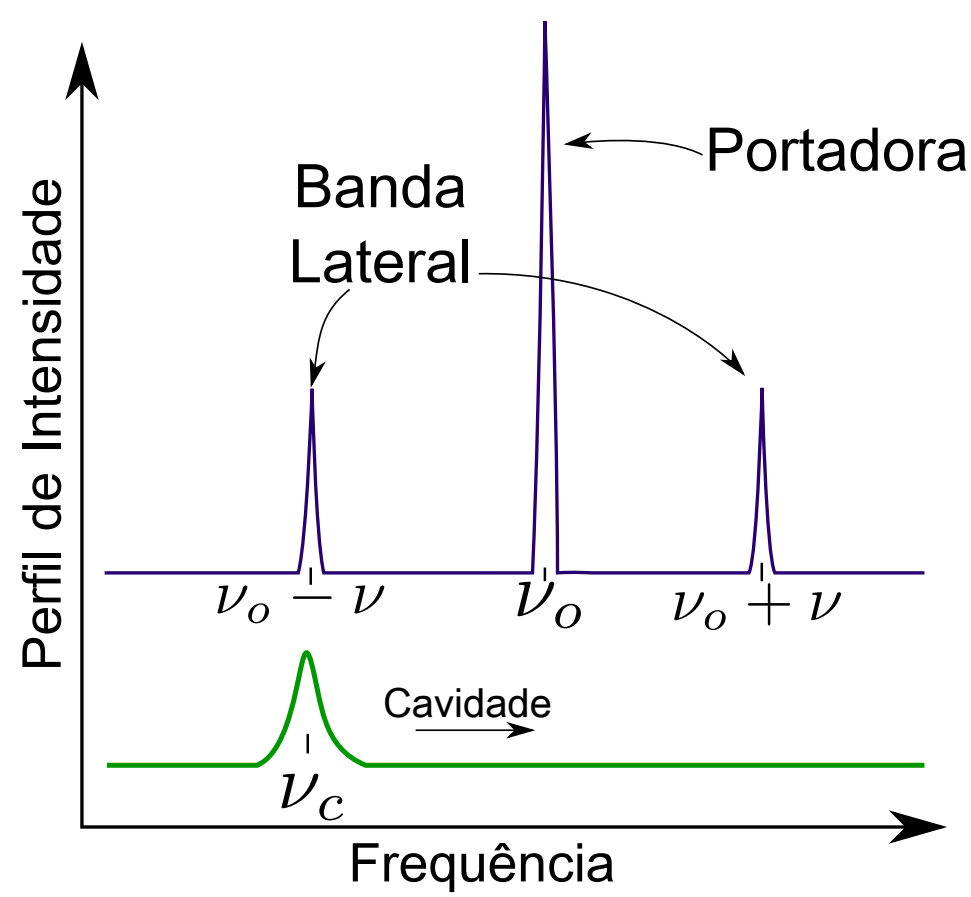

Figura 28. Representação da portadora com as bandas laterais como tamanho exagerado para ilustração. Em verde vemos a transmissão da cavidade. Fazendo a varredura da dessintonia da cavidade, passamos pela ressonância dela com as bandas laterais e com a portadora. Cada frequência que entra em ressonância com a cavidade é atenuada e muda a sua fase.

Na Figura 28 vemos uma ilustração das bandas laterais e da portadora e como a cavidade varre em frequência, passando pela ressonância com as bandas laterais e a portadora mudando a fase de cada uma por vez. A Figura 29 mostra o comportamento da refletividade da cavidade como função da dessintonia $\Delta$. Cada feixe que entra em ressonância com a cavidade é atenuado um fator $|r(\Delta)|$ e ganha uma fase $\theta_{r}$ entre 0 e $2 \pi$. Estes dois efeitos acontecem seguidos um do outro e combinados geram a transformação de ruído de fase para amplitude, como veremos na seguinte seção. 


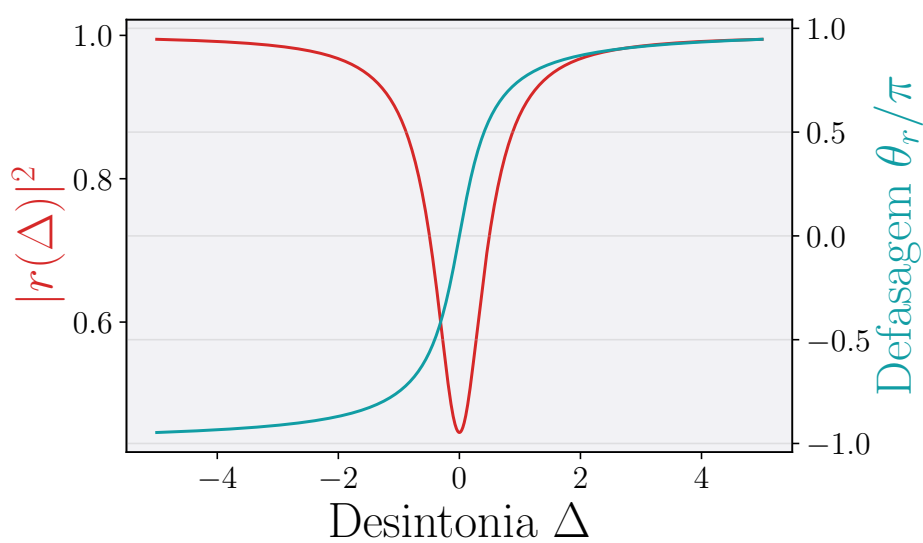

Figura 29. Conforme nos aproximamos na ressonância da cavidade, a refletividade diminui e o feixe refletido sofre uma defasagem de $2 \pi$.

\subsection{Elipse de Ruído}

O sinal que medimos no analisador de espectro corresponde ao espectro de ruído definido como [42]:

$$
S_{X_{\phi}} \delta\left(\nu-\nu^{\prime}\right)=\left\langle\delta X_{\phi}(\nu) \delta X_{\phi}\left(-\nu^{\prime}\right)\right\rangle
$$

onde $X_{\phi}$ é uma quadratura generalizada. Ele é representado mediante uma elipse de ruído no plano complexo, e simboliza as flutuações aleatórias nas quadraturas para uma certa frequência de analise (Figura 32). Todas as nossas medidas estão normalizadas pelo ruído quântico padrão $(R Q P)$, como discutido na subseção 3.2.1. Tomando a Equação 3.59 e aplicando-a na Equação 3.64 obtemos o espectro de ruído na amplitude:

$$
\begin{aligned}
S_{r}\left(\Delta, \nu^{\prime}\right)= & \left|g_{p}\right|^{2} S_{p_{i n}}\left(\nu^{\prime}\right)+\left|g_{q}\right|^{2} S_{q_{i n}}\left(\nu^{\prime}\right) \\
& +\left|g_{v p}\right|^{2} S_{v p}\left(\nu^{\prime}\right)+\left|g_{v q}\right|^{2} S_{v q}\left(\nu^{\prime}\right) \\
& +2 \operatorname{Re}\left[-i g_{p} g_{q}^{*} C_{p_{i n} q_{i n}}\left(\nu^{\prime}\right)\right]
\end{aligned}
$$

sendo $S_{v p}\left(\nu^{\prime}\right)=S_{v q}\left(\nu^{\prime}\right)=1$ a nossa referência de ruído (ruído quântico padrão) e $C_{p q}$ o termo de correlações entre as quadraturas [40]. Em geral, o termo $C_{p q}$ pode ser complexo e escrito como [47]:

$$
C_{p q}=\gamma+i \delta
$$

onde $\gamma$ indica um ângulo $\beta$ existente entre o campo médio $|\alpha|$ e a quadratura amplitude na posição do quadro 1 da Figura 33. Graficamente no espectro de ruído, podemos reconhecer o termo $\gamma$ quando a leitura da quadratura amplitude na ressonância do feixe com a cavidade (quadro 9 Figura 33), esta deslocado do zero, como ilustrado naFigura 30. O 
termo imaginário $\delta$ se entende como um desbalanceio de energia nas bandas laterais, que no espectro de ruído corresponde a uma assimetria no nível de ruído das bandas laterais (Figura 31) [47]. Em termos da elipse de rotação (Figura 32) a existência de correlações pode se representar por um desalinhamento entre os eixos principais da elipse e os eixos definidos com respeito à amplitude média do campo.

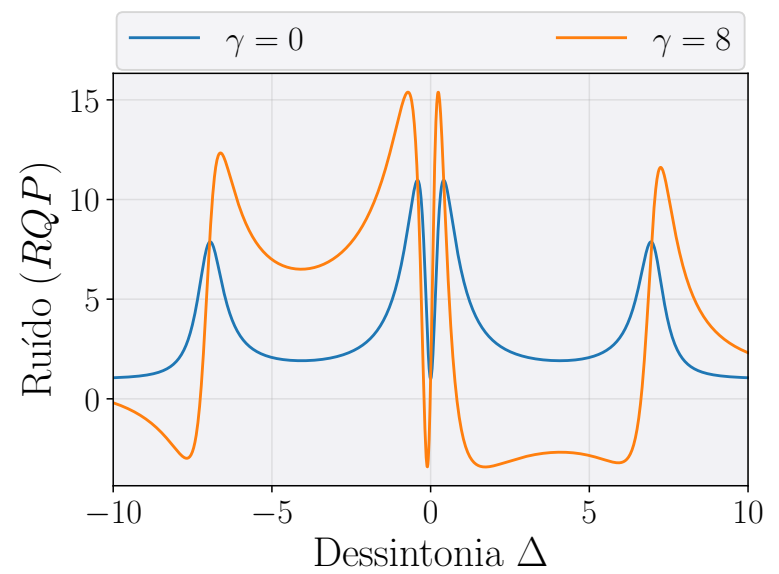

Figura 30. Exemplo da assimetria gerada pelo termo $\gamma$. Vemos que no caso de ter $\gamma \neq 0$, a medição da quadratura amplitude não corresponde à ressonância da cavidade. Parâmetros desta figura são: $\nu^{\prime}=7, S_{p}=1, S_{q}=10$, $\delta=0$, Perdas $=6 \%$ por volta.

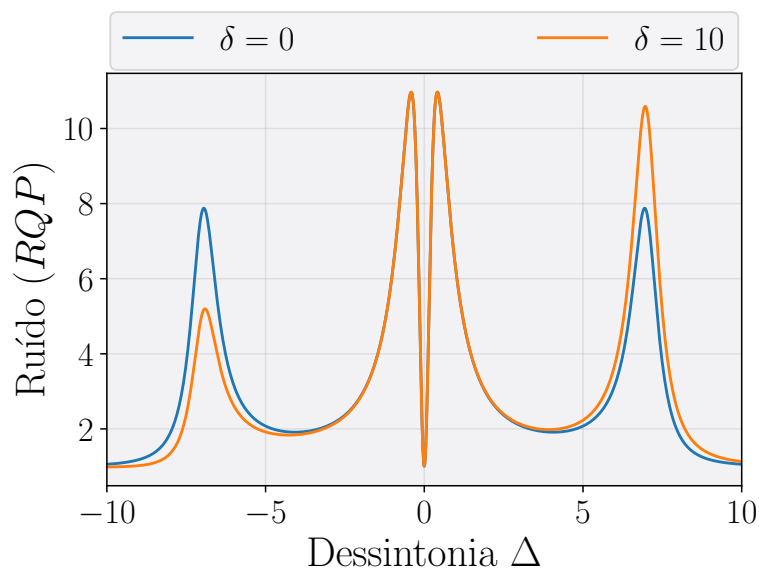

Figura 31. Se o termo $\delta \neq 0$, vemos que as bandas laterais tem altura diferente o que se interpreta como um desbalanceio na energia entre bandas. Parâmetros usados $\nu^{\prime}=7, S_{p}=1$, $S_{q}=10$ e $\gamma=0$, Perdas $=6 \%$ por volta..

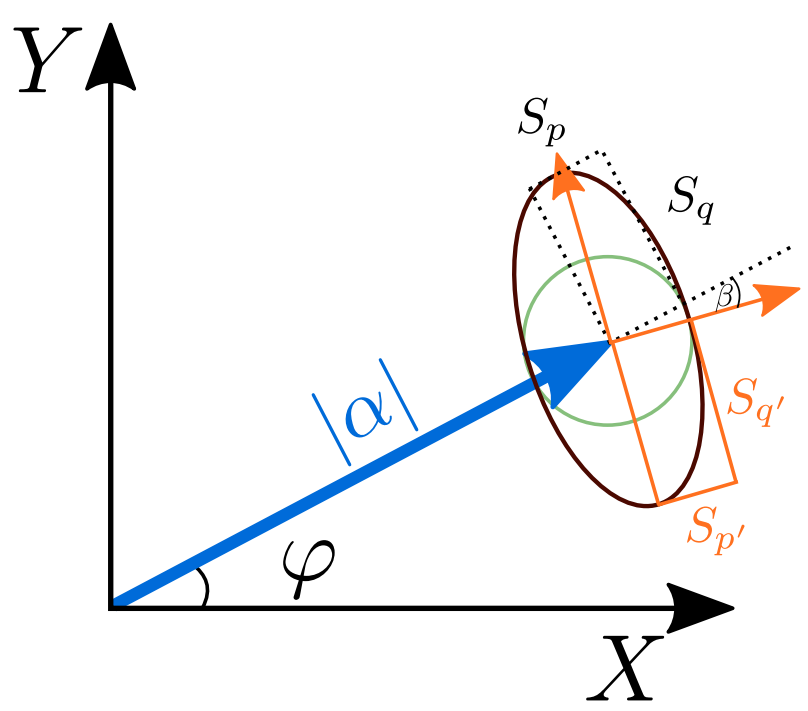

Figura 32. Elipse de ruído para um estado geral. A linha vermelha representa o nível minimo de energia. Os eixos $S_{p}$ e $S_{q}$ são os eixos alinhados com a amplitude media do campo. Os eixos $S_{p^{\prime}}$ e $S_{q^{\prime}}$ são os eixos principais da elipse. Quando eles não são iguais podemo afirmar que existe uma correlação entre quadraturas. $O$ ângulo $\beta$ está medido entre à amplitude media do campo e $S_{p^{\prime}}$. 
A Figura 33 ilustra o resultado de uma medida típica de rotação de elipse. Vemos ao redor da curva do espectro, o processo da elipse de ruído. Supondo que a quadratura amplitude tem menor ruído do que a fase e que começamos com a portadora e a amplitude alinhados (quadro 1), vamos mudando a dessintonia de esquerda para direita. Quando vamos nos acercando à ressonância com a banda lateral em $-\nu$, a elipse roda $\pi / 2$ (quadro 3) e estaremos fazendo a leitura da quadratura fase, justo como indicado anteriormente na Equação 3.48. No quadro 5 giramos novamente $\pi / 2$ e começamos a sobrepor a rotação da portadora, por isso não conseguimos medir de novo a amplitude. Uma vez que a portadora está em ressonância com a cavidade, é ela quem sofre alteração na fase, sem modificar as bandas laterias. Portanto, a elipse não vai girar (quadros 5 a 13), mas a amplitude media do campo vai, passando duas vezes pela quadratura fase, nos quadros 7 e 11, e uma vez pela quadratura amplitude, quadro 9. Vimos isto na Equação 3.49. Finalmente a cavidade é ressonante com a banda lateral $\nu$ (quadro 15) onde todo é simétrico respeito à banda oposta.

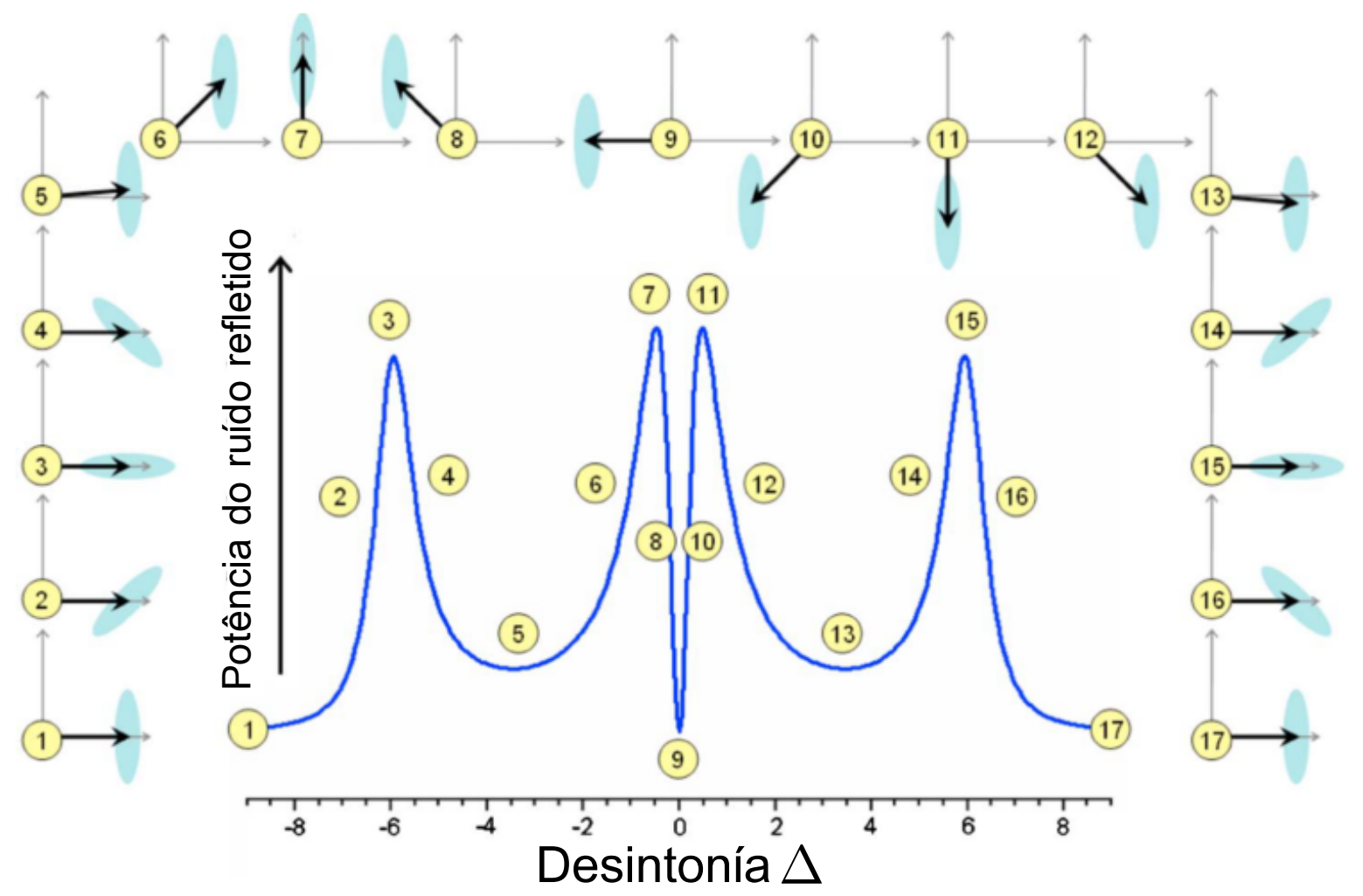

Figura 33. Espectro de ruído em função da dessintonia da cavidade. Ao redor da curva, vemos os quadros que representam as etapas da medição. Medição da quadratura fase se dá em 3,7,11,15 e da amplitued em 1,9,17. Esta figura foi feita para $\nu^{\prime}=6, S_{p}<S_{q}, R_{1}=0.95$ e $R_{2}=0.997$. Figura tomada de [7] .

Este sistema apresenta limites na hora de selecionar frequências de análises. Voltemos para a Figura 28. Se a largura à meia altura da cavidade de análises cresce, o efeito do solapamento entre banda lateral e portadora se evidenciaria por não ter um vale tão pronunciado na região 5. Do mesmo modo, se tivermos uma cavidade com uma certa 
largura de banda e selecionamos uma frequência de análise muito perto da portadora, temos novamente aumento do solapamento (Figura 34). Ou seja, dada uma largura de banda da cavidade, temos um limite que permite distinguir entre portadora e banda lateral permitindo o giro completo, limite que é dado por [7]:

$$
\nu^{\prime} \geq \sqrt{2}
$$

termo normalizado pela largura de banda da cavidade de análise (Equação 3.53).

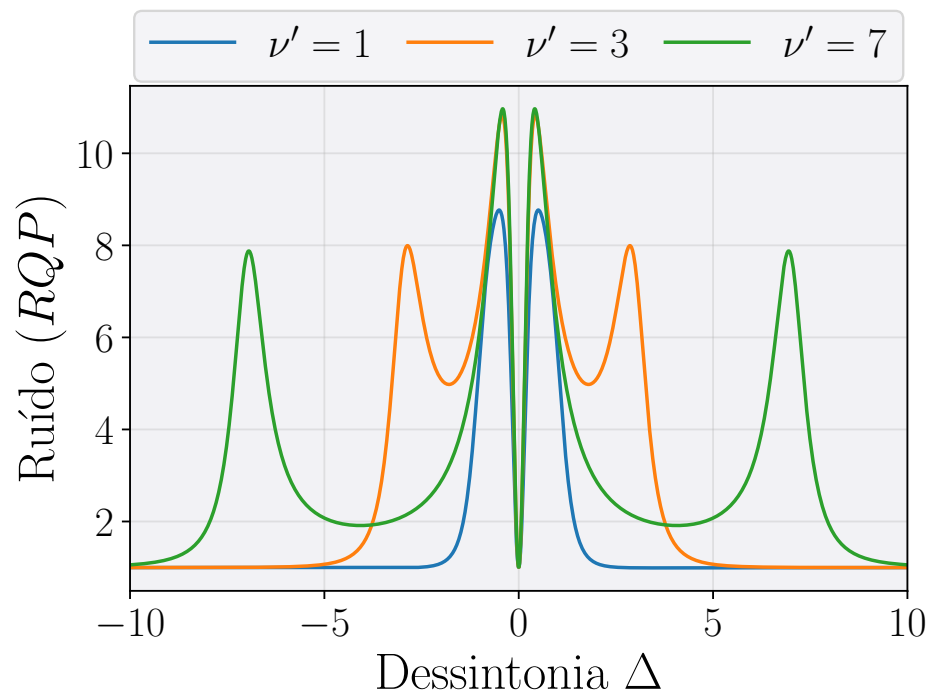

Figura 34. Espectro de ruído em função da dessintonia da cavidade mudando a frequência de análises para $\nu^{\prime}=1,3,7$. Para frequências de análises muito baixas o solapamanto entre bandas é muito alto e não conseguimos diferenciar entre elas. Conforme a frequência aumenta conseguimos fazer a leitura completa do ruído. $S_{p}=1, S_{q}=10, \gamma=0, \delta=0$.

Em termos da elipse de ruído, poderiamos entender isto como um processo incompleto onde começamos a rotação de elipse mas ficamos no meio do caminho. Se a Equação 3.67 não se cumpre, significa que temos a portadora e a banda lateral dentro da largura de banda da cavidade e ao serem refletidas todas elas ganhariam fases próximas e como o processo funciona justamente por manipular individualmente a fase de cada frequência, não teríamos conversão de ruído.

\section{Resumo do capítulo}

Neste capítulo descrevemos completamente a deteção de ruído das quadraturas do campo a medir. Começamos pela definição das quadraturas generalizadas e como entender a criação de bandas laterias por flutuações. Logo construímos a conceito do shot noise, passando pela quantização do campo e vimos como é possível exrair a informação das quadraturas com a deteção balanceada. Ao mesmo tempo definimos o shot noise como uma referência para as medidas dos capítulos posteriores e finalizamos com a descrição fenomenológica do método da rotação de elipse. 
Este capítulo finaliza a parte teórica necessária para o desenvolvimento e entendimento do projeto exposto. No seguinte capítulo mostraremos as estruturas mais importantes da montagem experimental e finalizaremos este trabalho mostrando os resultados cuja interpretação não seria possível sem o capítulo que está terminando agora. 
II

INSTRUMENTAÇÃO 



\section{4}

\section{INSTRUMENTAÇÃO}

Neste capítulo vamos fazer a descrição dos elementos mais importantes da montagem experimental, mostrando os detalhes, modificações e parâmetros usados para realizar o experimento.

\subsection{Laser Diodo em configuração Littrow}

No desenvolvimento do experimento, usamos um diodo em cavidade externa em configuração Littrow que como visto na Figura 35, é formada por uma rede de difração de 1800 linhas $/ \mathrm{mm}$ ), um diodo da empresa TOPTICA (Ref.: \#LD - 0785 - P200 - 1), de comprimento de onda centrado em $785 \mathrm{~nm}$ com coating anti-refletor na primeira face, um parafuso micrométrico para sintonizar o de onda e um PZT que é usado para estabilizar o sistema em um único modo.

A grade de difração ruled, está projetada para maximizar a eficiência da rede, isto é, a maioria da potencia difratada estará na ordem um e por sua vez, minimiza as perdas da ordem refletida (ordem zero). A reflexão depende fortemente da polarização do feixe incidênte, no caso de ter polarização perpendicular ao plano de incidência a refletividade pode atingir $\sim 85 \%$ e no caso de ter polarização paralela ao plano de incidência podemos obter $\sim 15 \%$ [48] . O comprimento de onda difratado pela rede está determinado pela equação da rede [49]:

$$
m \lambda=d\left(\sin \left(\theta_{i}\right)+\sin \left(\theta_{m}\right)\right),
$$

onde $m$ corresponde à ordem de difração, $d$ a distância entre ranhuras, $\theta_{i}$ o ângulo incidente respeito à normal da rede, positivo por ser medido em sentido anti-horário, e $\theta_{m}$ é o ângulo do feixe difratado que é negativo por ser medido em sentido horário (Figura 36). Para encontrar a Equação 4.1, consideramos a diferença de caminho ótico entre dois feixes 


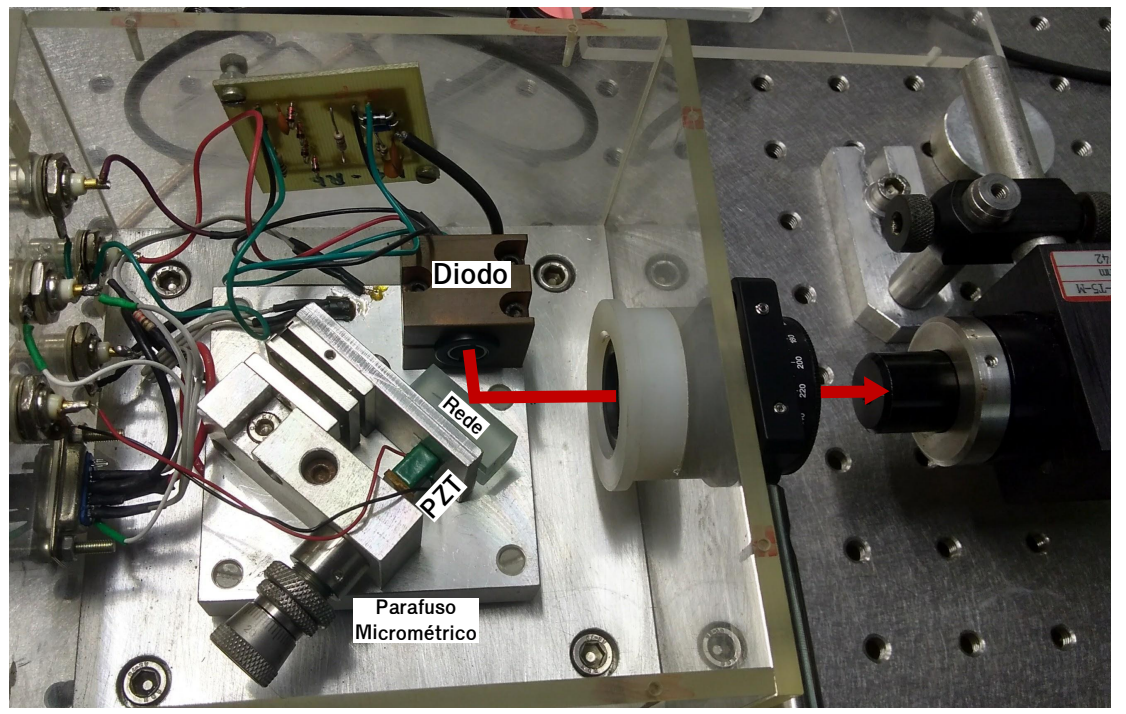

Figura 35. Montagem diodo em cavidade externa. Mostramos só o feixe de ordem zero que sai da cavidade mas levemos na conta que a ordem um está sendo retroalimentada no diodo.

paralelos que estão chegando na rede, como mostrado na Figura 36, corresponde aos segmentos $\overline{A B}$ e $\overline{C D}$. Temos interferência construtiva se a diferença de caminho entre os dois feixes é proporcional ao comprimento de onda da luz.

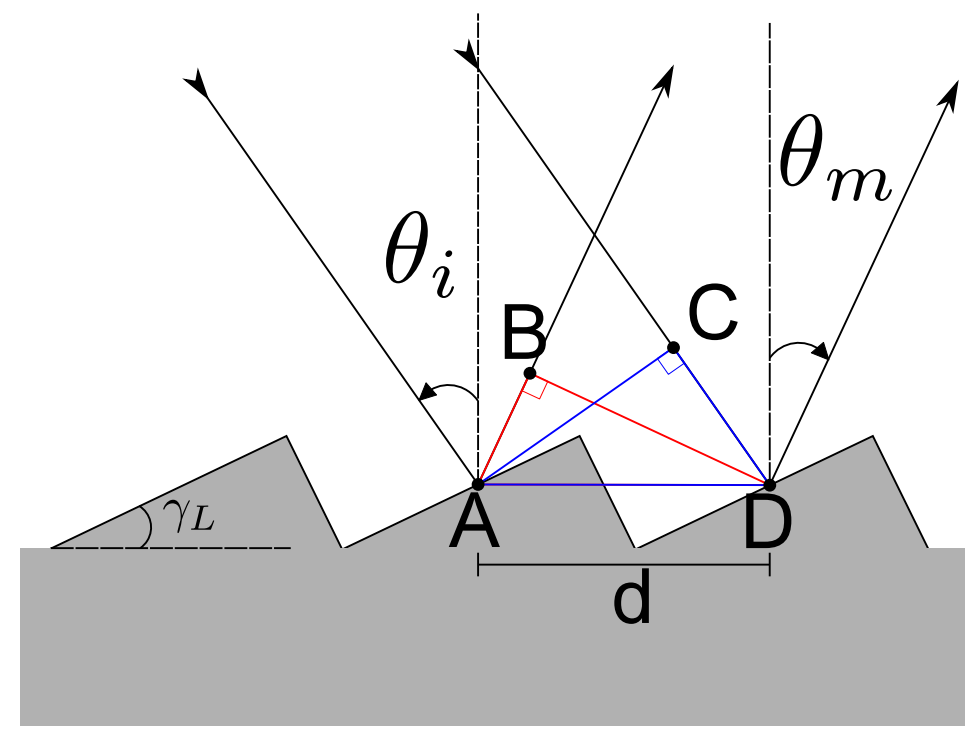

Figura 36. Geometria de feixes incidindo na rede de difração. Os ângulos $\theta_{i, m}$ estão medidos respeito à linha pontilhada. Tomando a diferença entre os segmentos $\overline{A B}$ e $\overline{C D} e$ exigindo a condição de interfernência construtiva, obtemos a equação da rede.

A configuração Littrow se refere à disposição da rede onde $\theta_{i}=\gamma_{L}$ e o ângulo do feixe difratado cumpre $\theta_{i}=\theta_{m}$. Com isto:

$$
2 d \sin \left(\gamma_{L}\right)=\lambda
$$

A cavidade externa, como mostrado na Figura 37, é composta pela rede difratora 
e uma das superfícies do diodo emissor que tem alta reflexão. O meio amplificador é a junção dentro do diodo e à ordem 1 da difração é a retroalimentação da cavidade.

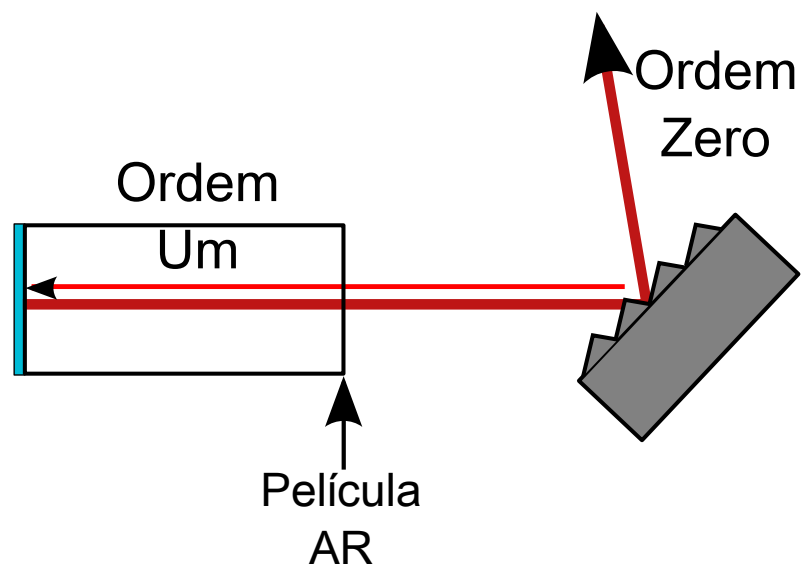

Figura 37. A cavidade externa em configuração Littrow é formada pela face traseira do diodo, a junção como meio de ganho e a rede de difração como o segundo espelho.

O comprimento de onda que oscila na cavidade depende do ângulo de incidência do feixe sobre a rede e do tamanho da cavidade. Logo, mudando esse ângulo podemos sintonizar o comprimento de onda de forma precisa [10]. Este também é a sua maior desvantagem pois mudar o comprimento de onda leva a mudar a direção do feixe e teríamos que alinhar o sistema de novo para variações grandes de $\lambda$.

\subsection{Laser Diodo SDL-8630}

O nosso sistema base consiste em um chip semicondutor da serie $S D L-8630$ (TL219) da antiga empresa SDL, Inc., constituído por um diodo afunilado em configuração de cavidade externa, bombeado eletricamente (corrente de injeção), um sistema ótico com lentes cilíndricas para corrigir o astigmatismo e um dissipador de calor esfriado por um ventilador.

Para os nossos propósitos, varias modificações no sistema foram feitas. Para usar o chip como meio de ganho (tapered amplifier), retiramos a montagem da cavidade externa deixando duas saídas de luz disponíveis, a que passa pelo sistema ótico de correção que será denominada como contrapropagante e aquela que sai pelo lado contrario será denominada propagante, justo como está ilustrado na Figura 38. O ventilador foi desligado dado que as vibrações que ele gera atrapalham a estabilidade do laser e em compensação, elaboramos um sistema com fluxo de água para estabilizar a temperatura (Figura 38). O sistema laser deve operar sempre entre 15 e $25^{\circ} \mathrm{C}$ [50], nós ajustamos o fluxo de água para que a temperatura fosse de $20^{\circ} \mathrm{C}$. 


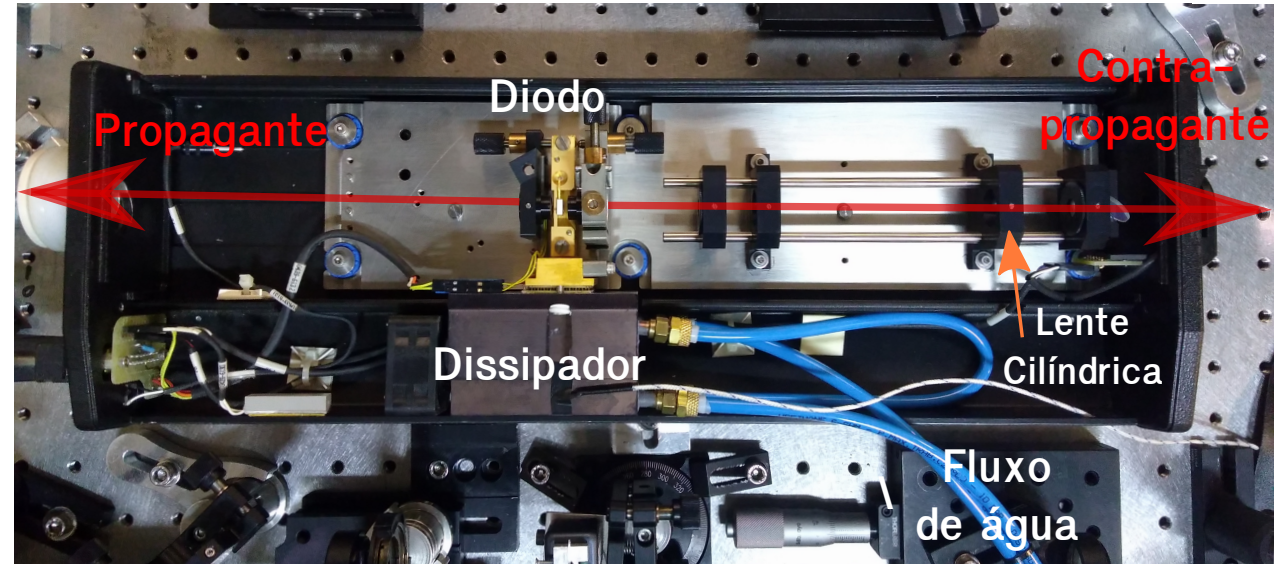

Figura 38. Montagem do SDL modificado. Retiramos a montagem da cavidade externa, desconectamos o ventilador e colocamos um fluxo de água.

\subsubsection{Cavidade Fechada}

Antes de fechar a cavidade, tivemos que resolver o problema do astigmatismo do feixe propagante para melhorar o acoplamento entre feixe propagante e contrapropagante. Usamos então prismas anamórficos, os quais funcionam mudando o tamanho de um só eixo do feixe dada a diferença de caminho ótico percorrido [51]. Os ângulos e a distância entre prismas determinam a correção sobre o eixo. A correção persiste por uma distância de um metro que é suficiente para fazer o acoplamento com o lado contrapropagante para reinjeção.

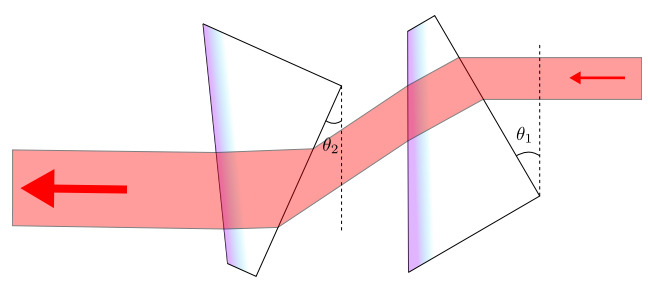

Figura 39. Esquema da correção dos prismas anamórficos sobre o feixe. Esta imagem corresponde a uma vista superior do sistema onde o eixo paralelo com o plano do desenho é o corrigido e o perpendicular não sofre modificação.

Na Figura 40 vemos a caracterização feita da transmissão da luz pelo etalon em função do ângulo incidente. $\mathrm{O}$ zero do ângulo foi definido como a posição do etalon na qual o feixe voltava pelo mesmo caminho. Vemos duas regiões de máxima transmissão ao redor de $70 \%$ perto de 1.5 graus e vemos que o zero está deslocado, isto devido à exatidão para definir o zero.

A Figura 41 ilustra a configuração da cavidade fechada. Na direção do feixe propagante vemos os prismas anamórficos, na caixa da linha tracejada vemos a configuração para a saída da cavidade composta por uma lâmina de meia onda ( $H W P 1)$, um isolador ótico e mais uma lâmina de meia onda ( $H W P 2)$. Seguindo a propagação do feixe encontramos duas lentes para o acoplamento entre o feixe propagante e o chip [52] e entre elas um 


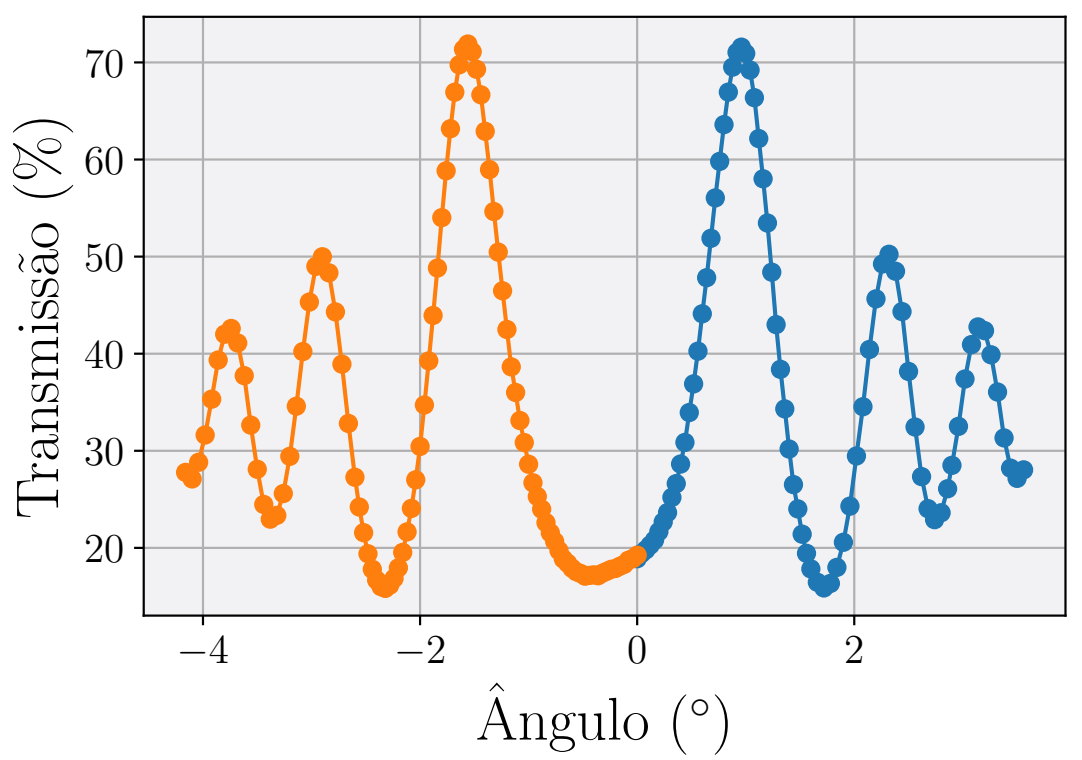

Figura 40. Caracterização da transmissão do etalon em função do ângulo incidente. A variação da transmissão ajuda na seleção dos modos intracavidade.

"etalon"(Figura 40) localizado perto do foco após a primeira lente para tentar ter algo próximo de uma onda plana. Finalmente temos a entrada pelo lado contrapropagante. A grande vantagem do etalon é que ele permite uma melhor seleção dos modos que vão oscilar na cavidade ao criar interferência construtiva ou destrutiva para o feixe transmitido dependendo do ângulo de incidência (2.2).

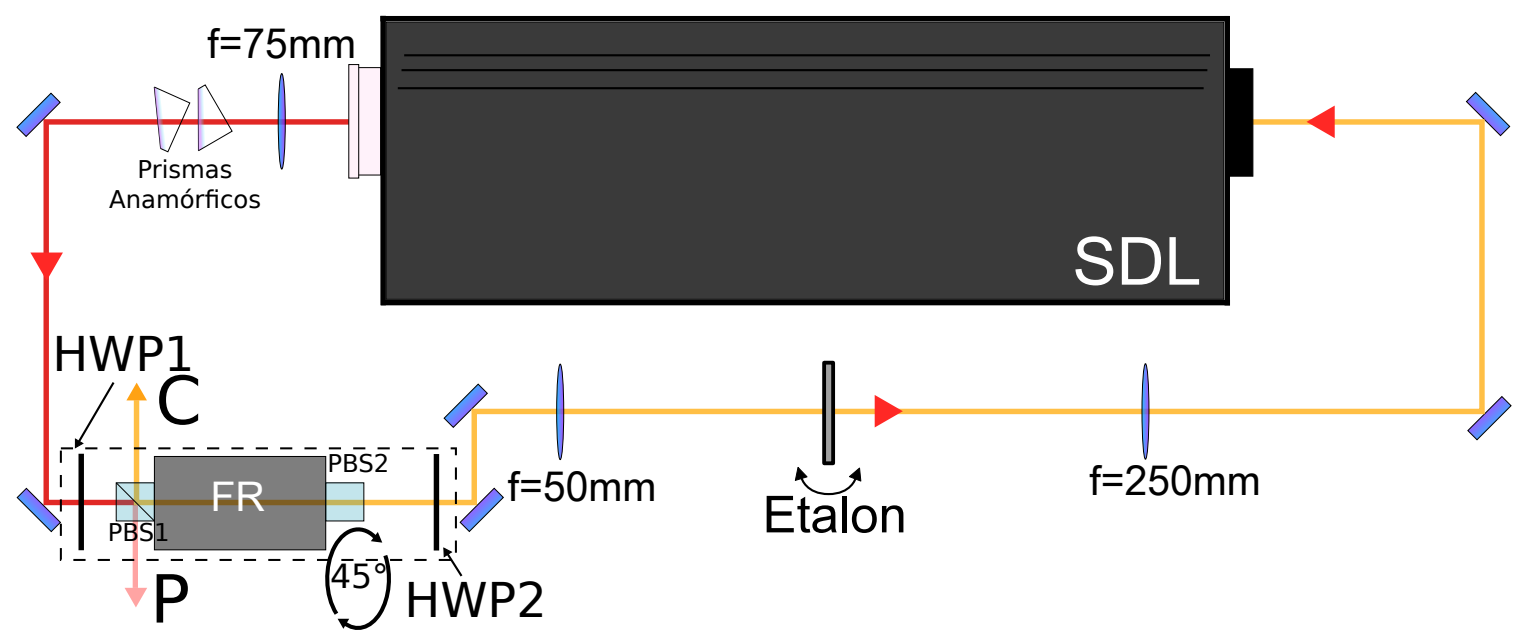

Figura 41. Esquema da cavidade fechada. No sentido do feixe propagante temos os prismas anamórficos, as perdas controladas da cavidade, o sistema de acople entre feixes e um etalon. A saída $\boldsymbol{C}$ são perdas não controladas.

O tamanho da cavidade $(190 \mathrm{~cm})$ foi dado pela estrutura e os elementos que iam compor-la e não por um estudo exaustivo e antecipando as propriedades que queríamos achar. A nossa cavidade tem duas saídas que chamamos de $\mathbf{C}$ para a contrapropagante e $\mathbf{P}$ para a propagante. A saída $\mathbf{P}$ são as perdas controladas da cavidade; está composta pela primeira lâmina de onda e o $P B S 1$. Variando o ângulo da placa podemos mudar a 
potência e a finesse da cavidade. A saída $\mathbf{C}$ é obtida pelo rotador de Faraday, o $P B S 2$ e a segunda lâmina de onda, controlando a polarização que chega no $P B S 1$ para que seja vertical. A saída $\mathbf{C}$ corresponde à reflexão na face do diodo. A segunda lâmina também tem uma segunda função que é devolver a polarização horizontal ao feixe propagante. Por outro lado, o etalon ajuda na seleção dos modos intracavidade privilegiando aqueles que tem transmissão alta. Todas a medidas aqui apresentadas foram tomadas para uma temperatura de $20^{\circ} \mathrm{C}$. A saída $\mathbf{C}$ é acoplada em fibra e enviada para o sistema de análise de ruído enquanto a saída $\mathbf{P}$ é enviada a uma cavidade de referência confocal Thorlabs SA200-5B com intervalo espectral livre $1.5 \mathrm{GHz}$ e finesse $>200$, que permite discriminar modos. Uma rampa de tensão aplicada sobre um PZT operante em um dos espelhos varia o tamanho da cavidade. No caso monomodo, a resposta deve ser semelhante à Figura 19.

Finalmente, temos a Figura 42 que representa a variação a partir da quarta casa decimal do comprimento de onda do laser, como função do tempo. O comprimento de onda é $782.958 \mathrm{~nm}$ para uma corrente de $0.80 \mathrm{~A}$ para a cavidade fechada. A medida for realizada usando o Bristol Wave Meter 671.

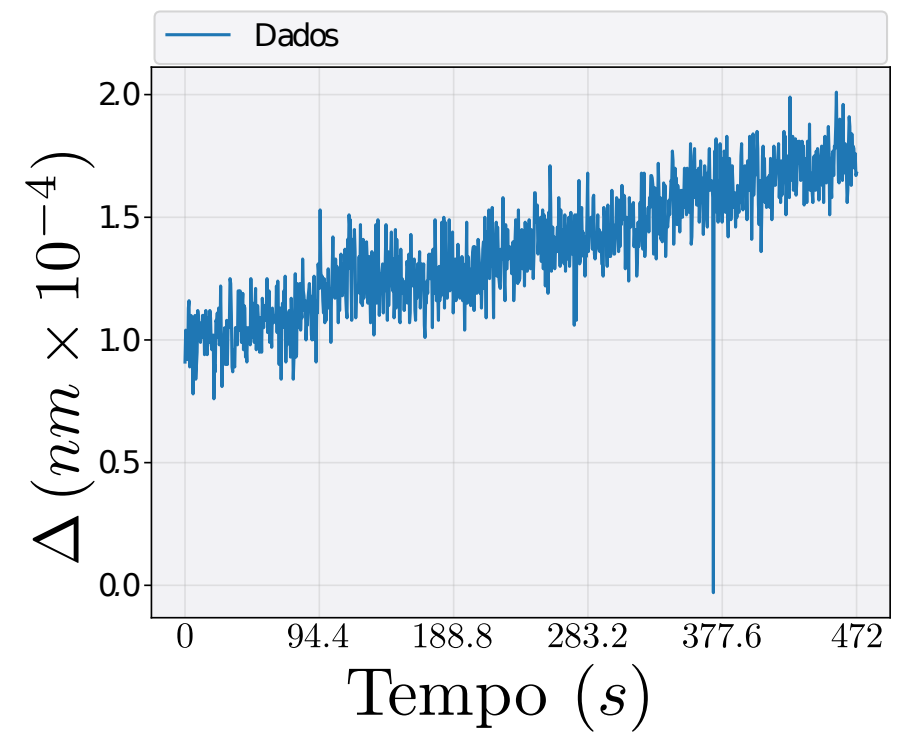

Figura 42. Estabilidade do comprimento de onda do laser, em função do tempo. O valor médio do comprimento de onda é $782.958 \mathrm{~nm}$ para uma corrente de injeção de $0,80 \mathrm{~A}$ cavidade fechada..

\subsection{Cavidade de Análise}

A nossa cavidade de análise é uma cavidade triangular, com $F S R \approx 538 \mathrm{M} \mathrm{Hz}$. O espelho de entrada tem transmissão de $1 \%$ para polarização horizontal, o espelho de saída e o espelho curvo são de alta refletividade para polarização horizontal. Com esta configuração de espelhos podemos obter uma finesse superior a 300 o que faz com que a largura de banda seja estreita e portanto, a nossa cavidade seja instável devido à falta de 


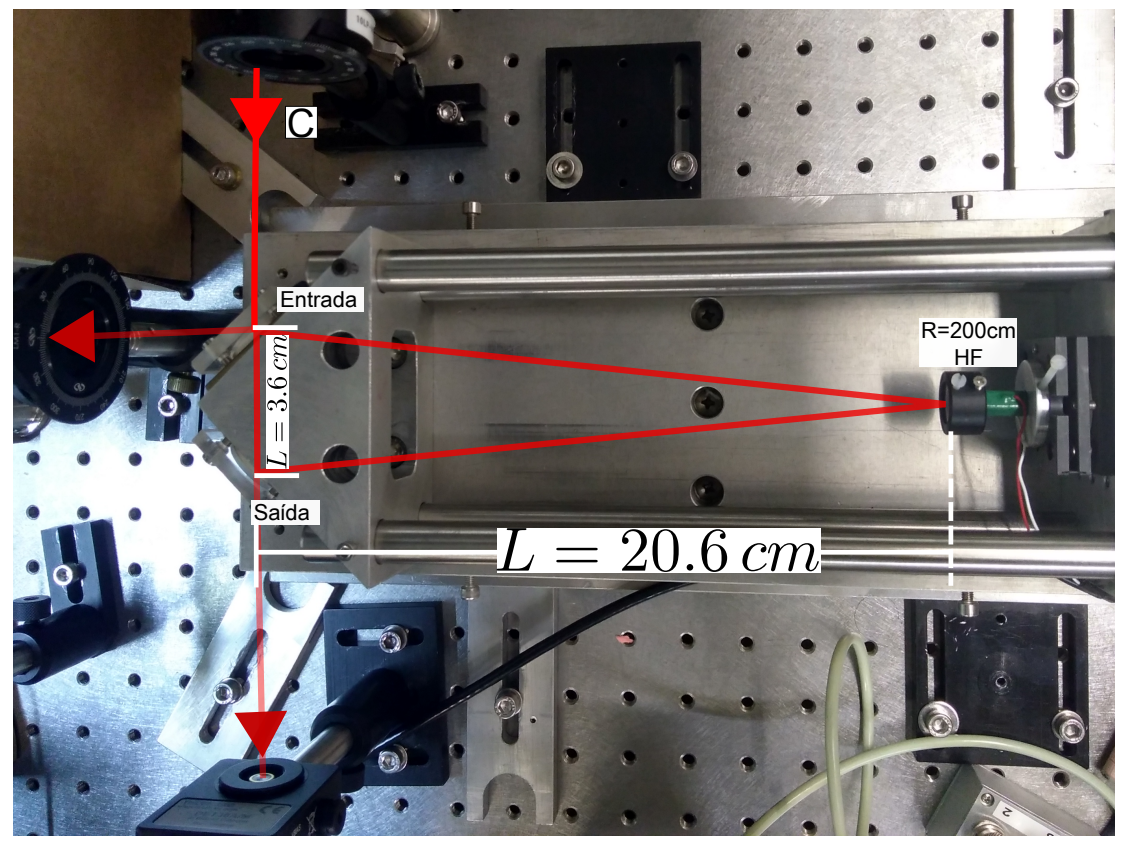

Figura 43. Montagem experimental da cavidade de análise. Vemos os feixe incidente, o refletido, o transmitido que vai para um detetor e o feixe intracavidade.

amortecimento na mesa ótica em que trabalhamos. Então mudamos a polarização da luz para vertical e assim diminuímos a finesse da cavidade alargando a sua largura de banda, obtendo uma finesse entre 60 e 75 e uma visibilidade ${ }^{\mathrm{I}}$ superior a $99 \%$. A largura de banda da cavidade estava usualmente entre 7 e $9 \mathrm{MHz}$, deixando a região acima de $12 \mathrm{MHz}$ para fazer a rotação de elipse completa.

\subsection{Analisador de Espectro}

Nesta seção vamos descrever os parâmetros usados no analisador de espectro para medir a grandeza da Equação 3.65, e vamos discutir sobre os problemas na hora da medição. Trabalhamos com o analisador de espectro eletrónico Agilent E4401B ESA-E Series que permite medidas para um rango de frequências entre $9 k H z$ e 1.5 GHz. A Tabela 1 mostra os parâmetros usados nas medidas finais reportadas neste trabalho. Vemos na coluna dois que aparece o resolution bandwidth $(R B W)$, parâmetro que se refere ao tamanho da janela de frequência em que vamos medir. Em outras palavras, se a nossa janela for pequena estaríamos medindo com mais detalhe o sinal detetado ou seja com maior resolução. O termo da terceira coluna, o video bandwidth ( $V B W)$, serve para filtrar e limpar as flutuações do sinal sem mudar o comportamento nem os valores do sinal.

Dado o número de pontos e o tempo de varredura, a resolução mínima com que poderíamos trabalhar é $60 \mathrm{kHz}$, porém, problemas com o sinal eletrônico da rede elétrica presentes na fonte do SDL geram flutuações no sinal medido como ilustrados na Figura 44,

I Se entende por visibilidade como a porcentagem de acoplamento entre o feixe incidente e a cavidade. 


\begin{tabular}{|c|c|c|c|c|}
\hline Rampa $(H z)$ & RBW $(M H z)$ & VBW $(k H z)$ & Varredura A.E. $(m s)$ & Pontos \\
\hline 50 & 1 & 100 & 10 & 600 \\
\hline
\end{tabular}

Tabela 1. Parâmetros do Analisador de Espectro. A primeira coluna corresponde à frequência de varredura da cavidade de análise, logo temos o Resolution Bandwidth e o Video Bandwidth, seguido do tempo de varredura do analisador de espectro e o número de pontos que o analisador mede.

onde se observa em verde, ruído que provem do sistema elétrico do laboratório $(\sim 60 \mathrm{~Hz})$ e dificulta obter um sinal adequado para analisar. O sinal roxo corresponde com a rotação de elipse junto com o ruído da rede. A solução para continuar a caracterização da montagem foi aumentar o $R B W$ fazendo médias sobre intervalos maiores de frequência o que diminui drasticamente o ruído da rede elétrica. Por exemplo, a Figura 44 mostra claramente o problema medindo com alta resolução. A curva verde mostra a soma do sinal dos detetores com a cavidade de análise bloqueada. Vemos que aparecem flutuações que sabemos são da rede elétrica devido a que trigando o analisador de espectro com o sinal da rede, as flutuações ficam paradas. O sinal roxo é a rotação de elipse contaminada pelo ruído de fundo da rede elétrica.

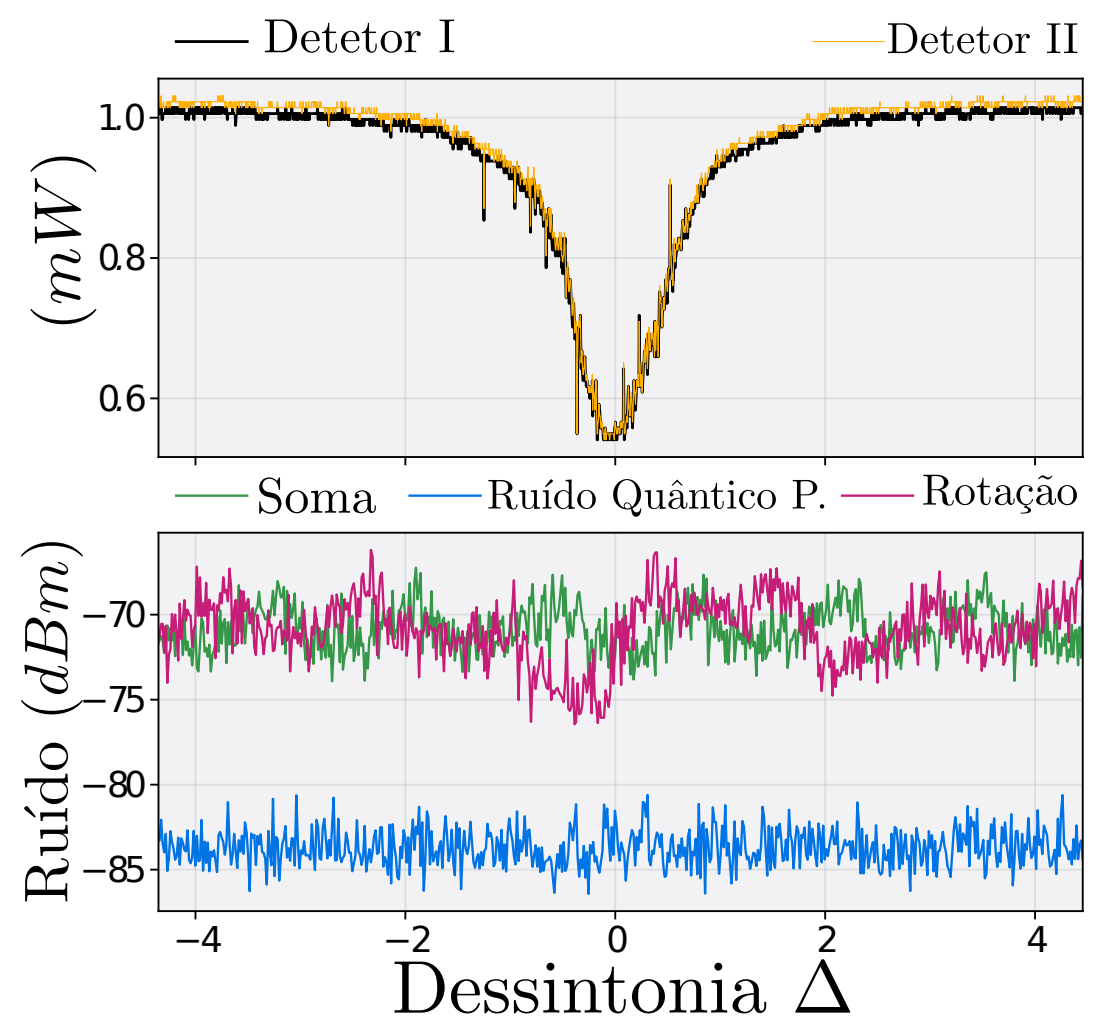

Figura 44. Vemos o sinal do ruído quântico padrão em azul, o sinal roxo é a rotação de elipse contaminado com o ruído verde graficado no fundo.

Por outro lado, também poderia ser melhor diminuir a frequência de varredura da cavidade aumentando o tempo de varredura do analisador de espectro para ter melhores 
e mais detalhes do sinal. O problema vem novamente com o sinal de $60 \mathrm{~Hz}$ como está na Figura 45 a), onde se mostra o sinal do feixe refletido da cavidade varrendo-la com $1 \mathrm{~Hz}$. Vemos como a flutuação da rede elétrica aparece múltiplas vezes no sinal refletido. A Figura 45 b) corresponde à medição feita varrendo a cavidade com $50 \mathrm{~Hz}$ e vemos que como com uma varredura mais rápida captamos menor número de vezes o sinal ruidoso extra. Os parâmetros que permitiram realizar as melhores medidas foram os especificados na tabela 1.

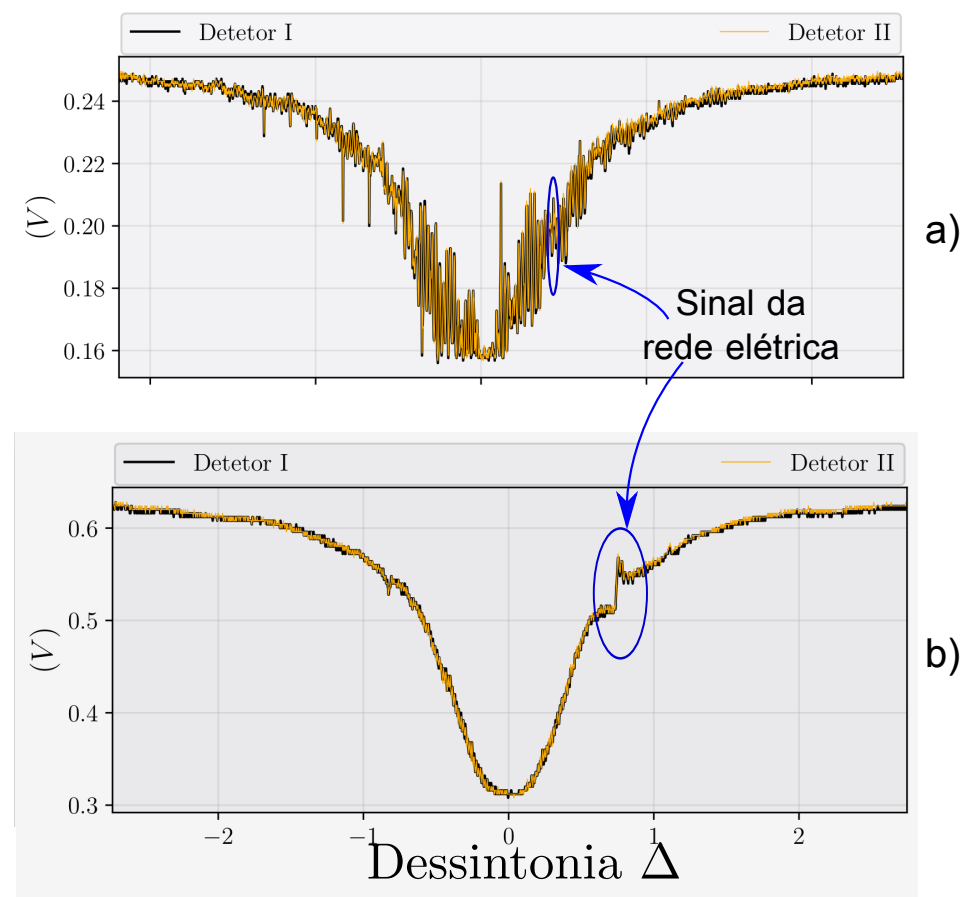

Figura 45. A figura a) mostra a reflexão da cavidade varrendo ela a $1 \mathrm{~Hz}$, onde captamos as flutuações passando varias vezes pelo sistema. A b) corresponde à medida feita em $50 \mathrm{~Hz}$ onde claramente vemos menos vezes o efeito do ruído da rede elétrica.

\section{Análise do sinal}

Para caracterizar a rotação de elipse devemos tomar três medidas diferentes do mesmo feixe, a saber, ruído eletrônico que corresponde ao sistema sem luz, ruído quântico padrão que corresponde a subtração dos sinais com a cavidade bloqueada e o sinal da rotação de elipse (soma). Por outro lado, também temos que salvar os dados dos picos de reflexão e transmissão da cavidade análise. Nos dispomos agora a explicar o tratamento dos dados.

1. Uma vez tomados os dados no analisador de espectro (Figura 46), mudamos a escala dos sinais salvados, de logarítmica para linear. Como o sinal do analisador de espectro está em $d B m$, passamos os dados a $m W$, isto para facilitar os passos seguintes.

2. Subtraímos o valor médio do ruído eletrônico do sinal do $R Q P$ e da rotação da elipse. Isto porque este ruído não pertence ao laser, ele é do sistema de deteção. Tomamos o 


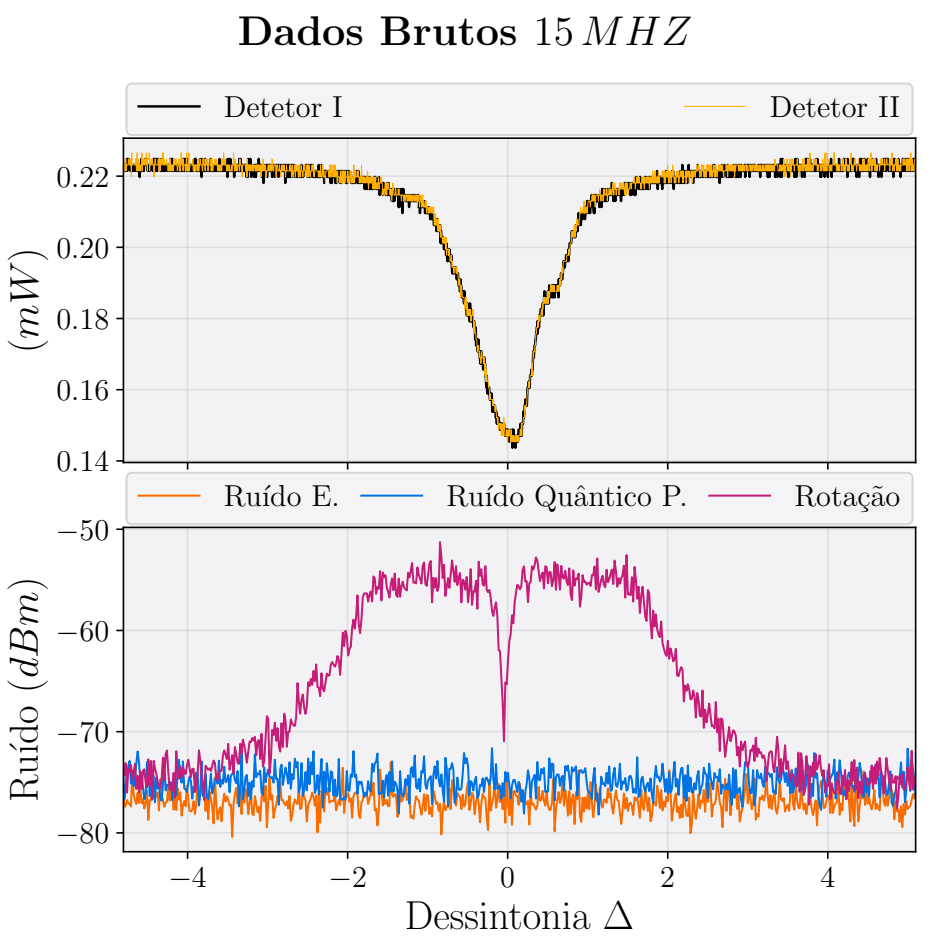

Figura 46. Exemplos dados brutos laser Littrow para uma potência de $0.223 \mathrm{~mW}$.

valor médio porque este sinal corresponde com flutuações da eletrônica no intervalo de tempo de medida.

3. O sinal refletido pela cavidade é ajustado como uma lorentziana. Ele é usado para normalizar o sinal da rotação de elipse ponto a ponto (rotação normalizada).

4. Normalizamos os sinais do shot noise e da rotação normalizada, pelo valor médio do sinal do shot noise. Assim, o shot noise é igual a um e serve como a nossa referência, como discutido na Equação 3.47.

5. Voltamos para a escala logarítmica. Com isto, o nível do shot noise fica no zero e a visualização é mais adequada quando o excesso de ruído for muito grande (Figura 47).

6. A Equação 3.65 foi desenvolvida numa escala linear. Como estamos fazendo o ajuste em escala logarítmica, o ajuste dos dados deve ser feito com a função $10 \log _{10}(S)$ para obter os valores do ajuste $\left(S_{p}, S_{q}, \gamma, \delta\right)$, cujo resultado estará em escala lineal. Teremos então que aplicar a função $10 \log _{10}(x)$ sobre os parâmetros ajustados. O ajuste é feito em python (livraria scipy, modulo curvefit [53]), que é capaz de interpolar qualquer conjunto de dados com uma função conhecida. Assim, o resultado do ajuste está na Figura 47.

O ajuste feito indica que os valores do ruído da quadratura amplitude está no nível do shot noise, $\Delta^{2} p=(0.00 \pm 0.24) d B$ e o ruído de fase é $\Delta^{2} q=(25.91 \pm 0.18) d B$. Este exemplo do análise permite observar que o laser Littrow mantém a quadratura amplitude 
Ajuste completo $15 \mathrm{MHZ}$

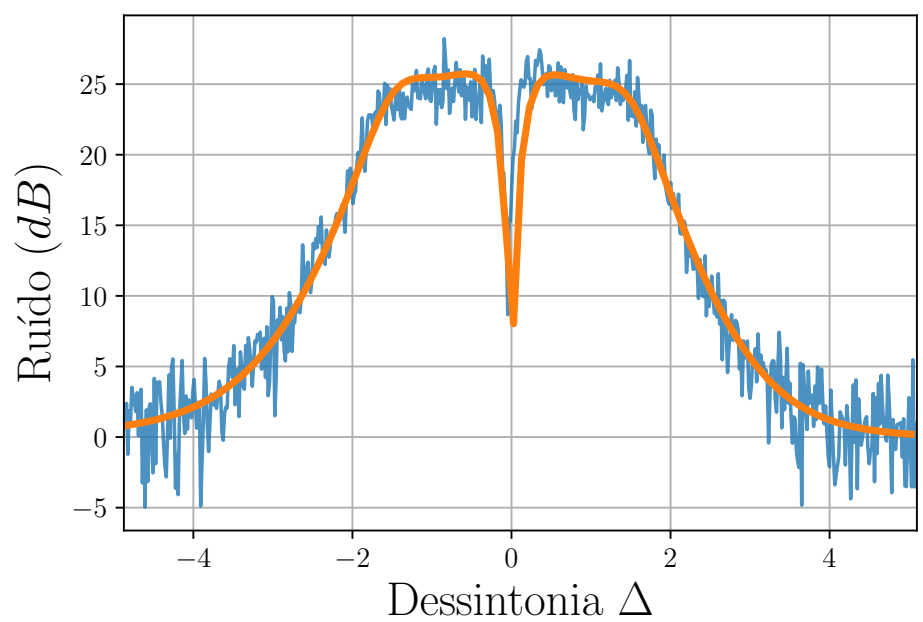

Figura 47. Ajuste dos dados do laser Littrow.

no nível do shot noise, enquanto o ruída da fase pode subir até $25 d B$ acima, conforme a referência [11]. 


\section{Resumo do capítulo}

Este capítulo permitiu apresentar a montagem experimental e mostrar alguns dos problemas no desenvolvimento deste trabalho. Definimos as saídas da cavidade $\mathbf{C}$ e $\mathbf{P}$, vimos o efeito do etalon e da corrente na estabilidade da cavidade e um exemplo de quanto estável ela pode ser. Também mostramos a estrutura da cavidade de análise e mostramos os principais problemas com o analisador de espectro e a estabilidade da cavidade. Finalmente discutimos sobre os passos para analisar o sinal e obter o ajuste dos parâmetros que estamos procurando. 
III

DESENVOLVIMENTO

EXPERIMENTAL E RESULTADOS 



\section{MONTAGEM EXPERIMENTAL E RESULTADOS}

Introduzimos agora cada um dos passos e montagens elaborados para o desenvolvimento deste projeto, tentando percorrer o caminho que permita ao leitor entender as práticas e os resultados aqui apresentados. Na medida que apresentamos as montagens experimentais, mostramos os resultados obtidos e o que conseguimos concluir para dar o passo seguinte.

\subsection{Características do Meio de Ganho}

O núcleo do nosso projeto é o $S D L$, especificamente o chip semicondutor que está dentro dele. Desta forma devemos primeiramente conhecer como ele se comporta. Na Figura 48 vemos a potência de saída do feixe propagante e contrapropagante (definido na seção 4.2) em função da corrente de injeção no chip na ausência de cavidade externa. Vemos como a partir de $0.70 \mathrm{~A}$ há uma mudança drástica na potência do chip indicando o seu comportamento laser.

Para corroborar isto, fizemos medidas do espectro do $S D L$ nas duas saídas, mudando a corrente de injeção no chip. Vemos na Figura 49 e Figura 50 que efetivamente o chip semicondutor tem uma região onde sua emissão é muito larga e conforme a corrente de injeção aumenta, a largura do seu espectro diminui notavelmente. Estas larguras reportadas não correspondem à largura real do laser, mesmo assim permite observar a diferença de comportamento entre fluorescência e laser. Medida feita com o espectrômetro Ocean Optics $U S B-4000$ que tem resolução de $\sim 0.1-10.0 \mathrm{~nm}$.

Das Figuras 48, 49 e 50 vemos que correntes inferiores a $0.50 A$ correspondem a emissão espontânea do sistema e acima de $0.60 A$ começamos a observar emissão estimulada, sendo mais evidente para correntes superiores a $0.70 \mathrm{~A}$. 


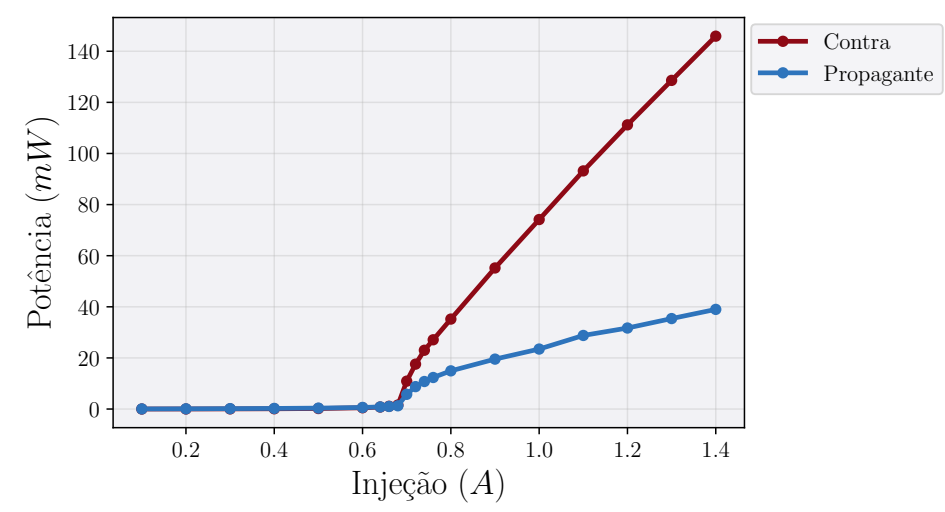

Figura 48. Com uma corrente de injeção acima de $0.7 \mathrm{~A}$ a potência muda drasticamente $e$ vemos que o nosso chip se comporta como laser.

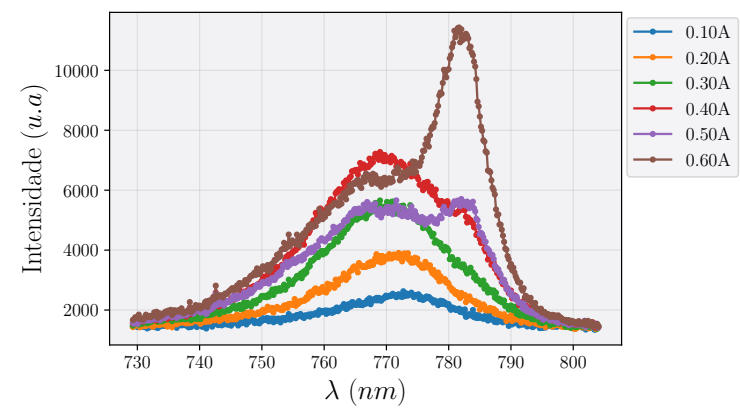

Figura 49. Estimação do espectro do chip abaixo do limiar. Quando o detetor se saturava tinha que se mover e por isso entre 0.4 e $0.5 \mathrm{~A}$ tem uma queda na intensidade. Estas gráficas correspondem a uma fluorescência, bastante larga. Em $0.6 \mathrm{~A}$ vemos que o chip começa a oscilar.

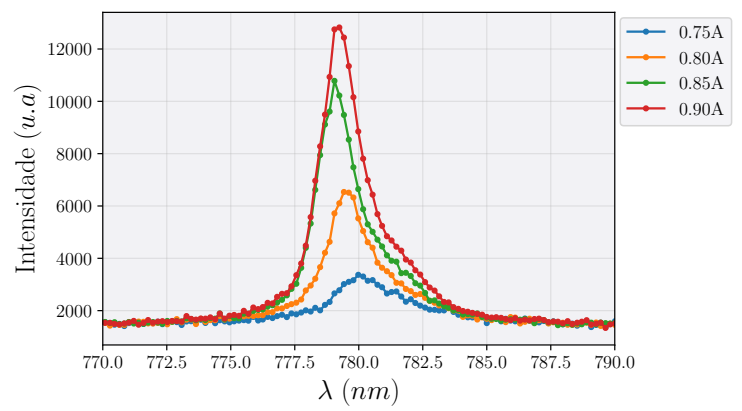

Figura 50. Estimação da largura de linha em função do comprimento de onda acima do limiar. Notamos a diferença entre a emissão acima e abaixo do limiar.

\subsubsection{Resposta do chip frente ao feixe de bombeio}

A primeira tentativa para estudar a resposta do semicondutor frente a um feixe de bombeio foi feita usando o diodo Littrow. Dado que a saída dele é astigmática, medimos posição e cintura de cada eixo e selecionamos um deles para se acoplar com um dos eixos do feixe propagante do $S D L$ que também é astigmático, este acoplamento foi feito com lentes esféricas. As saídas do SDL tem uma polarização horizontal e portanto configuramos a montagem para que o feixe de bombeio também seja de polarização horizontal.

\subsubsection{Sentido Contrapropagante}

Na Figura 51a, Figura 51b e Figura 51c vemos a porcentagem de amplificação como função da potência incidente. A medição foi feita mudando a corrente de injeção no diodo Littrow e medindo a saída no lado contrapropagante do SDL, para diferentes correntes de 
injeção no chip do SDL. Para conhecer a transmissão pelo sistema usamos a relação:

$$
T=\frac{P_{\text {saída }}-P_{\text {Fundo }}}{P_{\text {in }}} \times 100
$$

onde $P_{\text {saída }}$ é a potência total na saída contrapropagante do SDL, $P_{F u n d o}$ é a potência do SDL sem feixe incidente e $P_{i n}$ é a potência incidente. A linha pontilhada no valor de $100(\%)$ indica a porcentagem a partir da qual o sistema começa a amplificar. Podemos ver que quando a corrente de injeção do chip supera os $0.4 A$ obtemos amplificação. Na Figura 51c vemos a potência pulando bruscamente. Este comportamento vem da mudança da corrente de injeção para aumentar a potência do chip, pois desta forma os modos mudam. O problema também é gerado por não ter controle de temperatura preciso sobre o diodo Littrow, o que pode fazer com que o tamanho do semicondutor mude e, portanto o tamanho da cavidade externa.

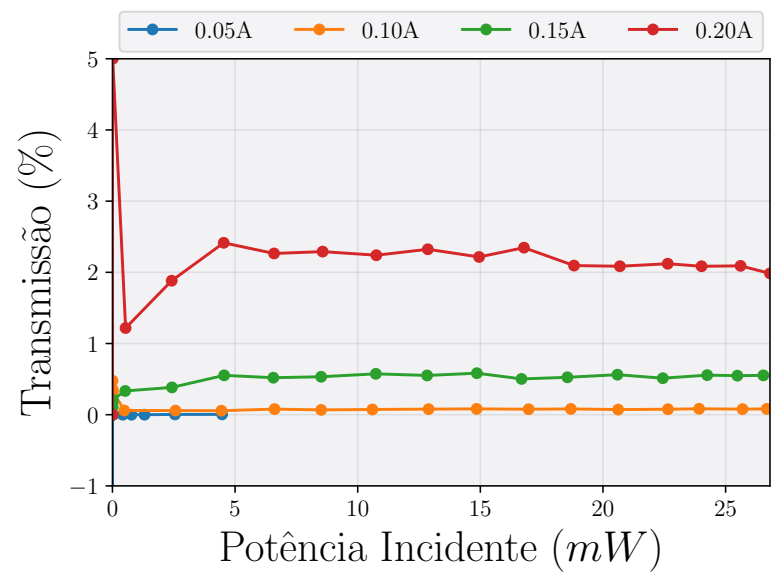

(a)

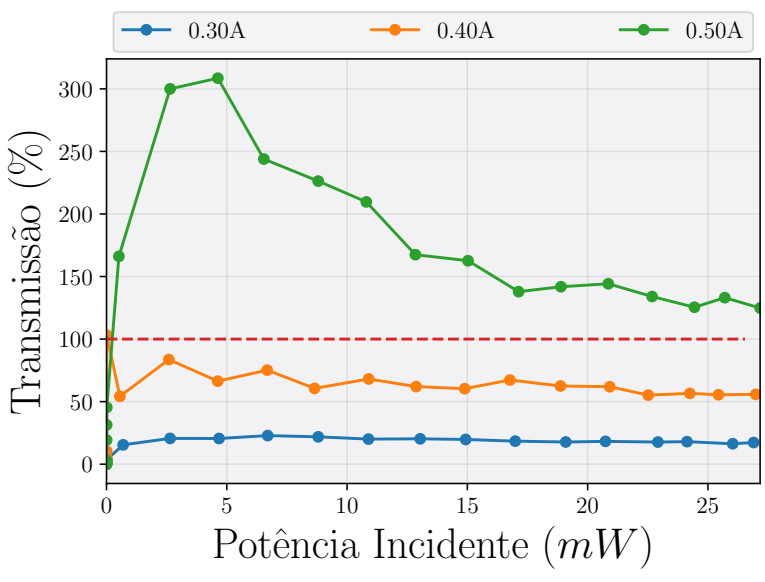

(b)

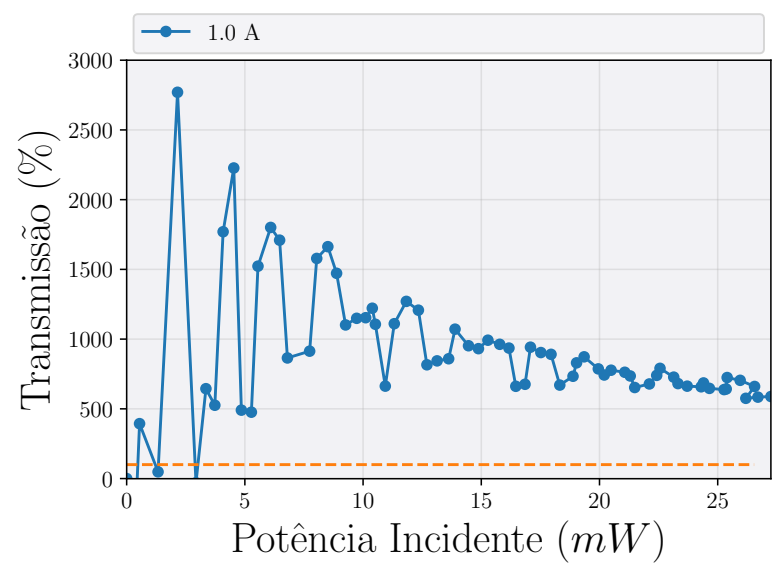

(c)

Figura 51. Resposta do chip frente ao feixe de bombeio, primeira montagem. Abaixo de $100 \%$ o sistema absorve. 


\subsubsection{Sentido Propagante}

Para corrigir o problema da temperatura usamos um circuito $H T C-3000$ que controla um dispositivo Peltier na base do sistema Littrow. Para não mexer na corrente, deixamos o chip com uma corrente e injeção de $0.97 \mathrm{~mA}$ e colocamos uma lâmina de meia onda e um $P B S$ para mudar a potência. Uma parte dessa luz ia para uma cavidade Fabry Perot onde observamos se o feixe que vai para o chip é monomodo. Pela dificuldade que gerou o acoplamento com só um dos eixos, por não saber quanta potência estava sendo perdida, decidimos acoplar o bombeio em fibra ótica. A saída da fibra foi jogada no lado contrapropagante. Acoplando com a fibra atenuamos muito a potência do feixe pois o acoplamento máximo atindindo foi de 35\%, mesmo assim temos a vantagem de corrigir o astigmatismo do feixe. Fizemos então o acoplamento entre a saída gaussiana da fibra e o lado contrapropagante do SDL que também é gaussiano (seção 4.2) garantindo eficiência no acoplamento do modo. Esta nova configuração se mostra na Figura 52.
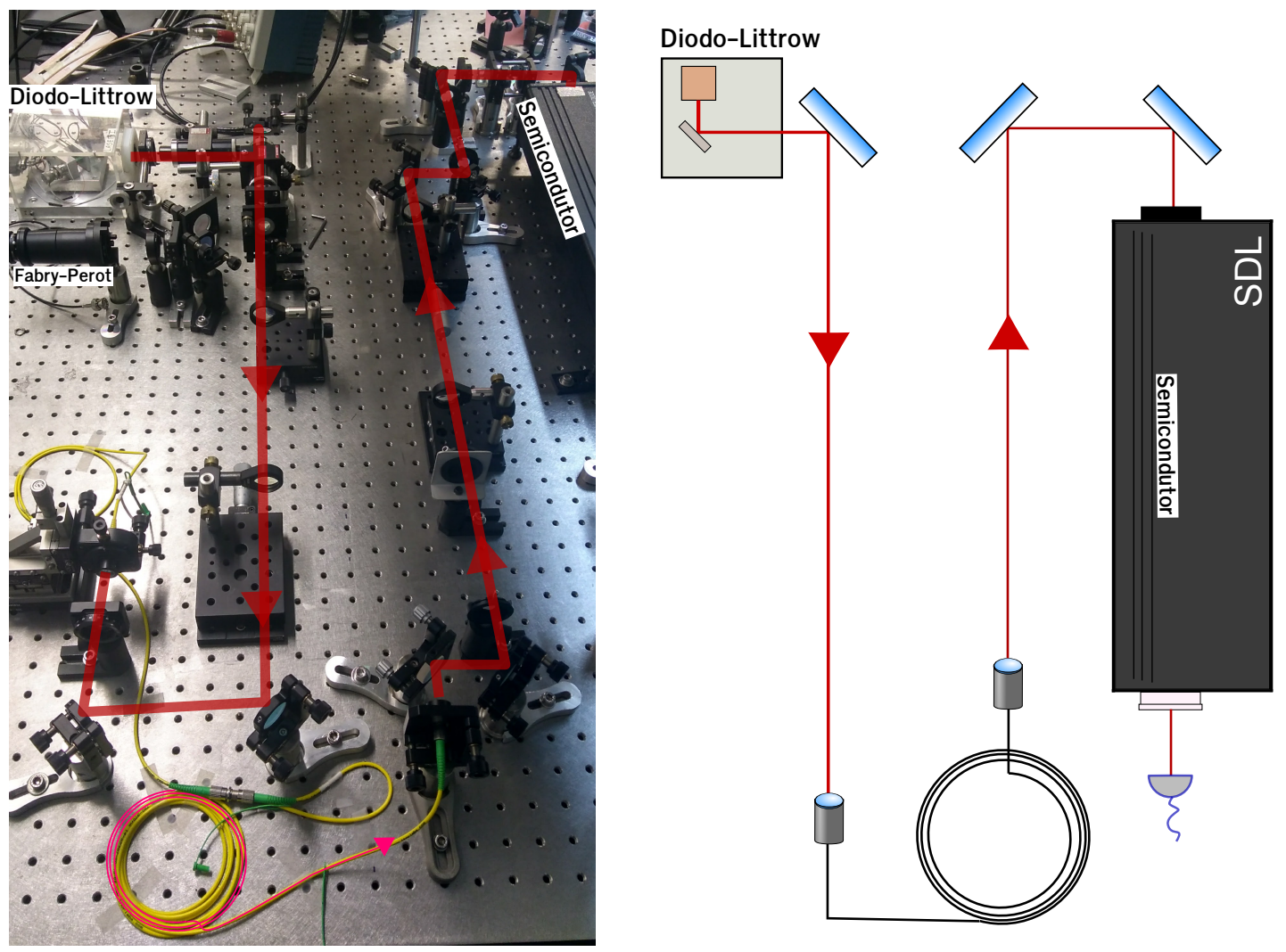

Figura 52. Montagem experimental para caracterizar o chip semicondutor do SDL.

Com este novo setup, a medição foi feita de novo e conseguimos os resultados da Figura 53a, Figura 53b e Figura 53c. Percebemos que o salto de modo da Figura 51c sumiu. Podemos observar que para uma corrente de injeção de $0.4 A$ no SDL, atingimos a saturação da absorção perto de $9 \mathrm{~mW}$ de potência incidente. Na Figura 53b vemos que já estamos amplificando fortemente, mas para $0.8 A$ tem uma queda na amplificação, que achamos que corresponde a bombear o sistema com um comprimento de onda que 
não corresponde com algum modo longitudinal da cavidade do chip [54] . Isto não é um problema de saturação porque vemos que novamente quando a corrente é maior (em $1.0 A)$ a amplificação é grande.

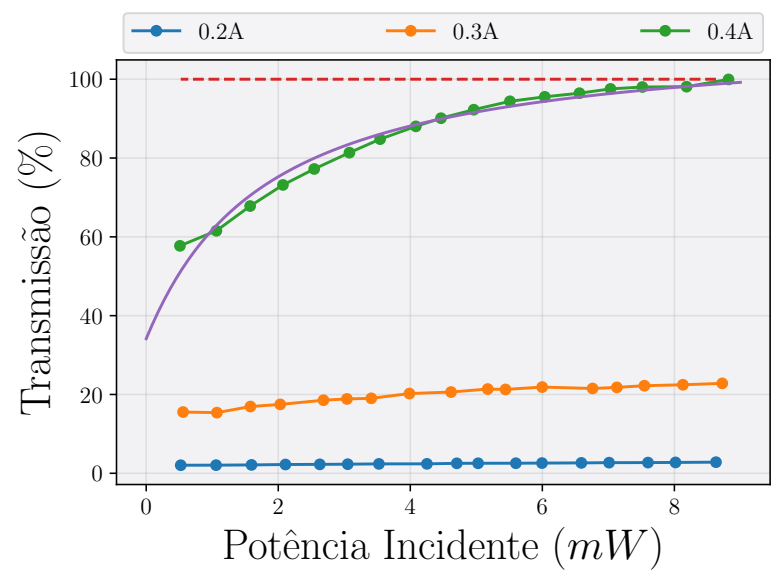

(a)

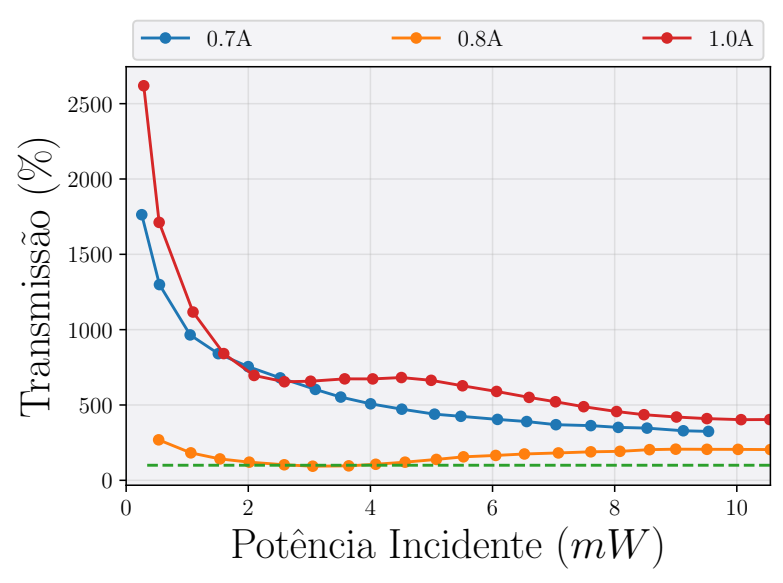

(c)

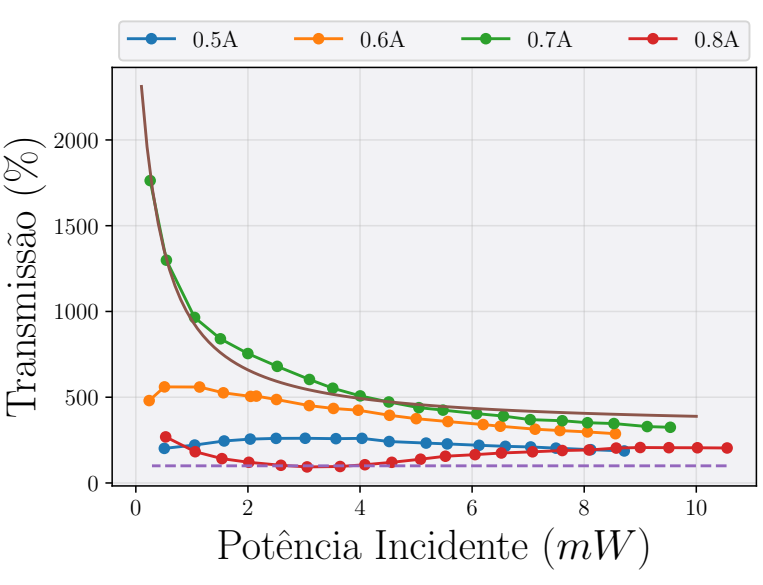

(b)

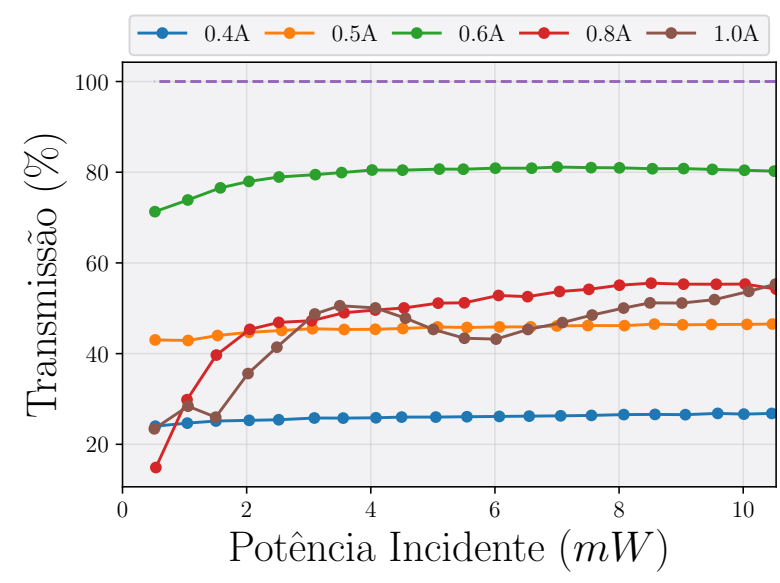

(d) Bombeio com polarização vertical.

Figura 53. Resposta do chip frente ao feixe de bombeio, primeira montagem. Para $0.4 \mathrm{~A}$ encontramos o a saturação do sistema. Em $0.8 \mathrm{~A}$ a dinâmica do sistema tem efeitos de desacoplamento entre modos do chip o da cavidade. Quando o bombeio tem polarização vertical, baixo nenhuma injeção o sistema consegue amplificar.

Finalmente estudamos o que acontece com a amplificação quando o feixe de bombeio tem polarização vertical, vemos isto na Figura 53d onde notamos que para nenhuma corrente de injeção e nenhuma potência obtemos amplificação pelo chip.

Para corroborar o comportamento do ganho visto na Equação 2.64, tomamos os valores da transmissão para uma potência de $\sim 0.5 \mathrm{~mW}$ e obtivemos a Figura 54 . Vemos que esta figura apresenta o comportamento proporcional à diferença de população (Ver Figura 15). Para correntes de injeção acima de $0.7 A$ o sistema já está oscilando e a dinâmica da cavidade com o chip gera efeitos como a competição entre os modos do chip e da cavidade externa. 


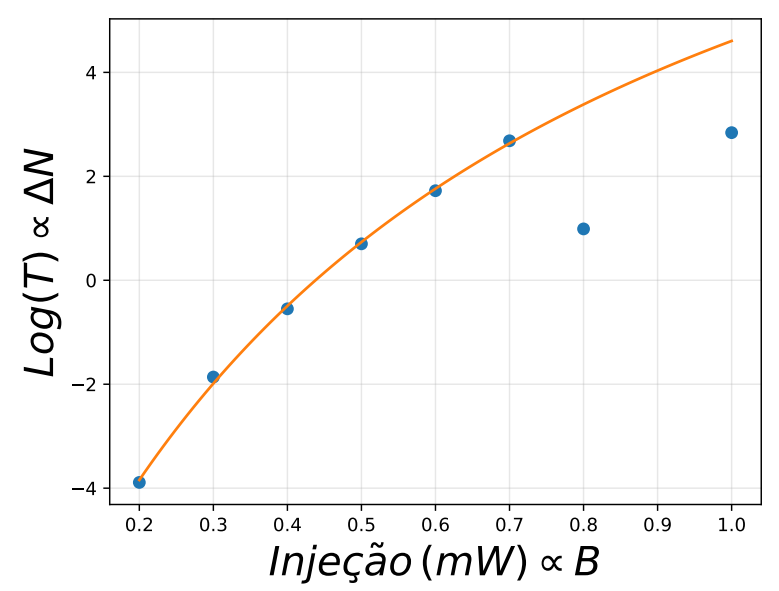

Figura 54. Montagem experimental definitivo para caracterizar o chip semicondutor do SDL. O ajuste mostrado é só uma guía para evidênciar o comportamento proporcional à diferença de população $\Delta N$ (Ver Figura 15).

Aqui termina a caracterização do meio de ganho, sabemos que ele mesmo é uma cavidade e sabemos que a partir de $0.4 A$ ele amplifica a luz incidente sempre que tiver polarização horizontal o que nos leva a pensar que nessa região poderíamos encontrar o limiar do laser. O fato de que o sistema apresente absorção deixa-nos associar este sistema como um laser de três níveis justo como discutido na subseção 2.1.2.

\subsection{Cavidade Fechada}

Caracterizado o amplificador, vamos verificar seu funcionamento dentro da cavidade (Figura 41). Para realizar as medidas aproveitamos os parâmetros proporcionados pela cavidade, a saber, corrente de injeção e perdas controladas.

\subsubsection{Saída da Cavidade em Função da Corrente de Injeção}

A primeira caracterização feita foi a potência das saídas da cavidade em função da corrente de injeção. Isto foi feito para diferentes ângulos do $P B S 1$. A linha denominada Cavitando corresponde à medida feita quando a cavidade estava fechada e a linha com nome Chip corresponde à saída do feixe com cavidade bloqueada. As figuras na esquerda representam as medidas feitas para a saída do feixe propagante $(\mathbf{P})$ e à direita temos as medidas para a saída do feixe contrapropagante $(\mathbf{C})$.

Das figuras 55 - 60 podemos concluir que podemos variar o limiar de oscilação do sistema mediante o controle da saída do PBS1. O menor valor obtido do limiar de oscilação foi de $0.41 A$, justamente perto do valor onde o sistema começa a amplificar (Figura 53a). Em geral as potências atingidas pelo lado $\mathbf{C}$ são maiores do que as do lado $\mathbf{P}$, primeiro por ele passar por um menor número de sistemas óticos e segundo por não estar afetado diretamente pela lâmina de onda. A configuração da Figura 55 parece interessante 


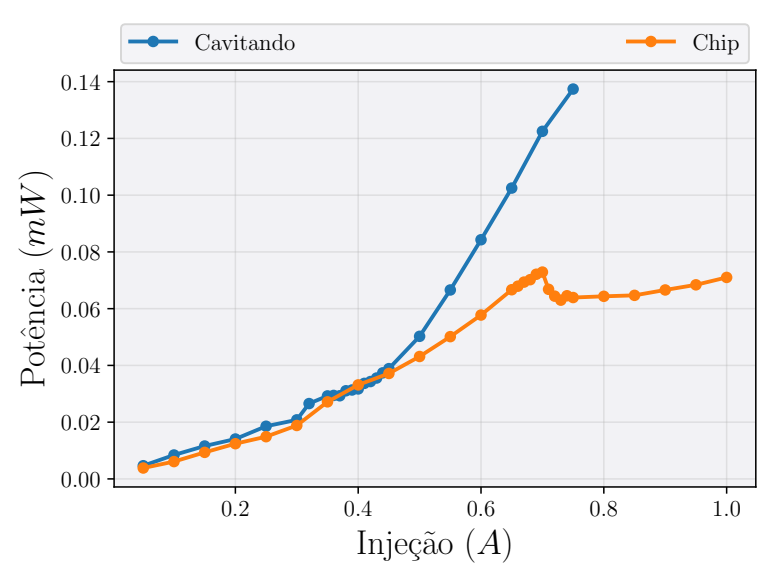

Figura 55. Quando a lâmina de meia onda está em $0^{\circ}$ a polarização do feixe propagante é horizontal e por tanto pouca potência é refletida no primeior $P B S$.

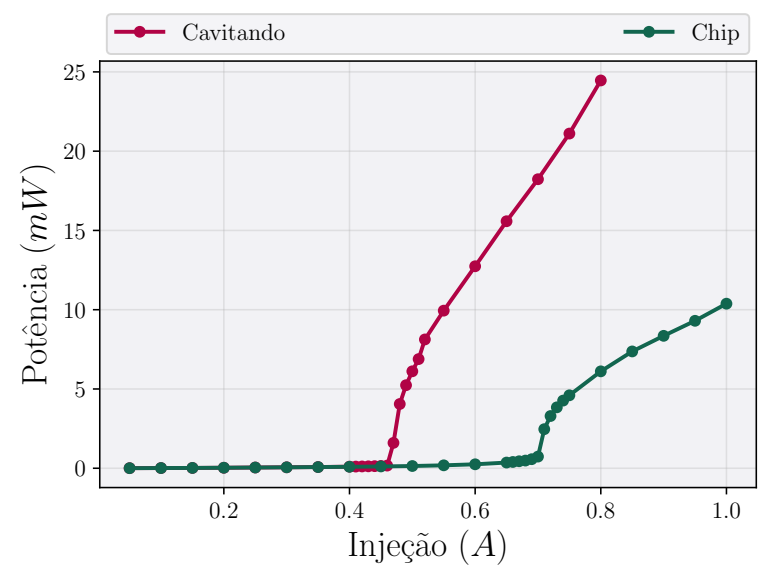

Figura 57. Se a polarização for diagonal a cavidade tem uma perda ao redor do $50 \%$ sendo uma cavidade bem aberta. Mesmo assim, o limiar está em $0.46 \mathrm{~A}$.

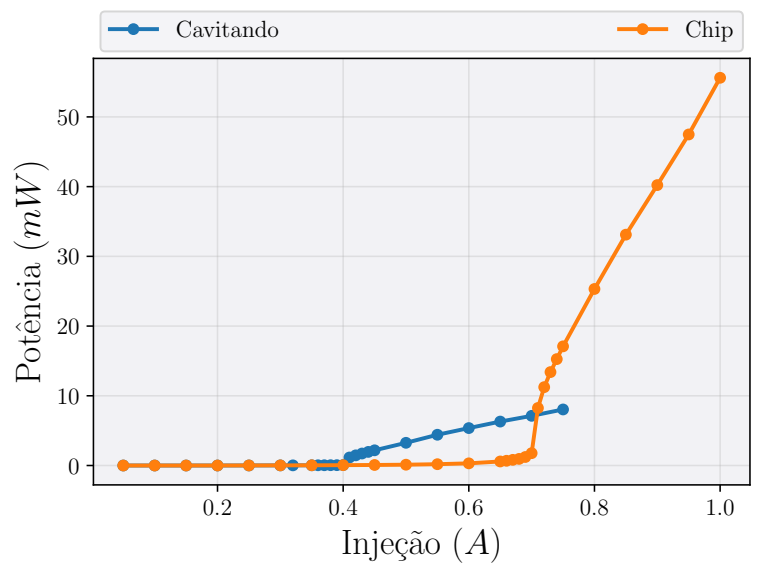

Figura 56. Na saída $\boldsymbol{C}$ quando o feixe propagante está $\mathrm{em} 0^{\circ}$, se tiver a cavidade bloqueada temos a mesma Figura 48. Liberando a cavidade conseguimos diminuir o limiar perdendo potência.

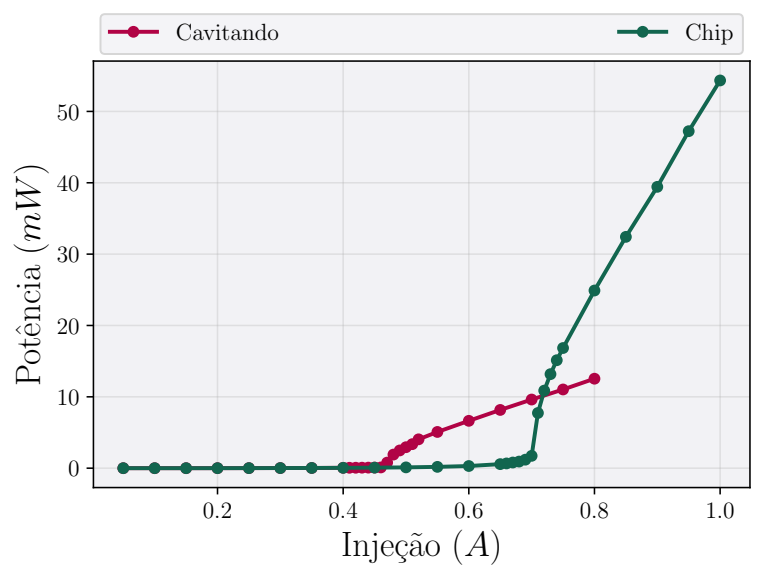

Figura 58. Com polarização diagonal o feixe contrapropagente sofre diminuição do limiar e da potência comparado com só o chip chegando a 0,46 A. Comparado com o caso da cavidade fechada, a potência neste caso aumentou.

porque tem um limiar baixo $\sim 0.45 \mathrm{~A}$ e atinge potências de $\sim 25 \mathrm{~mW}$. Um efeito curioso é a resposta não linear inicial do sistema (Figura 55) 


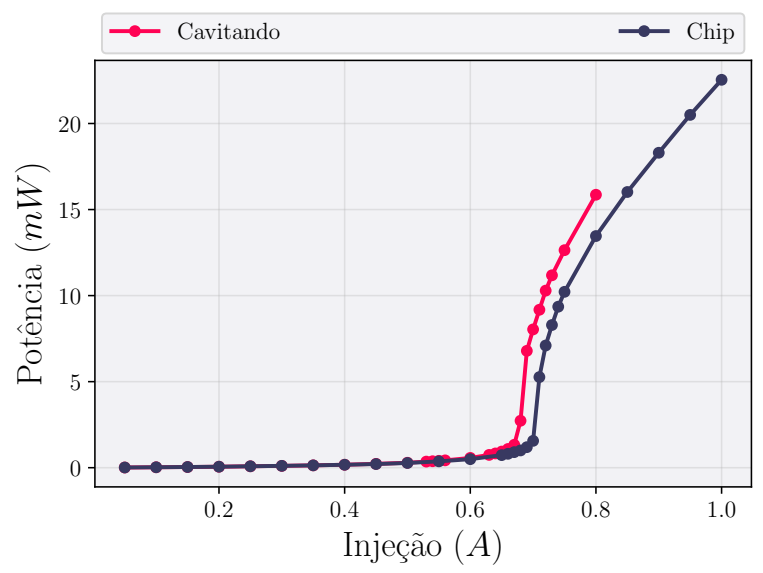

Figura 59. Com a polarização vertical do feixe $\boldsymbol{P}$ estamos tirando quase todo o feixe da cavidade e não temos realimentação do sistema. O limiar de oscilação está perto do limiar sem cavidade $(0,68 \mathrm{~A})$.

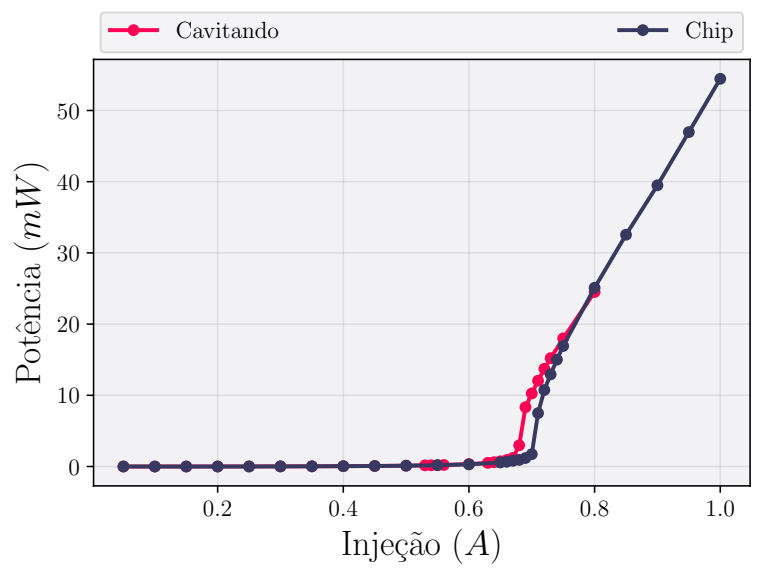

Figura 60. Dado que a polarização é vertical, não temos realimentação e a saída do feixe contrapropagante é a mesma com e sem cavidade. Obtemos um limiar de oscilação em 0,69 A.

\subsubsection{Saída da Cavidade em função das perdas}

Nesta caracterização, medimos a potência nas saídas $\mathbf{P}$ e $\mathbf{C}$ como função das perdas controladas da cavidade. Medimos para três valores de corrente de injeção diferentes, abaixo, perto e bem acima do limiar. A medida feita abaixo do limiar teve um comportamento esperado (Figura 61). Na saída $\mathbf{P}$, medimos uma potência baixa que aumentava conforme mudamos a polarização de horizontal para vertical. A saída $\mathbf{C}$ é inalterada pela lâmina de onda.

No caso de estar um pouco acima do limiar (Figura 62), entre 0 e $\sim 22(\%)$ temos cavidade e vemos que a potência na saída $\mathbf{P}$ aumenta, estamos tirando potência intracavidade sem desestabilizar a condição de saturação. Aumentando as perdas da cavidade chegamos ao ponto em que as perdas são maiores do que a amplificação e saímos da oscilação do sistema. No caso da saída $\mathbf{C}$, a potência na saída diminui até que perdemos a cavidade. O comportamento acima do limiar, Figura 63 é similar ao anterior. Para quando não temos laser, a potência das duas saídas volta para os valores medidos na Figura 59 e na Figura 60.

As figuras aqui apresentadas tem semelhança com o descrito na seção 2.3, Figura 21. Vemos que temos um máximo e que após um porcentagem de perdas o sistema volta para seu comportamento sem cavidade externa. Vemos na Figura 63 que o nosso sistema apresenta uma amplificação muito alta porque ele deixa de oscilar quando as perdas estão por volta do $80 \%$. Temos um laser capaz de atingir potências perto de $\sim 25 \mathrm{~mW}$, dotado de dois mecanismos que ajudam nessa variação da potência que são, corrente de injeção e perdas controladas. Essa região de potências é suficiente para trabalhar com sistemas atômicos [3], mas ainda falta estudar as propriedades de ruído para saber se ele poderia 


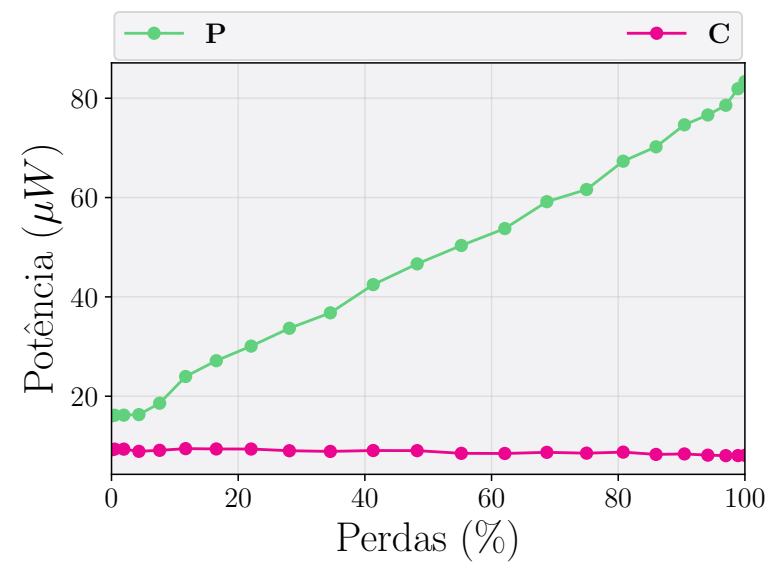

Figura 61. Corrente de injeção é $0.25 \mathrm{~A}$. Abaixo do limiar e com potência nas saídas muito baixa. $O$ aumento na saída $\boldsymbol{P}$ é efeito de mudar de polarização horizontal para vertical. A saída $\boldsymbol{C}$ não muda.

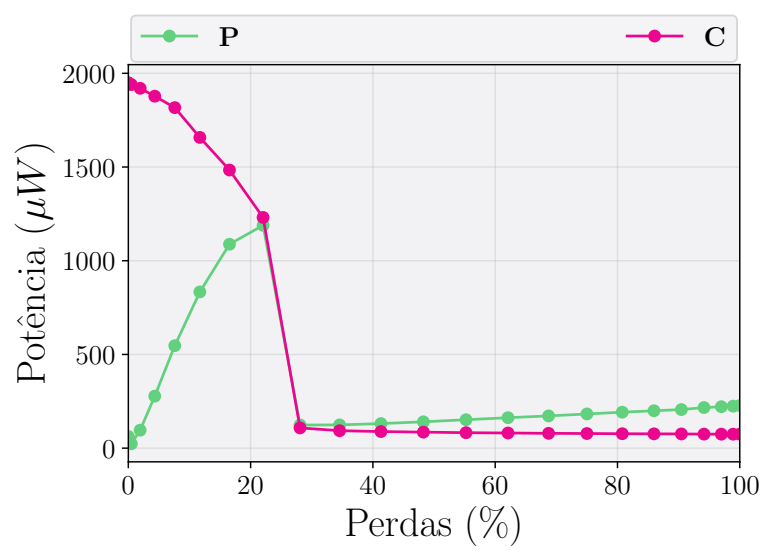

Figura 62. Corrente de $0.45 \mathrm{~A}$. Perto do limiar de oscilação, vemos na saída $\boldsymbol{P}$ que a potência aumenta até sair da oscilação no $22(\%)$. Na saída $\boldsymbol{C}$ a potência vai diminuindo suavemente até que o sistema deixa de oscilar. Logo voltamos ao comportamento da Figura 61.

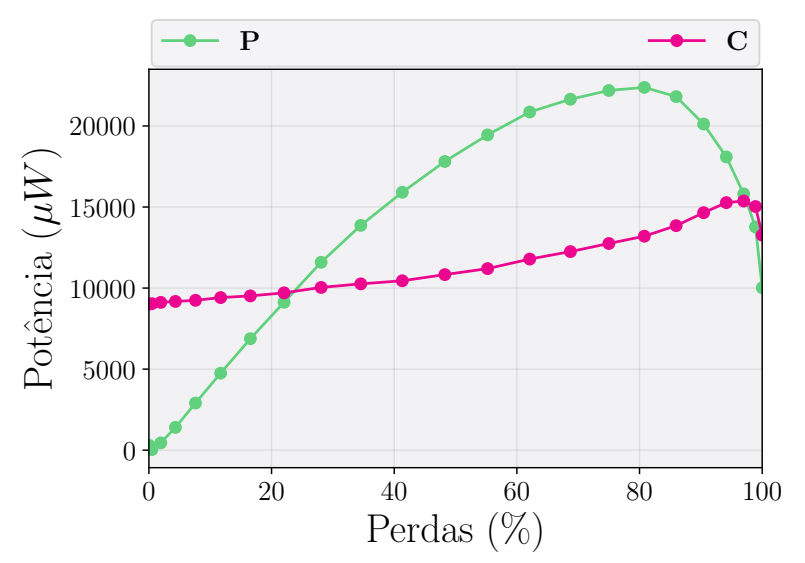

Figura 63. Corrente em 0.72 A. A saída $\boldsymbol{P}$ aumenta sua potência conforme aumentamos as perdas até o $\sim 80(\%)$ onde cai e chega nos valores típicos da oscilação do chip. A saída $\boldsymbol{C}$ tem um comportamento parecido mas não é tão variável quanto a saída $\boldsymbol{P}$. Isto é de esperar devido a que ele não é diretamente perturbado pela mudança das perdas.

funcionar como fonte para sistemas com fenômenos quânticos.

\subsubsection{Efeito do Etalon na Cavidade}

A Figura 64 mostra o comportamento monomodo e multimodo do laser. A linha vermelha é obtida com o laser de referência (Littrow) que será a nossa régua. Vemos na Figura 64 a) que o SDL é monomodo e na Figura 64 b) multimodo. Dado que conhecemos o FSR da nossa cavidade de referência $(1.5 \mathrm{GHz})$ que corresponde à distância entre picos da nossa régua, determinamos que a distância entre os picos do comportamento multimodo é $\sim 150 \mathrm{MHz}$ compatível com o comprimento do nosso laser. Por outro lado, 
como conhecemos o tamanho da cavidade, podemos usar a Equação 2.57 para obter o valor teórico do intervalo espectral livre da cavidade, que é igual a $\sim 158 \mathrm{M} \mathrm{Hz}$. Por conseguinte, o sinal que vemos com o laser multimodo é originado pelas flutuações no tamanho da cavidade.

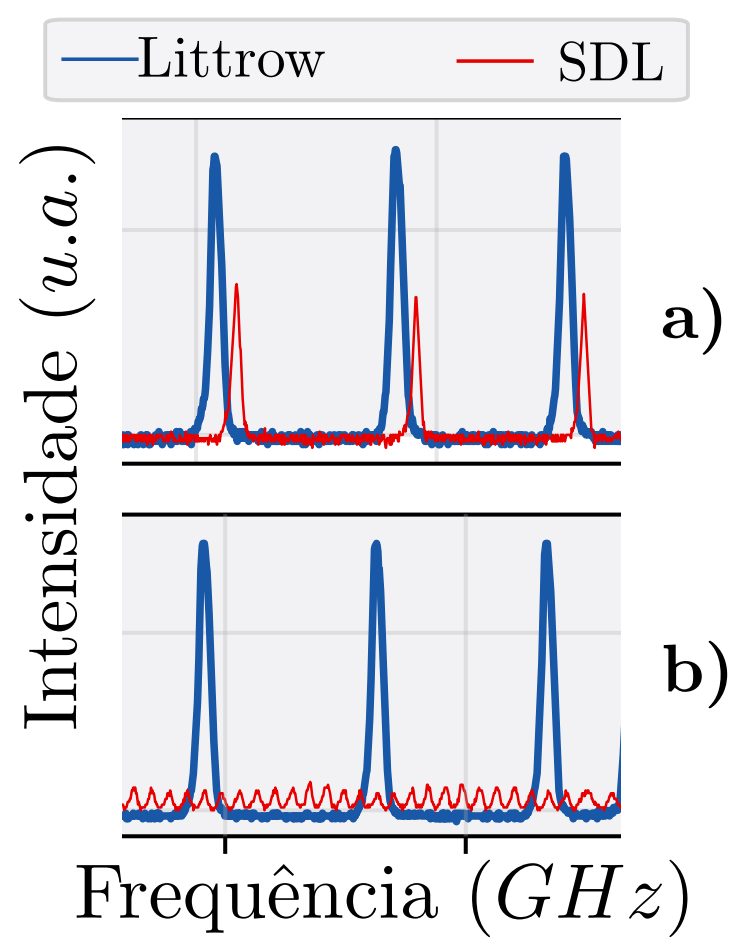

Figura 64. Girando a posição do etalon e a corrente do sistema, podemos estabilizar a cavidade. A linha vermelha é o sinal da cavidade de referência com o laser Littrow. $O$ sinal verde corresponde ao nosso laser onde, a) é o seu coportamento monomodo e b) o comportamento multimodo. A corrente de injeção no SDL foi de 0.63 A.

Colocar o etalon na cavidade estabiliza bastante o sistema já que como visto na Figura 40, ele ajuda na seleção de modos intracavidade atenuando aqueles modos que estejam fora da ressonância. Sem o etalon, o nosso sistema pulava bruscamente entre o estado monomodo e o multimodo sem se manter um tempo suficiente para realizar medidas.

\subsubsection{Largura de Linha}

Implementamos a montagem da Figura 65 para estimar a largura de linha do laser $S D L$. O sistema consiste na geração do batimento entre um laser de largura de linha conhecida (o Ti : Safira) e a largura de linha que queremos estimar, os dois com igual potência. O sinal do fotodiodo é enviado para o analisador de espectro onde podemos observar o sinal do batimento entre os feixes.

Para conhecer a largura de linha do laser Ti : Sa fira o mesmo método foi usado com dois laseres idênticos para diferentes tempos de adquisição. Esta medidas foram feitas pelo Renato Domenguetti, a Rayssa Bruzaca e o Dr. Breno Marques, e encontraram que 


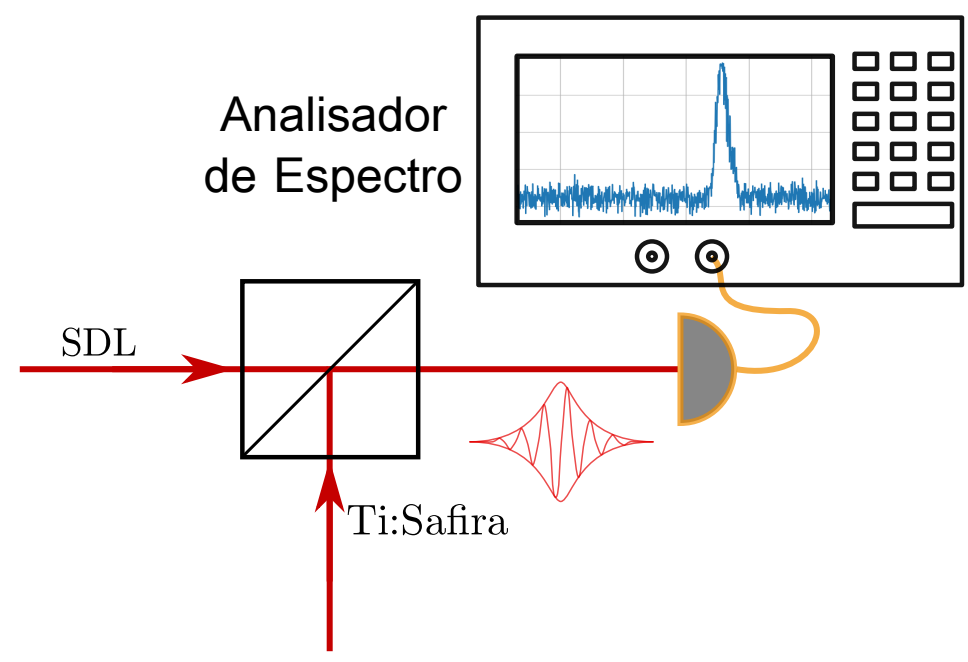

Figura 65. O sistema de deteção ilustrado permite estimar o valor máximo de largura de linha do sistema medindo o sinal do batimento.

para $10 \mathrm{~ms}$ a largura dele é por volta de $70 \mathrm{kHz}$. Assim, fazendo o ajuste do batimento por uma função gaussiana (Figura 66) para o mesmo tempo de $10 \mathrm{~ms}$, encontramos que a largura de linha do sinal é $\sim 390 \mathrm{kHz}$. Portanto, a largura de linha do nosso laser está por volta de $\sim 380 \mathrm{kHz}$.

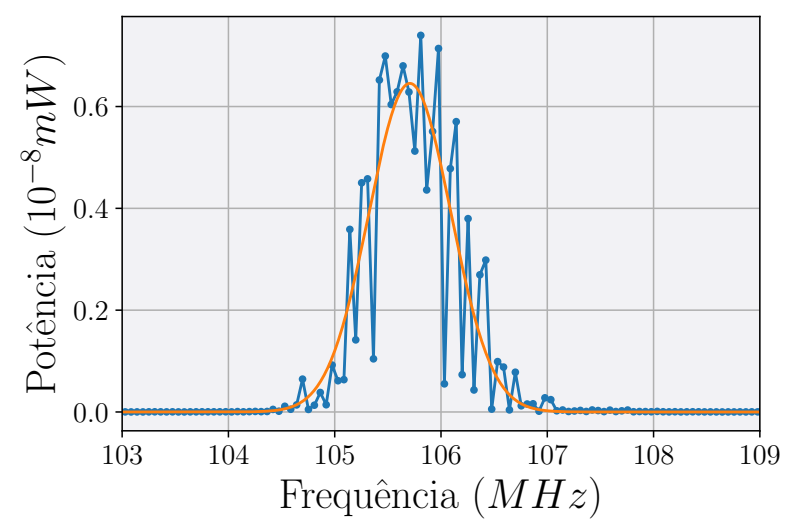

Figura 66. Ajuste gaussiano para batimento entre o Ti: Safire e o SDL. Encontramos que a largura do sinal de batimento é de $\sim 390 \mathrm{kHz}$ para um tempo de medida de $10 \mathrm{~ms}$.

\subsection{Ruído das Quadraturas}

Nesta seção vamos mostrar a caracterização do ruído nas quadraturas do nosso laser. Começamos pela caracterização do laser em função da corrente de injeção para diferentes frequências de análises e diferentes posições da $H W P 1$ (perdas controladas). A saída $\mathbf{P}$ do laser foi enviada para uma cavidade de referência Fabry Perot (Thorlabs FA200-5B, FRS=1.5GHz) para monitorar a estabilidade da mesma. A saída C, pela possibilidade de medir em faixas de potências maiores, foi usada como feixe para medição de ruído. Essa vantagem da potência se viu prontamente apagada porque nós queremos um feixe gaussiano para injetar na cavidade de análise e portanto acoplamos o feixe $\mathbf{C}$ em 
fibra ótica para eliminar o astigmatismo, conseguindo um acoplamento máximo de 50\%. A fibra permite ainda mudar facilmente do $S D L$ para o laser Littrow sem desalinhar o sistema. Como segunda experiência, mostraremos a caracterização das quadraturas em função das perdas controladas, para diferentes correntes de injeção e frequência de análises. Finalmente comparamos o ruído do nosso sistema com o diodo Littrow. A potência que será reportada nos gráficos corresponde à potência em cada detetor. A Figura 67 ilustra o sistema de deteção que consta de uma cavidade de análise trabalhando com uma largura de banda entre $7-9 \mathrm{MHz}$ (seção 4.3), um sistema de deteção balanceado e o analisador de espectro. O osciloscópio foi usado para monitorar quando estivéssemos passando pela ressonância da cavidade.

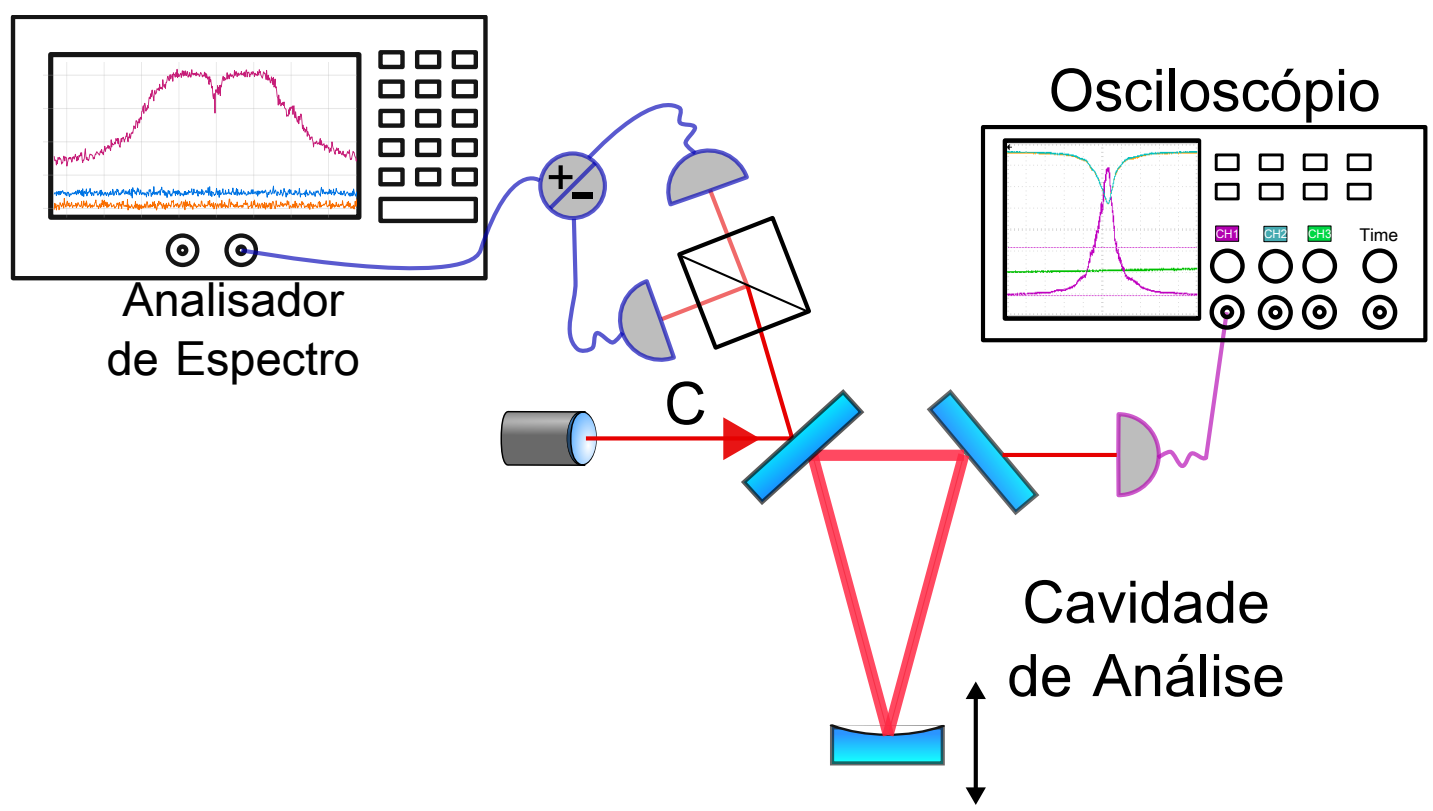

Figura 67. Sistema para rotação da elipse. Ele é constituido pela cavidade de análise um sistema de deteção balanceada, um circuito somador e subtrator e o analisador de espectro.

Pela instabilidade usual do sistema, o sinal do espectro obtido apresenta muitas flutuações o que dificultou bastante fazer o ajuste da curva (Equação 3.65), especialmente em $13 \mathrm{MHz}$ onde encontramos uma assimetria tão grande, que os valores ajustados para o termo de correlação $C_{p q}$ são bastante duvidosos. Mostramos varios exemplos deste problema para quatro frequências de medição, nas figuras 68a-68d. Como o problema na sua maioria está no termo de correlação e não no nível do ruído das quadraturas, continuamos o estudo do sistema confiantes nestes termos. Todos os exemplos mostrados foram tomados com os parâmetros da tabela 2 .

A pergunta imediatamente lógica é questionar a montagem da cavidade de análises para a rotação de elipse. Para garantir que efetivamente estamos com um sistema na capacidade de medir as quadraturas podemos retornar à seção 4.4 onde fizemos o análises da rotação de elipse do laser Littrow, o tratamento de dados e o ajuste. 


\begin{tabular}{|c|c|c|c|}
\hline Potência $(m W)$ & BW.Cav. $(M H z)$ & Visibilidade & Injeção SDL(A) \\
\hline 0.222 & $8-9$ & 99.25 & 0.61 \\
\hline
\end{tabular}

Tabela 2. Parâmetros usados na medição dos exemplos de rotação de elipse com cavidade fechada. A corrente de injeção só se refere ao SDL. No caso do Littrow só medimos a potência .

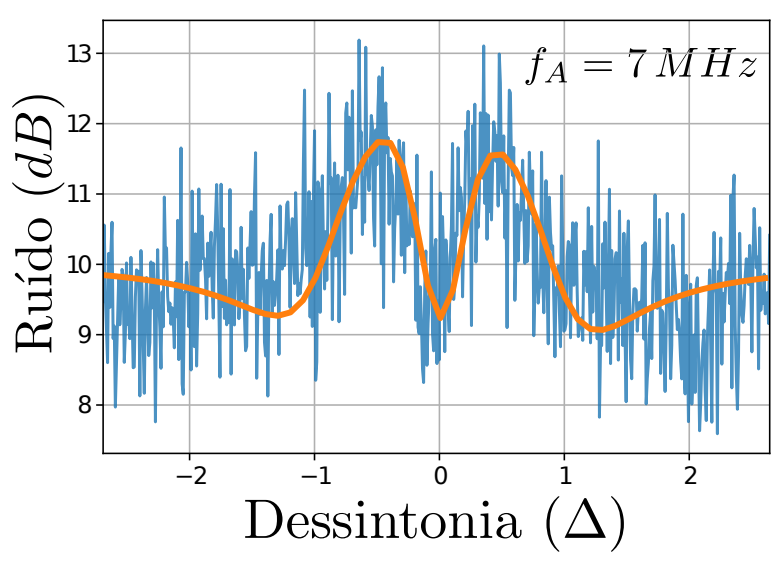

(a)

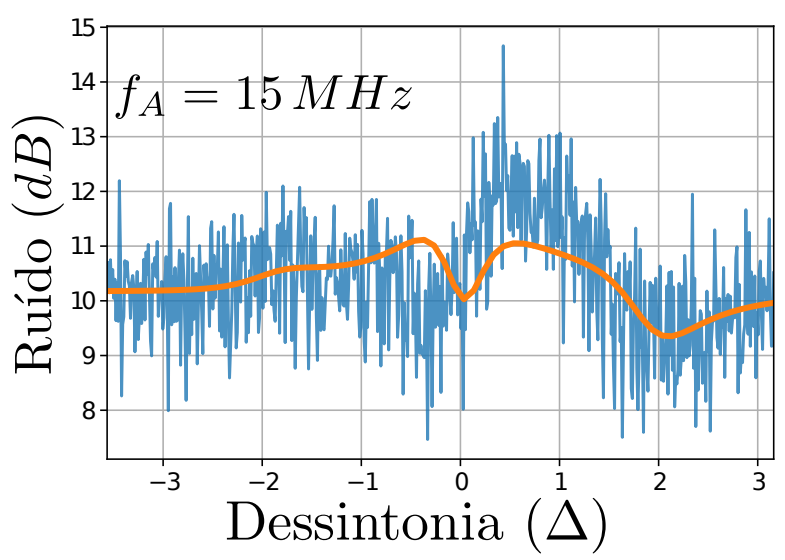

(c)

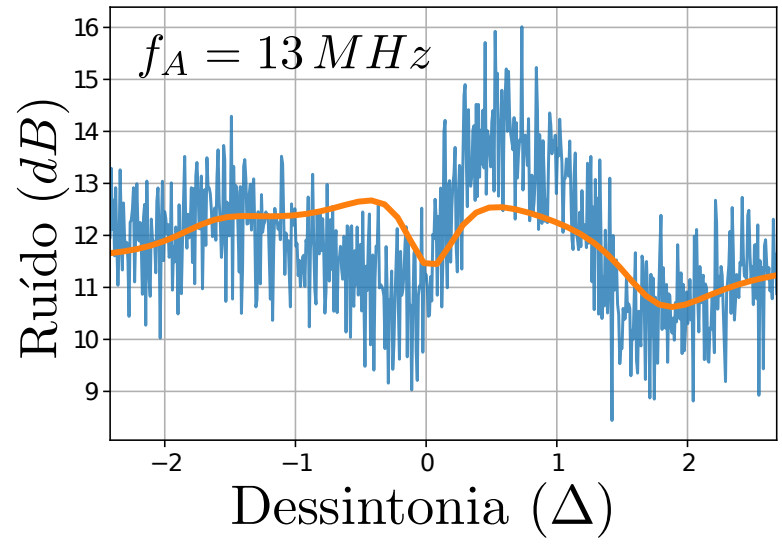

(b)

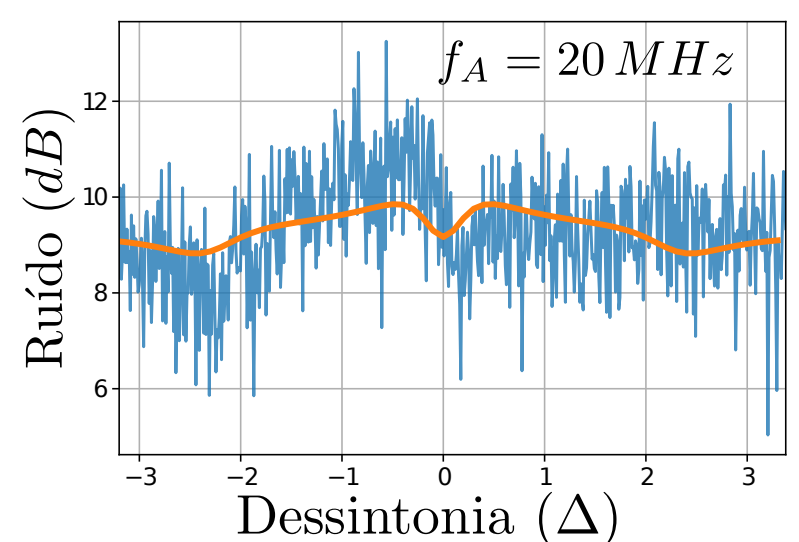

(d)

Figura 68. Exemplos de rotação de elipse para diferentes frequências de análise. Vemos que existe uma leve assimetría e que o sinal apresenta muitas flutuações o que dificulta o seu ajuste.

\subsubsection{Ruído em Função da Corrente de Injeção}

Caracterizamos o ruído do feixe para quatro frequências de análises diferentes, 7,13, 15 e $20 \mathrm{MHz}$, e para duas configurações com cavidade fechada ou mais aberta. As figuras que são mostradas, estão normalizadas pelo ruído quântico padrão ubicado no valor de zero.

Para a configuração da cavidade mais fechada que podemos ter (figuras 69a - -69d), notamos que o ruído aumenta com a corrente de injeção ( a potência incidente nos detetores). A medida em que vamos aumentando a frequência de análises, o ruído diminui porque 


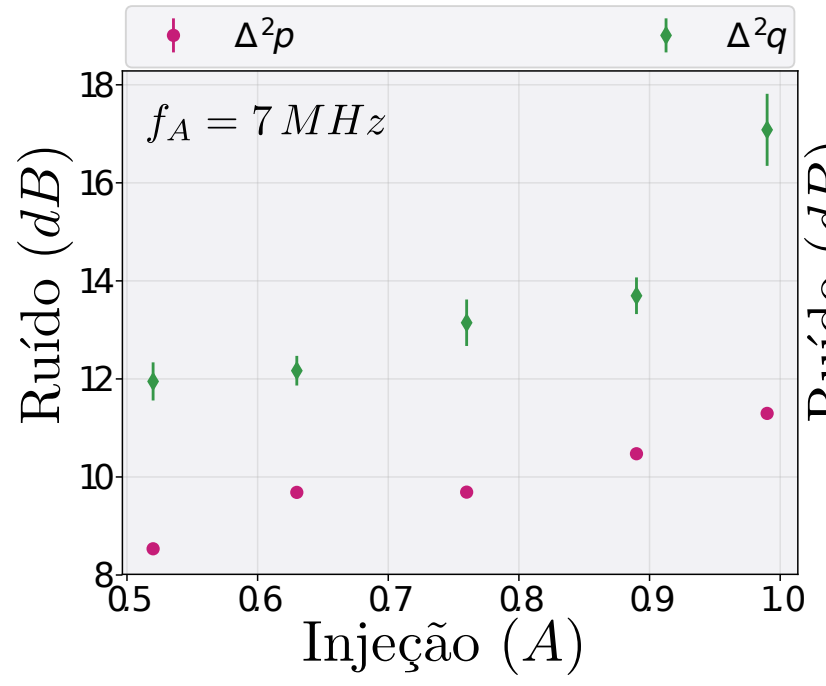

(a)

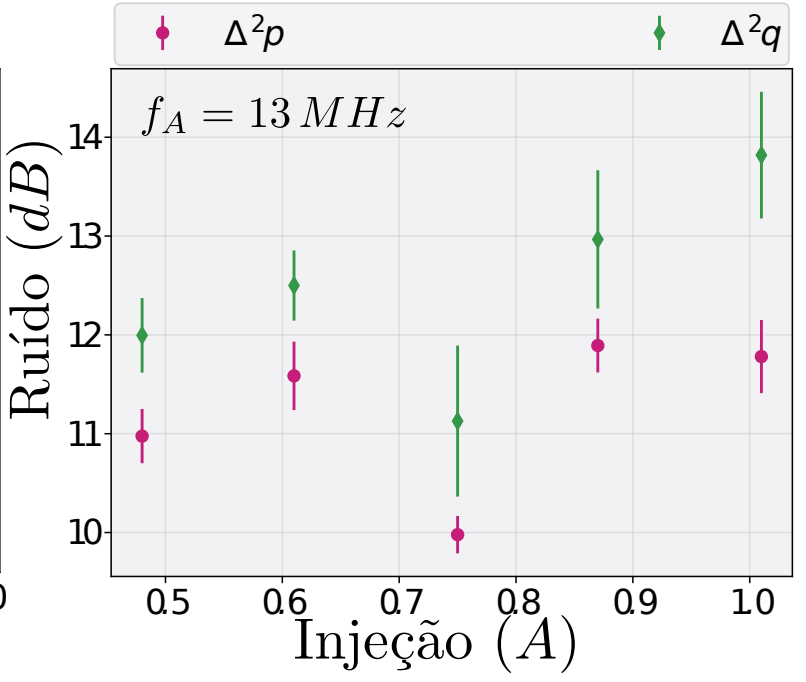

(b)

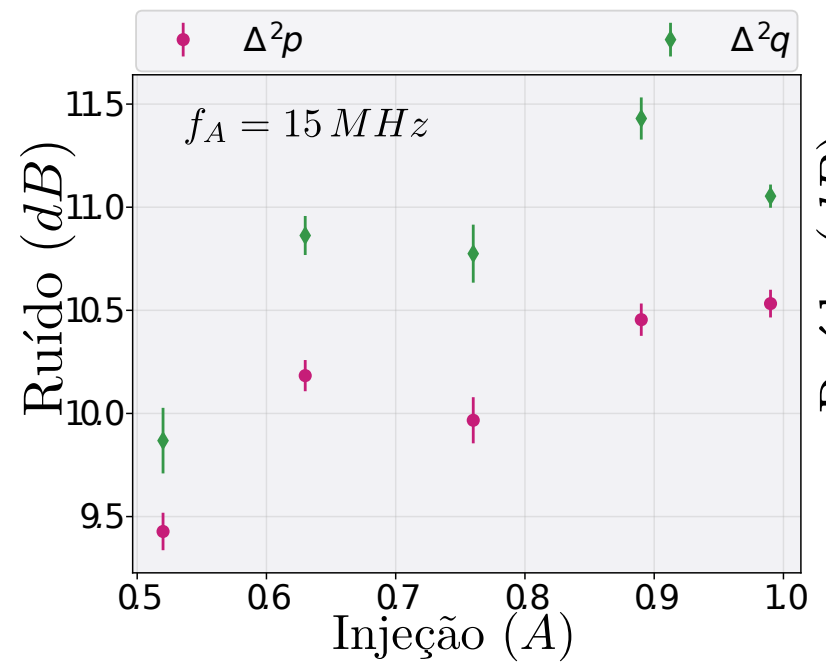

(c)

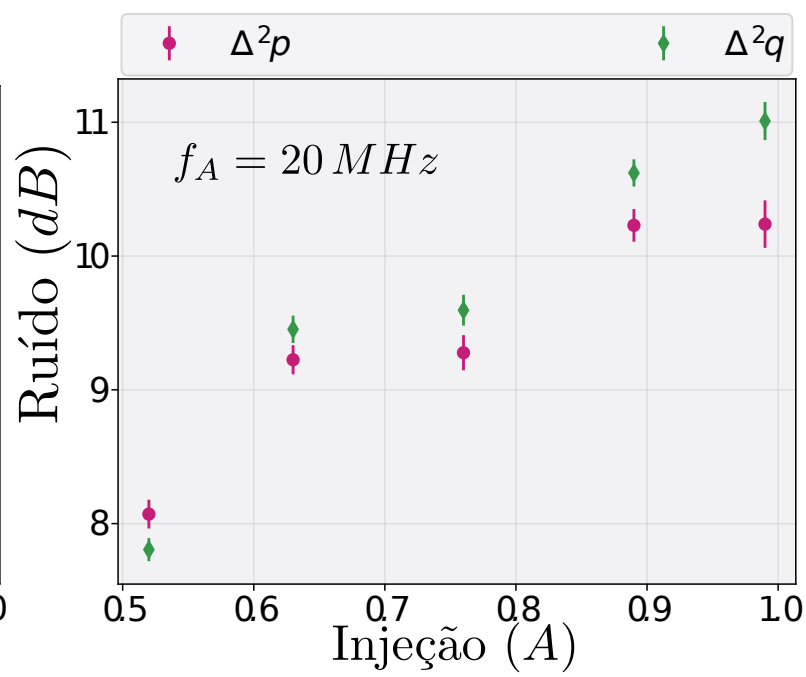

(d)

Figura 69. Ruído das quadraturas em função da corrente de injeção cavidade fechada. $O$ ruído de amplitude continua sendo maior mas essa diferença diminui conforme aumentamos a frequência de análise. Para a corrente de 0.75 A vemos que aparece uma queda no nível de ruído, isto devido a que nesta corrente a estabilidade da cavidade era muito boa.

estando mais longe da portadora, estamos mais perto de um estado de vácuo. Também vemos que o ruído de fase aumenta mais rapidamente com a potência do que o ruído de amplitude, mas em frequências de análises maiores o ruído das quadraturas é quase o mesmo.

As figuras 70a até 70d, amostram a configuração para um ângulo da lâmina de $22.5^{\circ}$ que corresponde a perdas ao redor de $50 \%$. Com a cavidade mais aberta, o ruído das quadraturas aumentou com respeito ao ruído com cavidade fechada. 


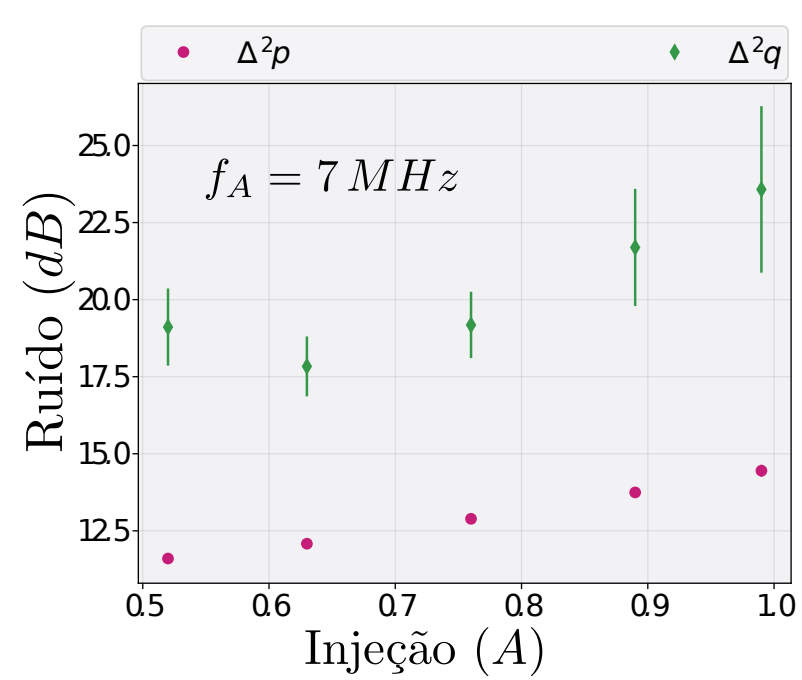

(a)

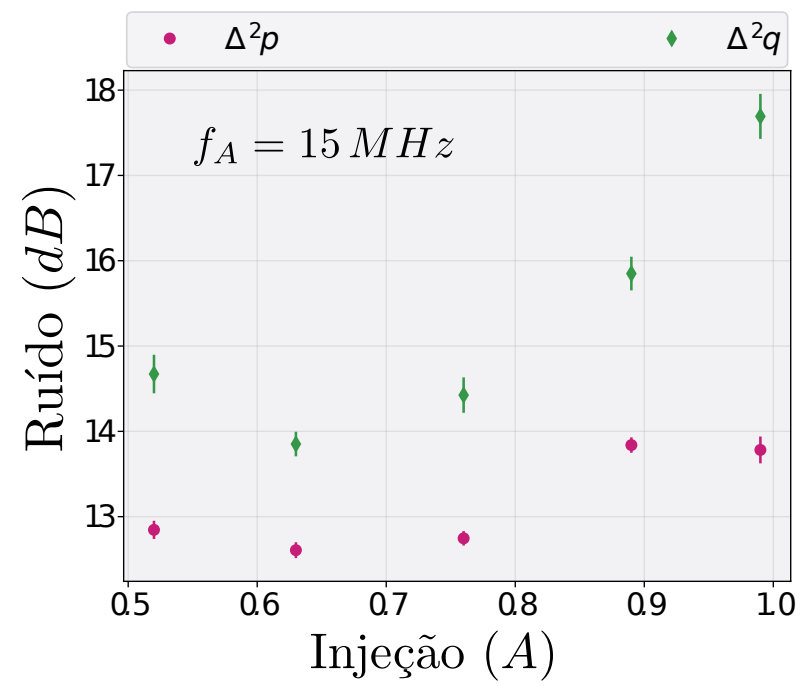

(c)

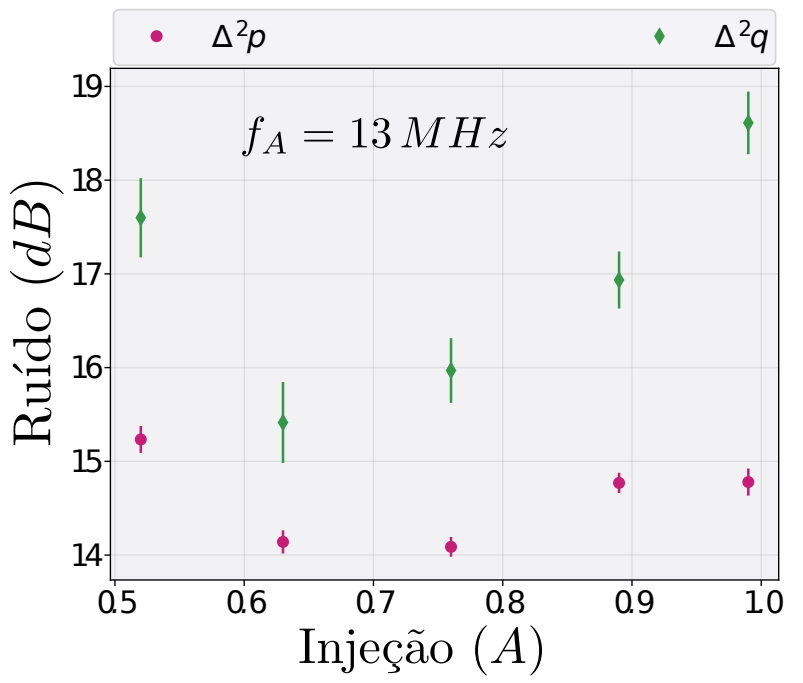

(b)

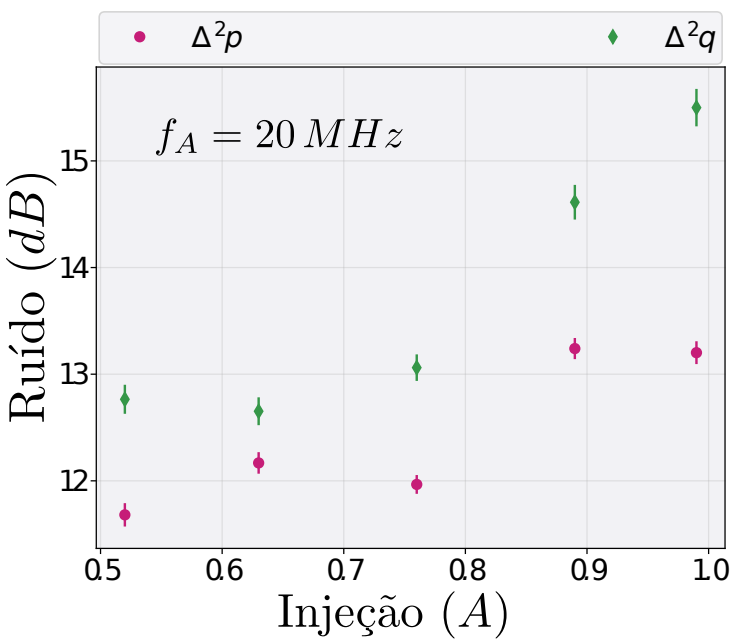

(d)

Figura 70. Ruído das quadraturas em função da corrente de injeção cavidade aberta. Comparada com o sistema fechado, o ruído aumentou nas duas quadraturas e a diferença do ruído entre as quadratura é maior. Novamente vemos uma queda do ruído em $0.75 \mathrm{~A}$.

Para maiores perdas não foi possivel estabilizar a cavidade porque não temos potência suficiênte para ter oscilação da luz (Figura 63).

A caracterização anterior permite argumentar que uma cavidade mais fechada apresenta excesso de ruído menor do que a cavidade aberta. Segundo os resultados obtidos na subseção 5.2.1, se a potência requerida é baixa, menor que $10 \mathrm{~mW}$, a configuração ótima em termos de ruído seria a cavidade fechada utilizando o feixe $\mathbf{C}$. Se uma potência maior é requerida, a cavidade mais aberta seria a melhor opção com o custo de aumentar o ruído pelo menos $5 \mathrm{~dB}$ e atingir até $25 \mathrm{~mW}$ tomando o feixe $\mathbf{P}$. O valor mínimo de ruído foi medido ao redor dos $\sim 10 \mathrm{~dB}$ acima do nível do shot noise. O espectro de ruído do laser apresenta assimetria nas bandas laterais e seu efeito será discutido mais para frente. 
Vemos que ao redor da corrente de injeção de $0.75 A$ o ruído se mantém ou em alguns casos diminui, ficando ao redor de $10 d B$ acima do shot noise. Pela experiência trabalhando com o sistema, esta corrente era a que mais estável deixava o laser o que poderia ser a cause dese comportamento.

\subsubsection{Excesso de Ruído em Função da Potência do laser}

Na seção anterior caracterizamos o ruído total do laser construído. Agora vamos estudar a variação do ruído em relação com a potência do laser e para isso vamos usar o fator $Q$ de Mandel, normalizado pela potência do laser em um dos detetores ${ }^{\text {I, }}$ assim:

$$
Q_{M}(\text { Norm }): \frac{\frac{\Delta^{2} p}{\Delta^{2} p_{o}}-1}{P_{\text {laser }}}
$$

sendo $\Delta^{2} p$ a flutuação lida, $\Delta^{2} p_{o}$ a flutuação do shot noise, 1 o ruído de um estado coerente e $P_{\text {laser }}$ a potência do laser num dos detetores. $O$ fator $Q$ de Mandel indica quantas unidades acima do ruído de um estado coerente se encontra o sinal medido, sendo zero quando o sinal corresponde com um estado coerente ${ }^{42}$. A normalização pela potência da cavidade ajuda para estudar o comportamento do ruído relativo ao aumento da potência.

As figuras 71a - - 71d mostram no fator de Mandel normalizado, em função da potência do laser. Vemos como o excesso de ruído diminui conforme aumentamos a potência do laser, começando em 60 unidades acima do ruído quântico padrão para potências baixas e atingindo 10 unidades para potências de $1.2 \mathrm{~mW}$, então, conforme aumentamos a potência estamos atingindo um estado coerente. O fato de ter diminuição do ruído conforme aumentamos a potência do laser indica que o nosso sistema está efetivamente filtrando ruído, caso contrario, o aumento do ruído acompanharia o aumento da potência com a mesma razão.

I Como a deteção é balanceada a potência nos dois detetores deve ser a mesma. 


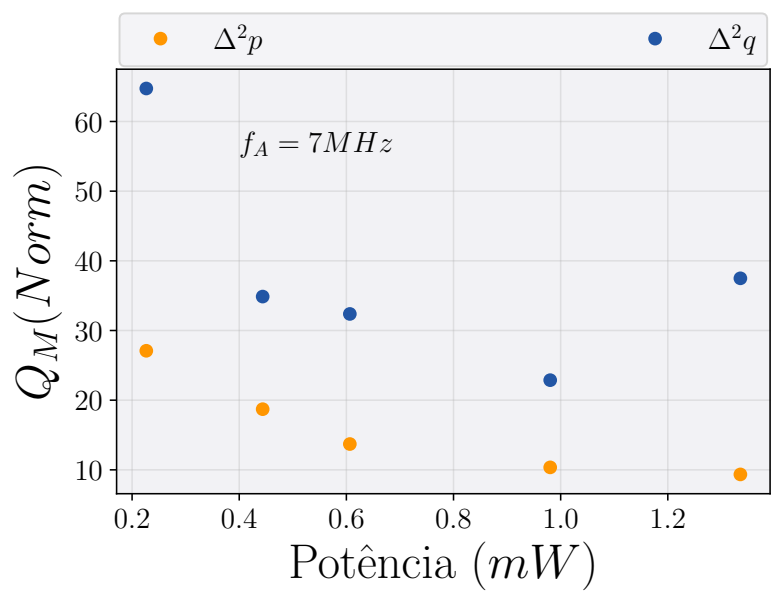

(a)

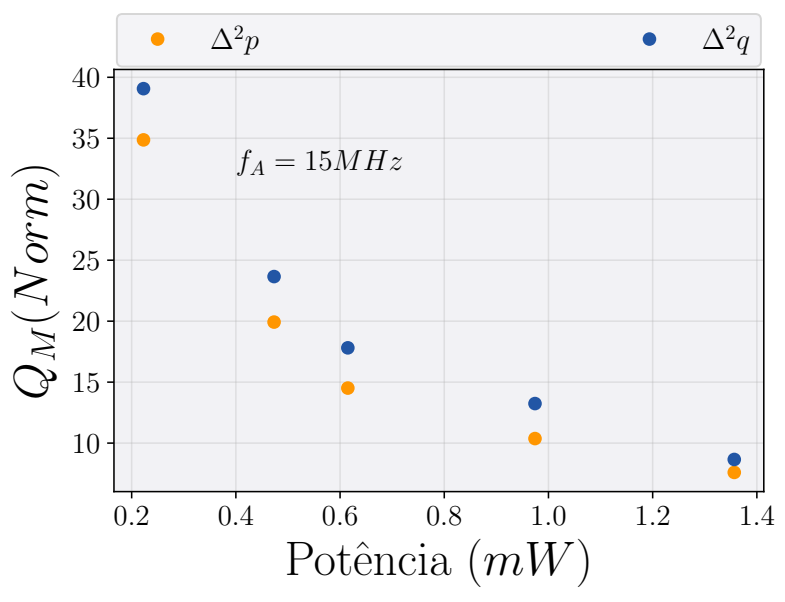

(c)

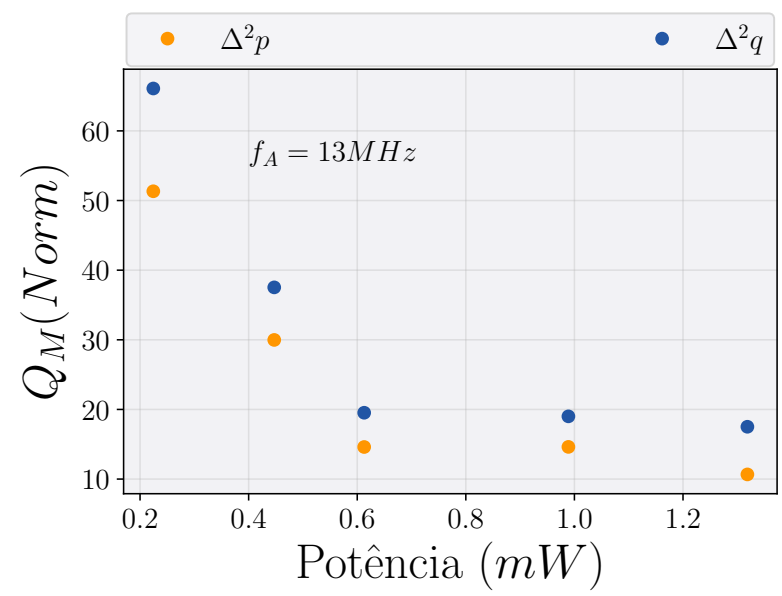

(b)

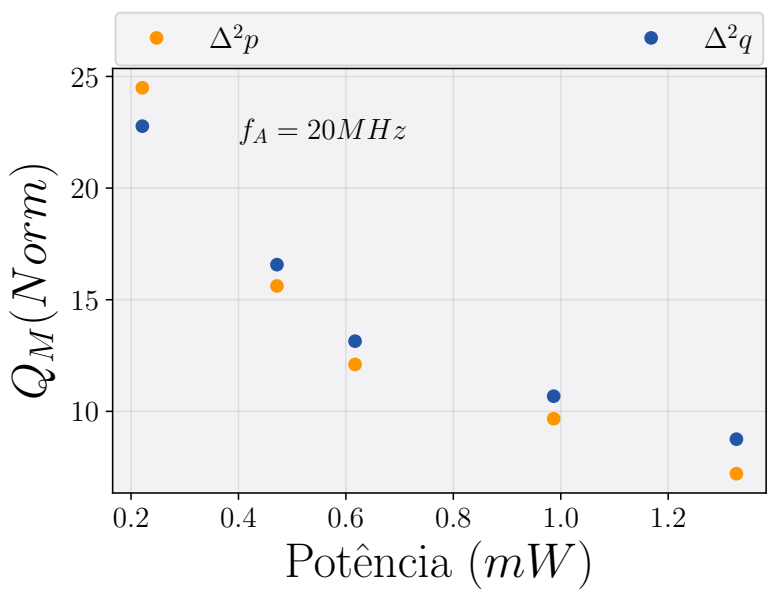

(d)

Figura 71. Fator Q de Mandel em função da potência do laser para diferentes frequências de análise e na configuração de cavidade fechada. $O$ excesso de ruído diminui conforme aumentamos a potência o que é um sinal de uma filtragem do nosso sistema sobre o ruído.

No caso da cavidade mais aberta, $50 \%$ de perdas, vemos novamente como excesso de ruído diminui conforme aumentamos a potência, mais no final vemos um pequeno aumento no ruído. Seria interessante estudar o que acontece para potências maiores mas a nossa montagem atual impossibilita isto porque já estamos trabalhando com o bombeio máximo sobre o chip. Vemos também, como o nível do ruído da quadratura fase para potências baixas é muito maior neste caso comparado com a configuração de cavidade fechada, por exemplo para $7 \mathrm{MHz}$ muda de 60 para cavidade fechada para 200 para cavidade aberta. 


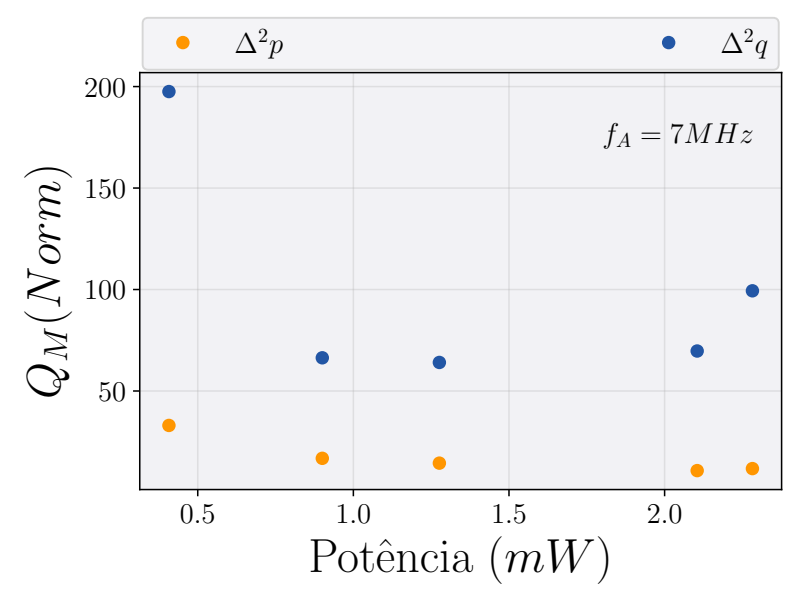

(a)

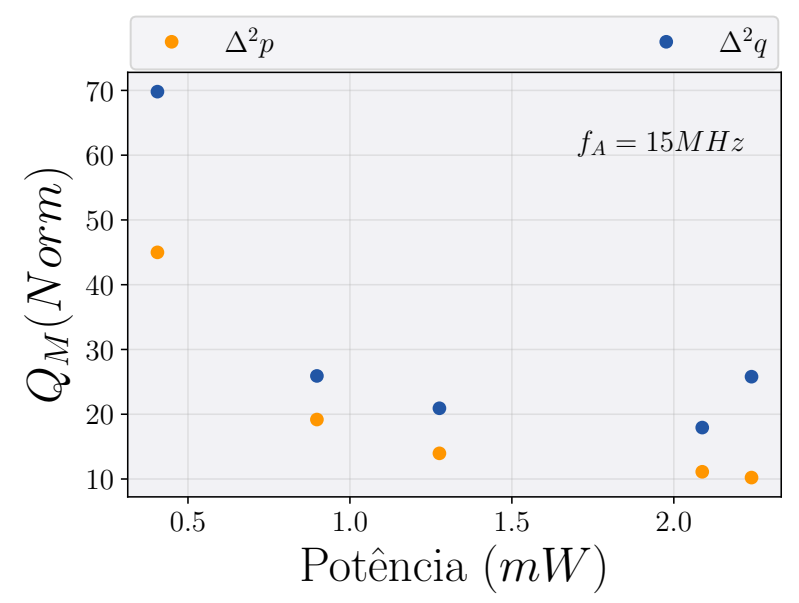

(c)

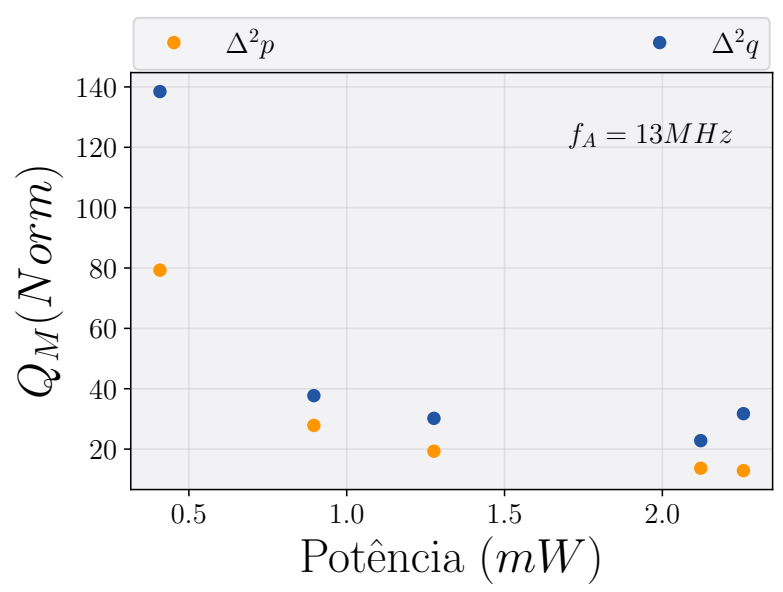

(b)

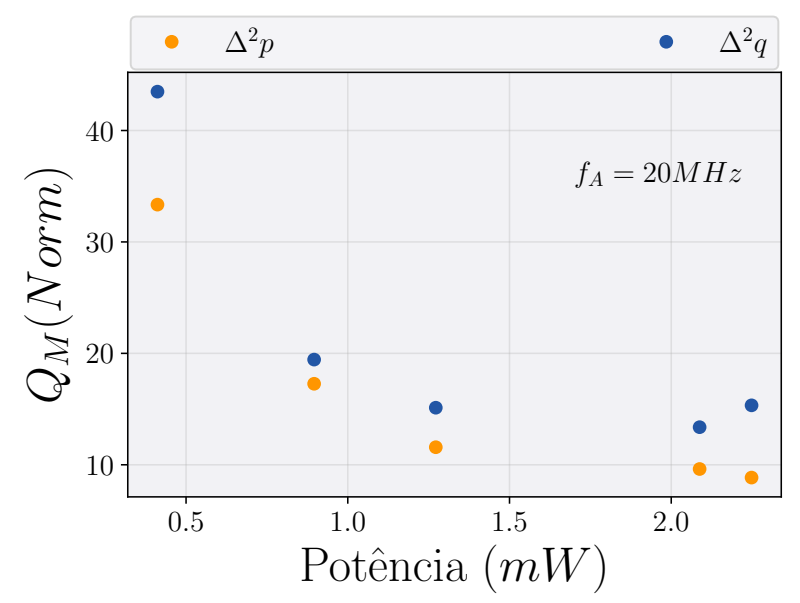

(d)

Figura 72. Ruído das quadraturas em função da corrente de injeção cavidade aberta. Comparada com o sistema fechado, o ruído aumentou nas duas quadraturas e a diferença do ruído entre as quadratura é maior. Novamente vemos uma queda do ruído em $0.75 \mathrm{~A}$. 


\subsubsection{Ruído em Função das Perdas da Cavidade}

Vamos mostrar agora a relação entre o ruído do nosso laser e as perdas controladas, ou seja a saída P. Este estudo foi feito para três configurações diferentes, a saber, correntes de $0.75,0.85$ e 0.65 com frequência de análises 7,13 e $15 \mathrm{MHz}$ respectivamente.

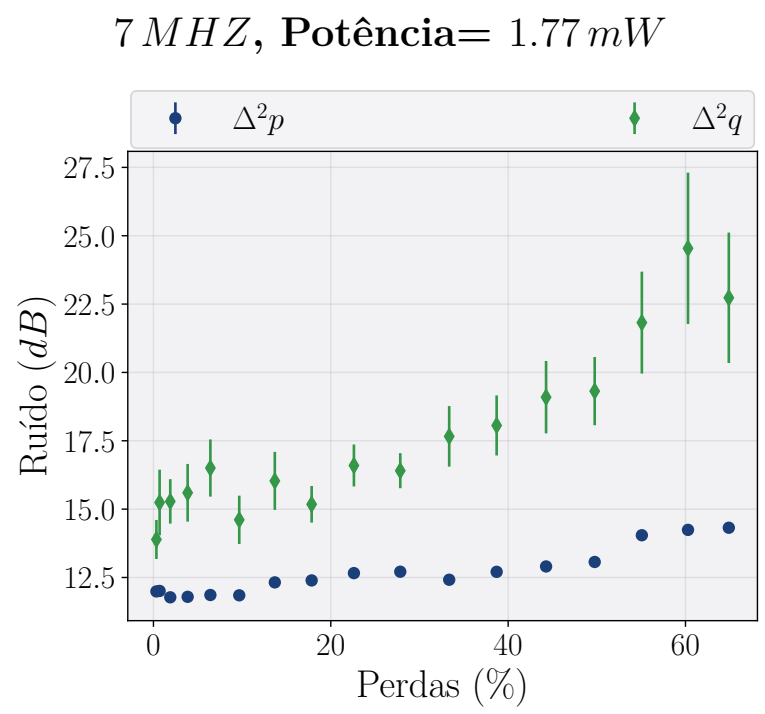

Figura 73. O ruído da quadratura fase sempre é maior do que o ruido de amplitude e aumenta mais rápidamente junto com as perdas. Injeção $=0.75 \mathrm{~A}$.
$13 \mathrm{MHZ}$, Potência $=1.28 \mathrm{~mW}$

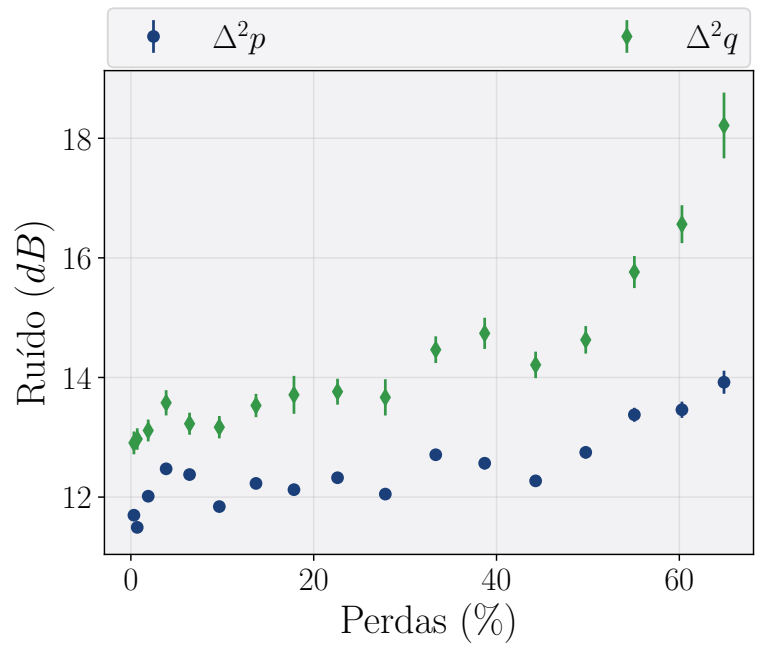

Figura 74. Observamos novamente que o ruído na fase sempre é superior ao ruído de amplitude mais a diferença entre níveis de ruído diminui respeito à medida em $7 \mathrm{MHz}$. Injeção=0.85 A.

\section{$15 M H Z$, Potência $=0.843 \mathrm{~mW}$}

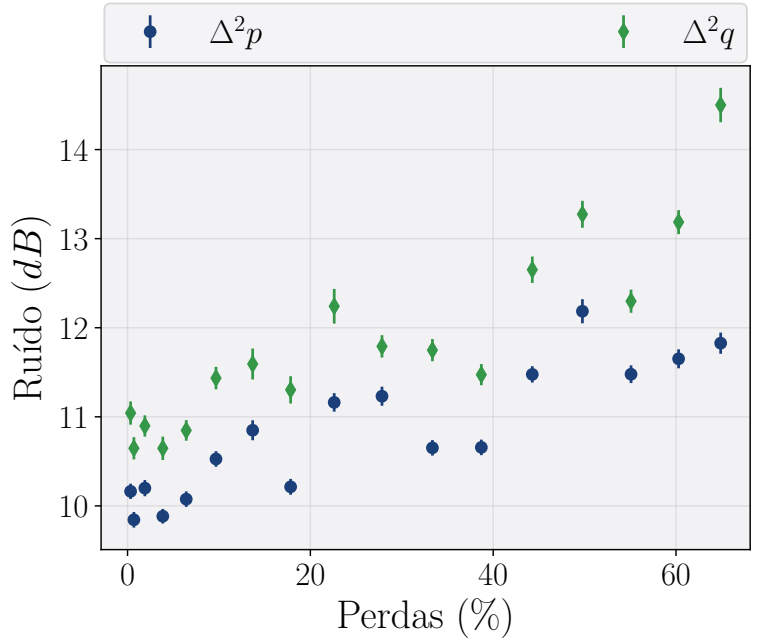

Figura 75. O ruído das quadraturas é quase o mesmo para qualquer perda na cavidade. Injeção $=0.65 \mathrm{~A}$.

O primeiro que devemos notar é que na Figura 73 a potência em cada detetor é maior do que na Figura 74, mesmo sendo a corrente de injeção da primeira menor do que 
a segunda. Este problema é gerado pela diferença no acoplamento da saída $\mathbf{C}$ com a fibra, tendo um acoplamento do $37 \%$ na corrente de $0.85 \mathrm{~A}$ e de $50 \%$ na corrente de $0.75 \mathrm{~A}$.

Vemos novamente que aumentando a frequência de análises obtemos os menores valores de ruído. Também vemos que em geral a razão de aumento do ruído de fase é maior do que do ruído de amplitude mas essa diferença diminui quando aumentamos a frequência de análise. Corroboramos também que uma cavidade mais fechada limita o ruído em relação a uma mais aberta e atingimos valores entre $\sim 10 d B$ e $\sim 16 d B$ na quadratura amplitude e de $\sim 11 d B$ e $\sim 27.5 d B$ para a quadratura fase.

\subsection{Comparação SDL - Littrow}

Esta seção tem como propósito mostrar o resultado final do trabalho e mostrar que o objetivo foi alcançado. Medindo o ruído das quadraturas da nossa nova fonte queremos comparar ela com o ruído do laser Littrow. Mudamos a potência da cada laser com um $P B S$ e uma lâmina de onda antes do acoplamento em fibra e medimos o ruído das quadraturas para duas frequências de análise 7 e $15 \mathrm{MHz}$. A comparação é feita entre a nossa cavidade na configuração mais fechada (ângulo $H W P 1=0$ ) e o diodo Littrow.

A Figura 76a mostra a comparação na quadratura amplitude entre os dois lasers. Vemos que o Littrow se mantém ao redor de $\sim 2 d B$ acima do shot noise, mas o $S D L$ está $\sim 10 \mathrm{~dB}$ acima do mesmo nível. Já na Figura 76b encontramos que o Littrow chega a ter os valores típicos de ruído [46] $\sim 40 d B$ enquanto o nosso sistema se matem abaixo dos $\sim 20 \mathrm{~dB}$.

No caso da medida em $15 \mathrm{MHz}$ encontramos o ruído da quadratura amplitude sendo maior para o $S D L$ do que para o Littrow, e o ruído de fase maior para o Littrow do que para o $S D L$. Para esta frequência novamente vemos que as quadraturas de amplitude e fase apresentam níveis semelhantes de ruído $\sim 10 d B$, já visto na Figura 75 . 


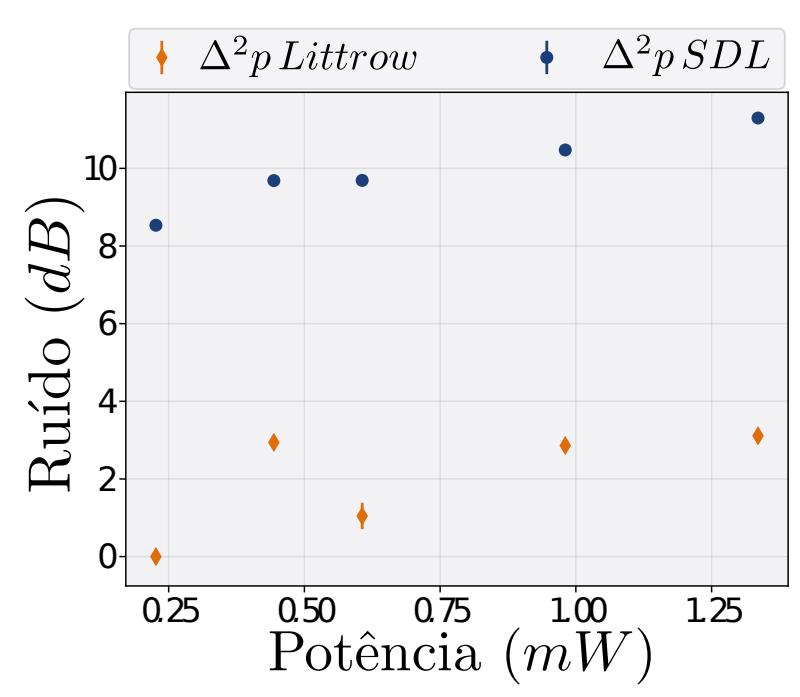

(a) $7 \mathrm{MHz}$

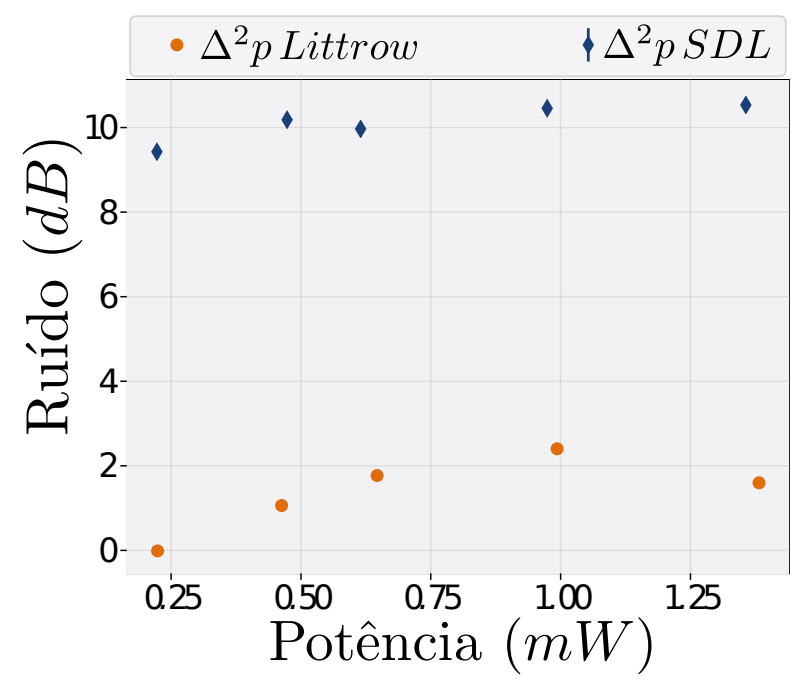

(c) $15 \mathrm{MHz}$

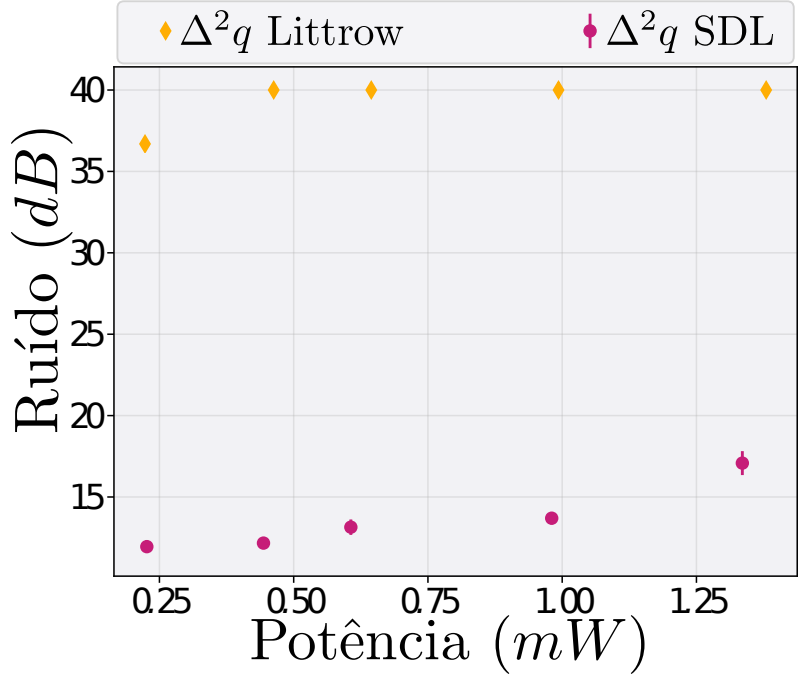

(b) $7 \mathrm{MHz}$

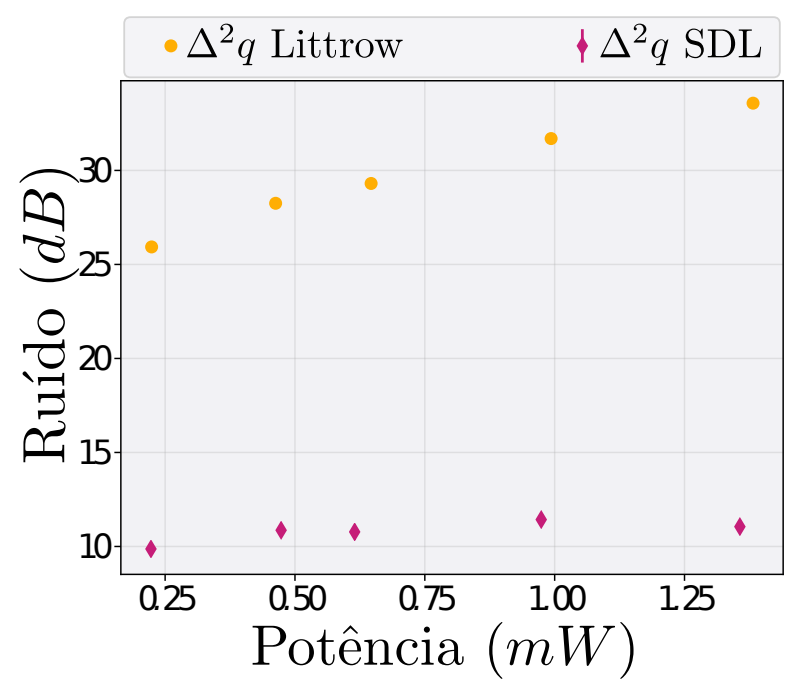

(d) $15 \mathrm{MHz}$

Figura 76. Comparação entre o ruído das quadraturas do laser Littrow e o SDL. Na quadratura amplitude, o laser Littrow tem um menor nível que não supera os $3 \mathrm{~dB}$ acima do shot noise. A quadratura amplitude do SDl está $\sim 8 d B$ acima do nível do Littrow. No caso da quadratura fase, o Littrow apresenta ruído $>30 \mathrm{~dB}$ acima do shot noise, enquanto o SDL chega no máximo até $\sim 20 \mathrm{~dB}$.

Usualmente o sistema semicondutor mantém o ruído da amplitude perto do shot noise, como registrado no sistema Littrow. Vemos que nosso sistema aumenta o ruído na amplitude mas também diminui fortemente o ruído na fase. Uma possível explicação para isto é que a potência intracavidade por ser tão alta esteja acrescentando o valor do fator de Henry (Equação 2.72), aumentando o acoplamento entre quadraturas, passando ruído de uma para a outra. Este acoplamento resulta em uma assimetria das bandas laterais e um deslocamento do espectro na dessintonia justo como mostrado na Figura 30 e na Figura 31. 



\section{Conclusões e Perspectivas}

Neste trabalho construímos e caracterizamos o primeiro protótipo de um laser em anel com um semicondutor como meio de ganho à procura de diminuir o nível típico de ruído característico do sistema. Começamos caracterizando a potência do meio de ganho e encontramos que ele mesmo é uma cavidade, com um limiar de oscilação de $\sim 0.72 A$. O meio de ganho quando injetado, amplifica o sinal para uma corrente de injeção superior a $\sim 0.4 \mathrm{~A}$.

Já com a cavidade em anel montada, temos uma disposição dos elementos óticos que permitiu ter duas saídas do laser, a saída $\mathbf{C}$ e a $\mathbf{P}$, possibilitando medir as propriedades do laser com uma das saídas, e monitorar a sua estabilidade com a outra. Caracterizamos a potência das duas saídas da cavidade. Conseguimos diminuir o limiar de oscilação, chegando a uma corrente de injeção de $\sim 0.41 \mathrm{~A}$. Com um controle sobre as perdas da cavidade conseguimos variar o limiar entre 0.41 e $0.72 A$, e a sua vez, ter um controle de potência nas duas saídas, atingindo valores entre $\sim 10$ e $\sim 25 \mathrm{~mW}$, potências funcionais em sistemas atômicos [3].

Também estudamos a características do ruído do laser, relativas às medidas das flutuações das quadraturas amplitude e fase mediante a técnica de rotação de elipse. O sistema apresentou instabilidades e sensibilidade a influências externas, obrigando o projeto definitivo contar um um controle ativo da estabilidade. Estudamos o ruído das quadraturas em função da corrente de injeção para diferentes frequências de análise e duas configurações da cavidade, a saber, cavidade fechada e cavidade com $39 \%$ de perdas na saída controlada $(\mathbf{P})$. Este estudo permitiu observar que o ruído na quadratura amplitude do nosso sistema varia entre $\sim 8$ e $\sim 15 d B$ e o ruído de fase entre $\sim 12$ e $\sim 23 d B$, acima do nível do shot noise.

Como segunda caracterização, estudamos o ruído como função das perdas controladas da cavidade para diferentes correntes de injeção. Com estas análises encontramos 
que o ruído de amplitude tem um ruído mínimo de $\sim 10 d B$ e não supera os $\sim 15 d B$ mesmo na configuração mais aberta da cavidade para uma potência do laser entre 0.8 e $1.77 \mathrm{~mW}$. No caso do ruído na fase, varia mais fortemente começando com valores mínimos de $\sim 11 d B$ e atingindo valores de $\sim 27 d B$, dependendo da frequência de análises.

A última parte do estudo consistiu na comparação entre o nosso novo sistema e o sistema de cavidade externa em configuração Littrow já disponível no laboratório. O ruído da amplitude do diodo Littrow $(\sim 2 d B)$ é sempre menor do que o ruído do nosso sistema, em torno de $\sim 7 d B$ de diferença. Por outro lado, encontramos ruído da fase do diodo Littrow está $\sim 25 d B$ acima do ruído medido do novo sistema $(10-15 d B)$. Não só conseguimos o objetivo principal de este trabalho, mas conseguimos um laser que apresenta níveis de ruído de quadratura semelhantes entre eles, facilitando a posterior filtragem do ruído restante.

A assimetria encontrada nas medidas de rotação de elipse sugerem que existe uma correlação entre as quadraturas do campo. Nós associamos este efeito com o fator de Henry o qual justamente associa a variação da fase e da amplitude do campo. Este comportamento deverá ser estudado mais para frente.

Dado que encontramos resultados animadores, este sistema passará por um segundo protótipo onde sistemas estabilização da cavidade serão implementados. Como forma de sintonizar o sistema, estamos pensando na elaboração de um sistema que forneça uma corrente de injeção da forma mais controlada e um sistema que permita a variação da temperatura. Esperamos que este sistema seja útil como feixe de bombeio ou como semente de um laser para futuros experimentos no nosso laboratório. 



\section{Referências}

1 TITTEL, W.; ZBINDEN, H.; GISIN, N. Quantum cryptography. Reviews of Modern Physics, v. 74, n. January, p. 145-195, 2002.

2 COElho, A.; BARBOSA, F.; CASSEMIRO, K.; VILlAR, A.; MARTINELli, M.; NUSSENZVEIG, P. Three-Color Entanglement. Science, v. 823, n. 2009, 2012.

3 MONTANA, A. Dissertação (Mestrado), Oscilador Paramétrico Ótico baseado em mistura de quatro ondas em vapor de rubídio. 2017.

4 LEVY, J. S.; GONDARENKO, A.; FOSTER, M. A.; TURNER-FOSTER, A. C.; GAETA, A. L.; LIPSON, M. Cmos-compatible multiple-wavelength oscillator for on-chip. Nature Photonics, v. 4, n. 37, 2002.

5 DEMTRÖDER, W. Laser Spectroscopy. 1ra. ed. Universität Kaiserslautern, Germany: Springer, 2004. 425 p. ISBN 978-3-540-73415-4.

6 SIEGMAN, A. E. Lasers. 1ra. ed. .: University Science Books, 1986. ISBN 0935702113.

7 VILLAR, A. S. Tese (Doutorado), Emaranhamento Multicolor entre Feixes Intensos de Luz. 2007.

8 MORAES, F. C. Dissertação (Mestrado), Construção e Caracterização de um Laser Contínuo de Titânio-Safira. 2013.

9 CAMPOLIN, F. Dissertação (Mestrado). 1997. 1-97 p.

10 HONG, W.; PAINTER, O. J. Design and Characterization of a Littrow Configuration External Cavity Diode Laser. p. 1-9, 2004.

11 MARIN, F.; BRAMATI, A.; GIACOBINO, E.; ZHANG, T.-C.; ET.AL. Squeezing and intermode correlations in laser diodes. Physical Review Letters, v. 74, n. 21, p. 252-255, 1995.

12 ZHANG, K. S.; COUdREAU, T.; MARTINELli, M.; MAÎTRE, A.; FABRE, C. Generation of bright squeezed light at $1.06 \mu$ using cascaded nonlinearities in a triply resonant $\mathrm{cw}$ periodically-poled lithium niobate optical parametric oscillator. Phys. Rev. A, v. 64, n. 3, p. 033815, 2001.

13 SAKURAI, J.; NAPOLITANO, J. Modern Quantum Mechanics. 2da. ed. .: Addison Wesley, 2011.

14 LEVINE, I. N. Quantum Chemistry. 5ta. ed. New York, NY: Prentice Hall, 1991. ISBN 0136855121. 
15 OMAR, M. A. Elementary Solid State Physics: Principles and Applications. 1ra. ed. .: Alddison-Wesley Publishin Company, 1993. 690 p. ISBN 0201607336.

16 ASHCROFT, N. W.; MERMIN, N. D. Solid State Physics. 1ra. ed. New York: Harcourt College Publishers, 1976. 826 p. ISBN 0-03-083993-3.

17 StREetman, B. G.; BANERJEE, S. K. Solid State Electronic Devices. 6ta. ed. New Delhi: PHI Learning, 2009. 608 p. ISBN 9788120330207.

18 SILFVAST, W. T. Laser Fundamentals. 2da. ed. .: Cambridge University Press, 2004. 619 p. ISBN 0521833450.

19 ZEGHBROECK, B. V. Principles of Semiconductor Devices. <https: //ecee.colorado.edu/\{ $\}$ bart/book/book/title.htm>. Data : 27-01-2018.

20 NUMAI, T. Fundamentals of semiconductor lasers. 1ra. ed. Kusatsu, Shiga: Springer US, 2014. ISSN 15561534. ISBN 978-4-431-55147-8.

21 YAMADA, M. Theory of Semiconductor Lasers From Bases of Quantum Electronics to Analyses of the Mode Competition Phenomena and Noise. 1ra. ed. Kanazawa University, Japan: Springer, 2014. ISBN 9784431548881.

22 SUAHARA, T. Semiconductor Laser Fundamentals. 1ra. ed. Osaka University, Japan: Marcel Dekker, Inc., 2004. ISBN 0824753739.

23 Maiman, T. H. Optical and Microwave-Optical Experiments in Ruby. Phys. Rev. Lett., v. 4, n. 11, p. 564-566, 1960.

24 LOUDON, R. The Quantum Theory of Light. 3ra. ed. New York: Oxford |Univertisy Press, 2000. ISBN 0198501773.

25 SHIRAZ, H. G. The Principle of Semicondutor Laser Diode and Amplifiers, Analisis and Transmission Line Modeling. 1ra. ed. Singapore: Imperial College Press, 1966. ISSN 00036951. ISBN 9780470068328.

26 YARIV, A. Quantum Electronics. 3ra. ed. California Intitute of Technology: Jhon Wiley \& Sons, 1989. ISBN 0-471-60997-8.

27 SCULLY, M.; SUHAIL, Z. Quantum Optics. 1ra. ed. University of Cambridge: Cambridge University Press, 1997.

28 JACKSON, J. D. Classical Electrodynamics. 3ra. ed. University of California, Berkeley: John Wiley \& Sons, 1999. ISBN 0-471-30932-X.

29 ZILIO, S. C. Óptica Moderna. 1ra. ed. São Carlos. Brasil.: Instituto de Física de São Carlos, Universidade de São Paulo, 2009. ISBN 9788588533424.

30 SALEH, B.; TEICH, M. Fundamentals of Photonics. 2da. ed. Hoboken, New Jersey: John Wiley \& Sons, 2007. ISBN 978-0-471-35832-9.

31 KENYON, I. R. The Light Fantastic a modern introduction to classical and quantum optics. 1ra. ed. University of Birmingham: Oxford University Press, 2008. ISBN 978-0-19-856646-. 
32 SCHAWLOW, A.; TOWNES, C. Infrared and Optical Masers. Physical Review, v. 112, n. 6, p. 1940-1949, 1958.

33 LAX, M. Classical Noise. V. Noise un Self-Sustained Oscillators. Physical Review, v. 160, n. 2, p. 290-307, 1967.

34 PASCHOTTA, R. Derivation of the Schawlow-Townes Linewidth of Lasers. [S.l.]: RP Photonics. <http://www.rp-photonics.com/Schawlow-Townes\{__\}linewidth. pdf $>$. Data : 02-02-2018.

35 GRYNBERG, G.; ASPECT, A.; FABRE, C. Introduction to Quantum Optics. 1ra. ed. París, France.: Cambridge University Press, 2010. ISBN 9780521551120.

36 FLEMING, M. W.; MOORADIAN, A. Fundamental Line Broadening of single-mode (GaAl) As diode laser. Applied Physics Letters1, v. 38, n. 7, p. 511-513, 1981.

37 HENRY, C. H. Theory of the Linewidth of Semiconductor Lasers. IEEE Journal of Quantum Electronics, v. 18, n. 2, p. 259-264, 1982. ISSN 15581713.

38 PASCHOTTA, R. Linewidth Enhancement Factor. 2008. <https://www. rp-photonics.com/linewidth\{_\}enhancement\{_\}factor.html>. Data : 19-03-2018.

39 VILLAR, A. S. The conversion of phase to amplitude fluctuations of a light beam by an optical cavity. American Journal of Physics, v. 76, n. 10, p. 922, 2008. ISSN 00029505.

40 SALES, A. C. Tese (Doutorado), Emaranhamento multicor para redes de informação quântica. 2013.

41 BACHOR, H.-A.; RALPH, T. C. A Guide to Experiments in Quantum Optics. 2da. ed. The Australian National University, Canberra. University of Queensland, Autralia.: Wiley-VCH Verlag GmbH \& Co. KGaA, 1998.

42 MANDEL, L.; WOLF, E. Optical Coherence and Quantum Optics. 1ra. ed. University of Rochester, New York: Cambridge University Press, 1995. ISBN 9780521417112 .

43 GERRY, C. C.; KNIGHT, P. L. Introductory Quantum Optics. 1ra. ed. .: Cambridge University Press, 2005. 1197 p. ISSN 00029505. ISBN 9780521820356.

44 FOX, M. Quantum Optics An introduction. 1ra. ed. University of Sheffield: Oxford University Press, 2006.

45 BARBOSA, F. A. S. Tese (Doutorado), Robustez do emaranhamento em variáveis contínuas e fotodetecção de feixes intensos no dominio temporal. 2013.

46 FLÓREZ, H. M. Tese (Doutorado), Espectroscopia de correlação em condição de Transparência Eletromagneticamente Induzida: regime dinâmico e ressonâncias das bandas laterais em átomos frios. 2016.

47 BARBOSA, F. A. S.; COElHO, A. S.; CASSEMIRO, K. N.; NUSSENZVEIG, P.; FABRE, C.; VILLAR, A. S.; MARTINELLI, M. Quantum state reconstruction of spectral field modes: Homodyne and resonator detection schemes. Physical Review A Atomic, Molecular, and Optical Physics, v. 88, n. 5, p. 1-16, 2013. ISSN 10502947. 
48 THORLABS, I. Grating Tutorial. <https://www.thorlabs.com/newgrouppage9. cfm?objectgroup $\left\{\_\right.$_id=26>. Data : 10-10-2017.

49 HECHT, E. Optics. 4ta. ed. Adelphi University: Addison Wesley, 2002. ISBN 0-321-18878-0.

50 SDL, I. SDL-8630 Operator's Manual. San Jose, CA: SDL, Inc., 1995.

51 THORLABS, I. Anamorphic Prism Tutorial. < https://www.thorlabs.com/ newgrouppage9.cfm?objectgroup $\{$ _ $\}$ id=149>. Data : 20-08-2017.

52 KOGELnIK, H.; LI, T. Laser Beams and Resonators. Applied Optics, v. 5, n. 10, p. $1550-1567,1966$.

53 The Scipy Community. Scipy Library. 2017. <https://docs.scipy.org/doc/scipy/ reference/generated/scipy.optimize.curve\{_\}fit.html>. Data : 20-11-2017.

54 AGRAWAL, G. P.; Niloy K. Dutta. Semiconductor lasers. 2da. ed. University of Rochester, New York: Kluwer Academic Publishers, 1967. 1818-1824 p. ISSN 1098-6596. ISBN 9781461275794. 
